Portland State University

PDXScholar

$1-1-1982$

\title{
Impacts of environmental design on residential crowding
}

Ed Tieh-yeu Huang

Portland State University

Follow this and additional works at: https://pdxscholar.library.pdx.edu/open_access_etds Let us know how access to this document benefits you.

\section{Recommended Citation}

Huang, Ed Tieh-yeu, "Impacts of environmental design on residential crowding" (1982). Dissertations and Theses. Paper 774.

https://doi.org/10.15760/etd.774

This Dissertation is brought to you for free and open access. It has been accepted for inclusion in Dissertations and Theses by an authorized administrator of PDXScholar. Please contact us if we can make this document more accessible: pdxscholar@pdx.edu. 
IMPACTS OF ENVIRONMENTAL DESIGN ON RESIDENTIAL CROWDING

\title{
by
}

ED TIEH-YEU HUANG

A dissertation submitted in partial fulfillment

of the requirements for the degree of

\author{
DOCTOR OF PHILOSOPHY \\ in \\ URBAN STODIES
}

PORTLAND STATE UNI VERSITY

1982 
TO THE OFFICE OF GRADUATE STUDIES AND RESEARCH:

The members of the Committee approve the dissertation of Ed Tieh-Yeu Huang presented August 1981.
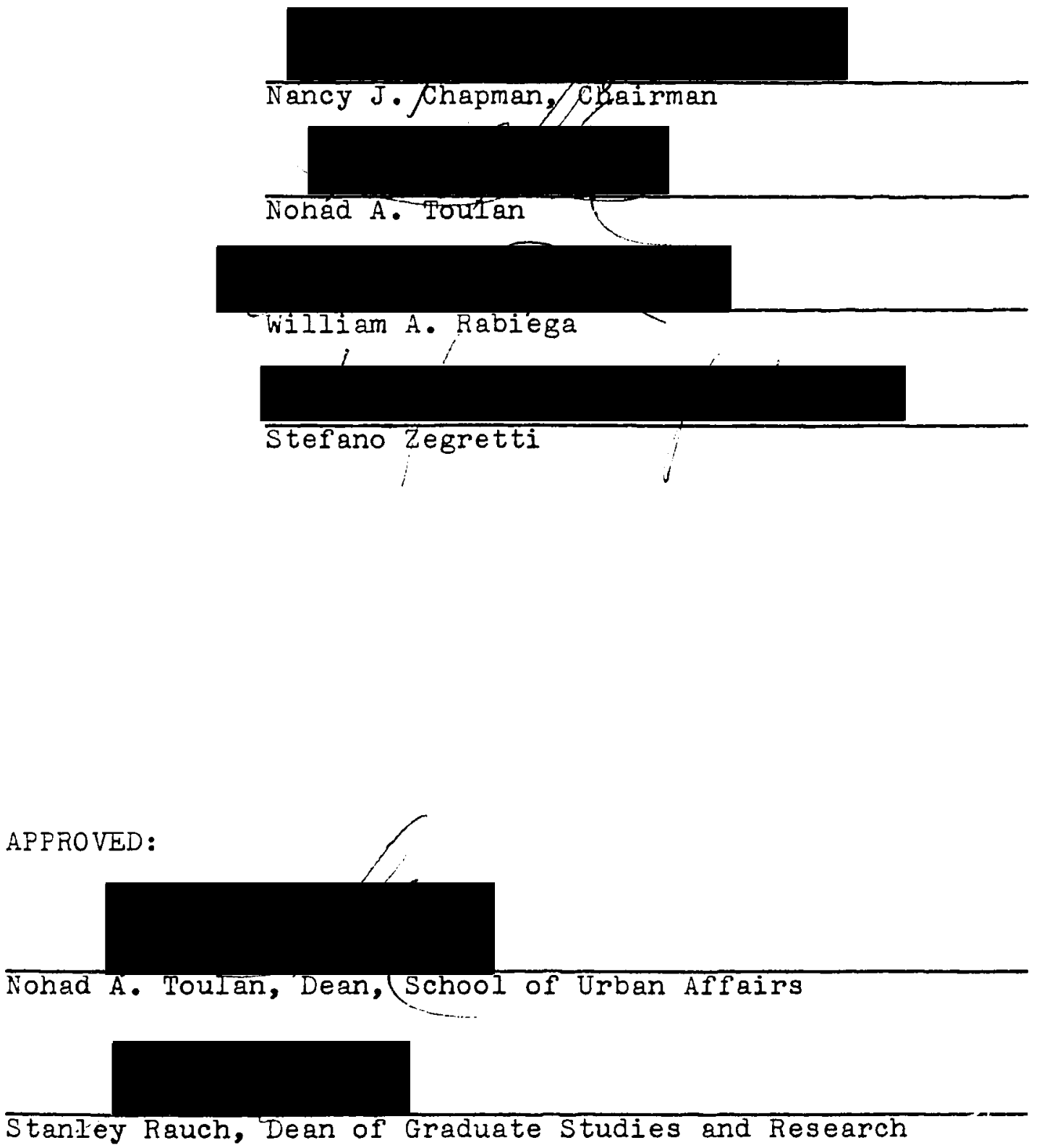
AN ABSTRACT OF THE DISSERTATION OF Ed Tieh-Yeu Huang for the Doctor of Philosophy in Urban Studies presented August 1981.

Title: Impacts of Environmental Design on Residential Crowding

APPROVED BY THE MEMBERS OF THE DISSERTATION COMMITTEE:

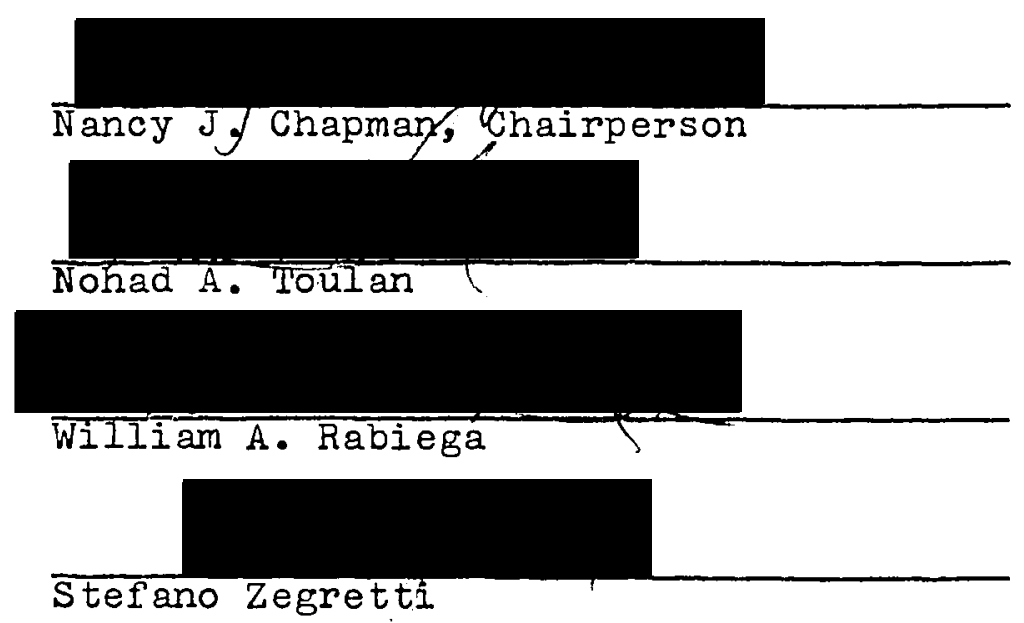

This dissertation addresses the following research questions: How do physical features of high density college dormitories affect residents' perception of crowding, and what kinds of design strategies are available for alleviating the perceived crowding? The data source was responses to a self-administered questionnaire from residents of living units which were randomly sampled from three dormitories of comparable physical density at Oregon State University. Seven hypotheses were used to examine the relationship 
between perceived crowding and physical features associated with different settings in selected dormitories. The first hypothesis sought to clarify how selected physical variables, compared with selected social and personal variables, contributed to perceived crowding both in dormitory dwellings (floor crowding) and rooms (room crowding). For the remaining hypotheses, comparisons were made to determine if differences existed between groups living on floors with varied corridor length, floor height (distance above ground level), and bathroom location, and between groups living in rooms with varied desk location, room location, and window orientation. Using multiple regression analysis and analysis of variance as the major tools for hypothesis testing, the study found that: 1) both room and dwelling crowding were not significantly affected by the selected physical, social, and personal variables; 2) floor crowding was significantly lower among residents of short corridors and among those who shared suite rather than community bathrooms. Variations in floor level did not affect perceived crowding; 3) room crowcing was not significantly affected by variations in desk location, room location, and window orientation, but rather by the interactive effects of window orientation and floor height. 


\section{ACKNOWLEDGMENTS}

This dissertation is the result of constant help and assistance which I received during the course of its preparation. It reflects the dedication of many friends and colleagues, each of whom contributed in one form or another to its completion. I am grateful that I was able to work very closely with my committee chairperson, Dr. Nancy Chapman, who patiently offered continual help and guidance in the completion of this document. Without her academic excellence in advising me this dissertation would not have been possible.

Sincere appreciation is extended to other committee members, Dr. Nohad Toulan, Dr. William Rabiega, and Dr. Stefano Zegretti for their invaluable support, encouragement, and constmuctive criticism throughout the development and completion of this study.

Respect and appreciation is also extended to Dr. Roger Fischer at the Housing Office of Oregon State University, who provided with me the material about the gtudent halls used in this study, and the Feads and assistants of the student halls who helped me to complete the questionnaire survey. In addition, I offer my sincere gratitude to all students who participated in this sicudy.

I thank the School of Urban Affairs for financial and academic support during the preparation of this study. 
Special mention should be made of Dr. Zegretti, Dr. Toulan and Mr. Naurie Clark who have alleviated my financial strain during the preparation of this document.

Finally, my parents, High-Pone and Yeen Huang, and my wife, Caroline, deserve a special vote of appreciation. Caroline typed the document five times and shared in the trials of its preparation. My parents' financial support in this past year as well as their expectation and confidence in me made the completion of this dissertation possible. 
TABLE OF CONTENTS

PAGE

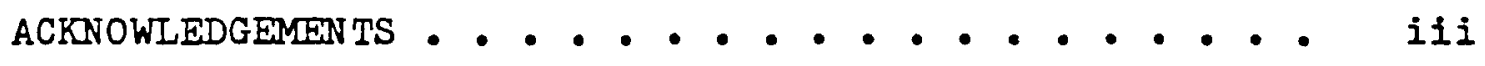

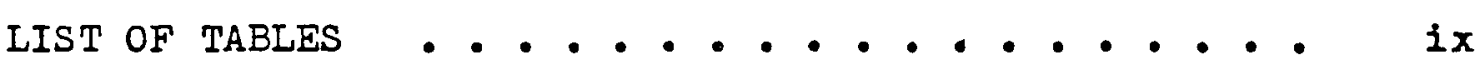
LIST OF FIGURES . . . . . . . . . . . . . . . . x x

CHAPTER

I INTRODUCTION

Definitions . . . . . . . . . 3

Density ........... . 3

Crowding .............. 8

Research Problem: High Density Living • 9

Designing for Multi-Unit Housing . . . 13

Limitations . . . . . . . . . 17

strengths . . . . . . . . . 19

II CROWDING THEORIES AND DETERMINANTS • • • • 22

Theories of Crowding . . . . . . . 22

Stimulus Overload . . . . . . 23

Behavioral Constraint . . . . 27

Ecological Affordance . . . . 31

Summary •. • • • • • • • • 35

Determinants of Crowding Perception. . . 36

Physical Determinants . . . - 36

Personal Determinants . . . . . 43 
Social Determinants .. . . . . 46

Summary . . . . . . . . . 49

III DESIGN OF THE RESEARCH . . . . . . . . 50

Conceptualization of the Research . . 51

Research Setting . . . . . . . 54

Study Design and Hypotheses . . . . 61

Study I: Effects of Physical,

Social, and Personal Factors?. . 61

Study II: Effects of Floor

Variation .......... 62

Study III: Effects of Room

Variation .......... 66

Methodology Design . . . . . . . 68

Survey Method . . . . . . 68

Sampling and Subjects . . . . . 69

Operational Design of

Questionnaire and Variables . . . 72

Construction of Crowding Indices . . 78

Statistical Design . . . . . . 81

IV ANALYSIS OF THE DATA . . . . . . . . 85 Analysis of Study I . . . . . . 85

Correlation and Principal Component

Analyses of Crowding Determinante. . 87

Regression Analysis of

Room Crowding . . . . . . . . 92

Regression Analysis of

Dwelling Crowding . . . . . . 95

Sumary •. • . . . . . . 98 
$\nabla i 1$

CHAP TER

PAGE

Analysis of Study II . . . . . . . 99

Variance and Correlation of the

Effect of Corridor Length . . . .

Variance and Correlation Analyses

of the Effect of Floor Height . .

101

Variance Analysis of the Effect

of Bathroom Location

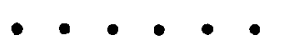

103

Summary ... . . . . . . 105

Analysis of Study III . . . . . . 106

Variance and Correlation Analyses

of the Effect of Desk Location.

Variance analyses of the Effect

of Window Orientation .......

Variance and Correlation Analyses of the Effect of Room Location .

Summary • • • • • • • • • •

Determinants of Room and

Dwelling Crowding . . . . . . .

Overload and Floor Crowding . . .

Overload, Constraint, and

Room Crowding . . . . . . . .

Summary • • • • • • • • • •

Implications . . . . . . . . •

Implications for

Design Practice... . . . . .

Implications for

Future Research . • • • • • • 


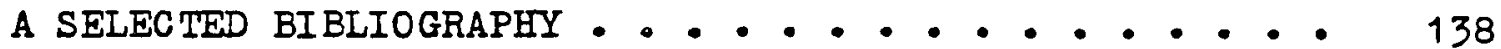

\section{APPENDICES}

A Locations of Selected Dormitories in Oregon State Campus . . . . . . 148

B Letter from Committee for Protection of Human Subjects, Oregon State University. • 149

C Letter to student Participants and Self-Administered Questionnaire . . . • 150

D Correlation Matrix for Overall Perceived Crowding . . . . . 157

E Correlation Matrixes for Personal and Social Variables . . . . 158 


\section{LIST OF TABLES}

TABLE

PAGE

I Comparisons of Building Characteristics . . . 60

II Comparisons of Sample Characteristics . . . 71

III Frequency Distribution of Ethnicity . . . . 73

Iy Sumary of Measurement Descriptions . . . . 76

V Varimax Rotated Factor Matrix with

Factor Score Coefficients of Overall

Perceived Crowding . . . . . . . . . 80

VI Reliability Analyses for Room, Floor and Dwelling Crowding . . . . . . . . .

VII Sumary of Hypotheses, Variables, and

Statistical Design . . . . . . . . . 84

VIII Intercorrelations among Physical Variables. • 89

IX Varimax Rotated Factor Matrix of

Personal and Social Variables....... 91

$X$ Overall Explanatory Power of Predictors

on Perceived Room Crowding . . . . . . . 93

XI Overall Explanatory Power of Predictors

on Perceived Dwelling Crowding . . . . . . 96

XII Analyses of Variance: Floor Crowding by

Corridor Length, Floor Height, and

Bathroom Location . . . . . . . . . 100

XIII Correlations between Floor Height,

Number of People Seen in Hallway.

and Perceived Floor Crowding . . . . . . 102

XIV Contrast Coefficient Matrix and

T Statistics: Floor Crowding

Controlling Corridor Length and

Bathroom Location . . . . . . . . . 105 
TABLE

PAGE

XV Analjses of Variance: Room Crowding by Desk Location, Window Orientation, and Room Location... . . . . . . . 108

XVI Correlations between Locations of Desk and Room, Territory, Noise, and Measures of Room Crowding . . . . . . . 109

XVII 3-Way Analysis of Variance: Room Crowding by Window Orientation, Floor Height, and Desk Location ......

IIST OF FIGURES

FIGURE

PAGE

1. Model of the Crowding Process . . . . . 52

2. Typical Floor Plan of McNary Hall • . . . 56

3. Typical Floor Plan of Finley Hall . . . . 57

4. Typical Floor Plan of Bloss Hall . . . . 58

5. Typical Room Plans... . . . . . . . 60

6. Cell Means for Floor Height by Window Orientation .................. 


\section{CHAPTER I}

\section{INTRODUC TION}

With the population growth and urbanization throughout the world, it has been estimated that by the end of this century, a substantial percentage of the world's population will live in densely populated urban areas (Ehrlich \& Errlich, 1970). In the United States the results of continuing population increase and concentration are that 70 percent of the populace now lives under high density conditions in urban centers and surrounding areas and that the population density of our metropolitan areas will be considerably higher in the future (Freedman, 1975).

While population pressure makes our cities experience the strains of traffic congestion, air pollution, noise, housing shortages, etc., a growing concern over the quality of human life in large urban centers has led scientists from various disciplines to speculate about the effects of dense living conditions. A body of classic urban sociological thought, of which Louis Wirth's (1938) writings are repre-

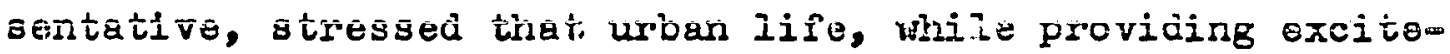
ment, availability of resources, and access to cultural opportunities, has an equaliy formative influence on human behavior and the development of the urban personality. Wirth 
described the nature of dense urban living in terms of impersonality and anonymity, and he characterized urban social relations as superficial and anomic.

The phenomenon that high rates of various morbidities and infectious diseases have been traditionally reported in densely populated settings such as urban slums and military training camps has motivated a group of epidemiologists and psychiatrists to examine the relationship between human physical and mental illness and population density. Using correlational methods or studying individual patients, they have generally found that poor health of many types associates positively with the density of the subject's living environment (Lantz, 1953; Plant, 1930). However, poor health in dense environments, especially in slums or ghettos, may be a reflection of poverty and poor conditions of sanitation or ventilation rather than density per se.

Meanwhile, many biologists and ethologists, studying the effects of density on animal behavior, have found that excessive population density is associated with problems of social and psychological functioning in various animal species (Christian et al, 1960; Calhoun, 1962). For example, Calhoun (1962) reported that, as population increased, laboratory rats developed actively abnormal behaviors such as heightened mortality, exaggerated aggression, and social wi thdrawal.

In recent decades the notion that high human density itself may act as a physiosocial stressor responsible 
for some portion of urban malaise has motiveted numerous studies to examine the consequences of residing in a dense environment. A group of behavioral scientists has suggested that density is not always problematic for people but leads to such syndromes of crowding stress as social pathologies and behavioral impaiments only to the extent that it precludes privacy or places other limitations on behavior (Proshansky et al, 1970; Freedman, 1979). In order to begin discussing the issue, we need to define and differentiate the terms "density" and "crowding".

\section{DEFINITIONS}

In the early studies of the effects of population concentration, the terms density and crowding were used interchangeably; they were not systematically defined nor were they well differentiated from each other until just a few years ago.

Density

Aggregate Measures of Density. Density cormonly refers to the number of social units (e.g., persons or households) per unit of space. Early sociological and planning analyses employed a variety of aggregate density measures such as population density (persons per acre or per census tract), accomodation density (dwellings per acre or per census tract), and occupancy rate (persons per dwelling or per room) without giving systematic attention to their differences. 
One might, for instance, live in a dense household but In a low density neighborhood. The differences were well 1llustrated by Zlutnick and Altman (1972) who distinguished between inside housing-unit density, referring to the number of people per unit of space within a residence, and outside housing-unit density, referring to the number of people per unit of space in a larger spatial unit such as an acre. From this two-level framework, 1.e., the macro and micro levels, four situations are generated.

1. High inside and high outside density (e.g., many people living in a dwelling that is in a highly populated neighborhood such as an urban ghetto).

2. Low inside and high outside density (e.g., a luxury apartment in an urban setting).

3. High inside and low outside density (e.g., a rural situation with many people living in a dwelling).

4. Low inside and low outside density (e.g., a subLrban setting).

This type of analysis implies that the unit of measurement of persons or dwellings per acre does not reveal the number of persons per dwelling or per room and that if taken alone can be misleading since, in Jenson's (1966) terms, "it is not necessarily a relevant indication of actual living conditions or residential amenities (p. 8)."

To examine the different density effects on micro and macro levels, a group of sociologists have conducted correlational studies with the basic strategy of using census 
data to relate various density measures such as persons per acre and per room to various pathological indices such as disease, mental illness, crime, and mortality rates. For example, a Honolulu study (Schmitt, 1966) reported that when other density measures were held constant, persons per room correlated most strongly with death and crime rates among all density measures. A Chicago study (Galle et al, 1972) also reported that the highest correlations occurred between persons per room and mortality, fertility, public assistance, and juvenile deliquency once the effects of socioeconomic status and ethnicity were controlled, while a New York study (Freedman et aI, 1975) found practically no relationship between persons per room or persons per acre and pathology. lioreover, an extension of the Chicago study (Galle \& Gove, 1979), in addition to reconfirming the earlier findings, found that percent of housing units that were occupied by one-person households was positively correlated with the rate of admissions to mental hospitals; which implied that isolation rather than limited size of space related to the mental illness.

In general, results from these correlational studies indicate that there is little relationship between various measures of pathology and the more molar indicators of density such as persons per acre, and that there are some relationships between pathologies and micromeasures of density such as persons per room and percent of single household units, which suggests that number of persons within a 
dwelling unit is a more important pathological indicator than number of persons in a neighborhood.

Spatial Density versus Social Density. The increasing awareness that different patterns of population concentration may have different effects has also led to psychological research distinguishing between spatial density and social density. The former involves comparisons of same-size groups in different size spaces; the latter involves constant-size space but different numbers of peoplo. For example, the density in two settings might be twelve square feet per person, but in one case there might be 200 people in an assembly hall and in the other 4 people in a small dormitory room. Even though each of these two may be designated as being high density conditions, socially and perceptually these two situations are very different.

A number of studies have examined the effects of different social and/or spatial densities on psychological reactions, performance on personal or group tasks, verbal and nonverbal responses, interpersonal behaviors, etc., in either laboratory or field settings. Several laboratory experiments found that, when room size was held congtant, children in large groups were found to be more aggressive (Griffit \& Veatch, 1971), and to perceive more interference with tasks and less comfort (Saegert, 1975), than children in small groups. When group size was held constant, while several studies found no significant effects of spatial density on simple task performance (Freedman et al, 1971; 
Sherrod, 1974) or on complex task performance (Freedman et al, 1972, study \#3), other studies found adverse effects on complex task performance (Evans, 1978; Paulus et al, 1976); one study found no simple effects on task performance and comfort (Worchel \& Teddlie, 1976). Horeover, positive effects of high spatial density were also found on task performance, pleasantness, liking for others, and friendliness among male students (Sundstrom, 1975).

Meanwhile, several field studies found that, when physical density was held constant in dormitory settings, residents living along double-loaded central hallways and sharing a bath and a lounge with all other residents on the floor (large size group) reported more frequent unwanted interactions, less satisfaction, greater desires to avoid neighbors, and more difficulty in regulating social contacts than did residents living in dormitories which dispersed people in 4- to 6-person suites, each containing its own bath and lounge (small size group) (Baum et al, 1979; Baum \& Valins, 1977). In a study conducted in public settings, subjects with lower social density showed less anxiety and sadness in a railroad station and better recall for objects but fewer positive feelings toward people in a shoe storo (Saegert et al, 1975).

When group size was held constant, high spatial density was found not to affect students' learning tasks (Rodin, 1976) and to have a negative effeot on children's aggressive and destructive behaviors in play rooms (Rohe \& Patterson, 
1974). Positive effects of high spatial density were also found; children showed less aggression in a small play room (Loo, 1972).

Taken as a whole, this body of psychological research indicates that high social density relates to various human dysfunctions such as social withdrawal, decrements in task performance, and dismuption of interpersonal relations, while high spatial density appears to produce inconsistent and diverse effects under different circumstances. This implies that social density is more importani than spatial density in affecting human behavior.

\section{Crowding}

Although the term crowding is frequently used as synonymous with high density, there appears to be ample justification for distinguishing betweeil these terms. While Proshansky et al. (1970) postulated that crowding could be situationally defined as a condition in which the number of people present were sufficiently large to reduce an individual's behavioral freedom and choice, Stokols (1972a) sharply distinguished density and crowding on the basis of a physicalpsychological distinction. Density is regarded as a physical condition of limited space; crowding, on the other hand, is a paychological state, a subjective and experiential process.

Density is a necessary though not sufficient condition for the feeling of being crowded. Crowding arises from conditions of high density only in the context of social and 
personal factors that sensitize one to the inconveniences of limited space (Stokols, 1972b). People may also experience crowding when their goals are blocked by the mere presence of other poople even if there is sufficient physical space for all (Stokols, 1976), and they may feel uncrowded with a group of friends even when sharing a restricted amount of space (Freedman, 1975). In Stokols' (1972a) terms:

The experience of crowding, thus, can be characterized as a motivational state directed toward the alleviation of perceived restriction and infringement, through the augmentation of one's space supply, or the adjustment of social and personal variables so as to minimize the inconveniences imposed by spatial limitation ( $p .276)$.

Other writers have offered somewhat similar ideas though different emphases. Conceptualizing crowding as a motivational state involving, for example, the desires for increased privacy (AItman, 1975), for reduced stimulation (Rapoport, 1975), or for achieving a psychological-physiological harmony (Esser, 1973), most agree that density is an objective descriptor to be measured in terms of persons per spatial unit and that crowding is a subjective perception. Once this point is made, the next question is, what conditions will make high density living tolerable?

\section{RESEARCH PROBLEM: HIGH DENSITY IIVING}

While the work of several writers, such as Howard's "Garden Cities" (1898) and Wright's "Broadacre City" (1958), illustrated the prospect of low density amenities, others have pointed out the negative aspects of low density 
development and positive effects of dense living. For example, Le Corbusier (1933) claimed that high density made civilization possible because innovation rests on intense communication enhanced by proximity; he proposed utilizing high-rises amid beautiful parks to achieve the density. Jenson (1966) argued that low density urban expansion absorbed more agricultural land and open space for housing, streets, and other supportive uses; cost more in creating work places, schools, service facilities, and all kinds of infrastmcture; required more time and energy consumption commuting between home and work; and increased air pollution which in time obstmucted solar energy. Soleri (1969) further stressed an ecological concern as a basis for building huge megastructures miles in diameter housing up to two miliion people so as to have fewer miles of impermeable asphalt surface, less dismuption of topsoil and vegetation, and shorter travel distance, resulting in less pollution and less consumption of energy.

Meanwhile, Hawley (1972) viewed density as an economizing factor: it minimized both the time and cost of economic exchanges while creating a wide source of accessible social relations. Verbrugge and Taylor (1980) suggested that although high density might spur competition for local environmental resources such as service facilities, local social resources increased as density increased. Moreover, Jacobs (1961) viewed density as a positive 
social force that not only generated public life and provided many "eyes" in city neighborhoods and parks and on the streets to ensure city health and safety, but also contributed to the diversity of city life in districts with mixed functions. In order to achieve the diversity, Lynch (1965) advocated "a city-wide system of differentiated, compact centers, each reinforced by high density housing". While pro-density writers perceive various forms of population concentration as a crucial factor for social, economic, and ecological aspects of human development, there is a prediction of greater demand for multi-unit housing cver the next decade (Colton, 1980) which indicates a trend toward dense living. A number of factors point in this direction:

First, there is evidence that during recent years single family housing has become more costly for the political jurisdictions within which it is located as well as for the consumers. Costs per household of such services as police and fire protection, trash pick-up, and mail delivery tend to rise as development density decreases. At the same time, the costs of providing these services are increasing at a precipitous rate and are being passed along to area residents. Added service charges in the form of taxes, together with skyrocketing costs of new homes in recent years, have reduced the ability of many consumers to purchase new single-family dwellings. 
Second, as the availability of gasoline decreases and its price rises, the demand for housing at great distances from employment and shopping centers will constrict. Conversely, there will be increases in demand for housing units concentrated around major centers of activity (Marans \& WeIlman, 1976).

Third, census data has shown a great increase in the percent of one-person housenolds (e.g., young singles, divorced persons, and elderly persons) in the United States Thus, there should be an increase in the demand for multiunit housing which is suitable for single person households. The drastic increase in cost and the new demand of home owners and renters is likely to encourage urban housing administrators and builders to work toward the production of multi-unit dwellings to accommodate large concentrations of people in our metropolitan areas.

On the other hand, it is generally known that in designing multi-unit housing, especially for low income groups, architects are usually required to utilize the land as well as possible and keep the initial cost down. This restricts design of projects to a congested mold in the form of multi-story flats with small dwelling units. Mumford (1956) compared public housing projects for low income people to standardized dormitories which have traditionally been built in massive scales and with numerous identical units double loaded along long and narrow corridors leading only 
to stairways and elevator shafts. Economy coupled with lack of imagination in designing multi-unit housing "produced boxlike rows which left tenants feeling like occupants of packed sardine tins on grocery shelves" (Green, 1965, p. 164).

In fact, a body of research has reported that multiunit housing is associated with various adverse outcomes such as negative attitudes toward the environment, perceived crowdedness, social withdrawal, and even deliquency among residents of low-income public housing (McCarthy \& Saegert, 1979; Mitchell, 1971; Newman, 1973; Yancey, 1973), social isolation and dissatisfaction among the elderly (Cranz \& Schumacher, 1977) and among young mothers with small children (Fanning, 1967), and dissatisfaction and unwillingness to help others among dormitory residents (Bickman et al, 1973; Holahan \& Wilcox, 1979).

Since high density living will continue at least in the foreseeable future for part of the world's population, and since certain types of dwelling must be designed to accommodate high density, the problem becomes one of finding designs that will ameliorate any negative effects of dense living.

\section{DESIGNING FOR MULTI-UNIT HOUSING}

The most direct response to greater spatial needs is to increase the amount of space available, but this strategy is not feasible for most low income groups. Since 
the distinction between crowding and density implies that density based on a simple ratio of persons per unit of space is not adequate to predict the subjective feeling of crowding, the manipulation of physical density alone may not be enough to alleviate negative consequences of crowding. ile must go beyond the simple spatial ratio and pay attention to other dimensions which may interact with the spatial dimension to mediate the perception and expression of crowaing. Fortunately, we have at least two sources of suggestions about what kinds of change in high density dwellings could be made-- the architectural literature and the psychological Iiterature.

A body of architectural literature suggests that the appropriate screening of individuals from each other permits a higher concentration of people (Alexander, 1974; Chermayeff \& Alexander, 1963; Jacobs, 1961). For example, Chermayeff and Alexander (1963) suggested that "the individual requires barriers against the sounds and sight of innumerable visitors". Safdie (1970) argued that satisfactory living in high density structures such as Habitat in Toronto is possible if privacy and family identity are guaranteed through sophisticated design.

The recent environmental psychology literature has also explored physical parameters which may ameliorate the effects of spatial restriction. For example, Hayward and Franklin (1974) indicated that the experience of openness of space can be mediated by physical design and need not depend on 
actual extended space. In Mitchell's (1971) terms: "High densities can be architecturally arranged in different ways." Another parameter relates to individual or cultural difference in perception of the living environment; people perceive the environment in different ways. They define needs and their priorities differently, they have different demands of persongl space and territory (Hall, 1966; Sommer, 1969), and they define standards and domains such as space and density differently (Lee, 1968).

The psychological literature also points out that white, university-trained, middle-class designers may not know the world of the person who lives in the housing projects they design. If the architect experiences a different world from the inhabitant, perhaps the architect's intuitions should not serve as a basis for designing the inhabitant:s residence. In addition, when a particular intuition is translated into a design and constructed, there is usually no evaluation of the social psychological success of the building. On the other hand, designers may have some notion that what they are reading is relevant to their work, but they receive little help from the psychological source in translating the behavioral findings into design because psychologists do not usually include any specific design implications of their work.

Since the problem now is to ensure that the design of high density housing is undertaken in the soundest possible way so as to contribute a real solution to high density 
housing and not a stage in creation of the future slums, architects and psychologists need to work together on the problem. It is the coordination of these different types of expertise which facilitates the development of the knowledge for environmental design that will provide the solution for our question: what kinds of design strategies are available for high density housing which would reduce the degree of perceived crowding?

Urban design and architecture involve variations in the physical environment at many different levels of scale, from the macroscopic (e.g., neighborhood and site plans) to the microscopic (e.g., the placement of rooms and walls). Since one purpose of the current research is to increase our ability to create multiple unit dwellings that can economize on space demand and still be comfortable to live in, it focuses on the microenvironment, $1 . e .$, the application to the design of immediate, interior spaces at a field residential setting.

Various high density residential settings have been employed for crowding studies, such as naval vessels (Dean et al, 1975), offshore oil-drilling platforms (Cox et al, 1979), jails and prisons (HcCain et al, 1976; Paulus et al, 1975), housing projects (McCarthy \& Saegert, 1979; Mitchell, 1973), and college dormitories (Baron et al, 1976; Baum \&: Valins, 1977; Bickman et al, 1973; Mandel et al, 1980; Schiffenbauer et al, 1977; Valins \& Baum, 1973). There have been a great number of crowding studies on dormitory population accumulated in recent years. This is partly because 
college students have been easily accessible for research within the academic community and partly because the results obtained in such a real-life setting are relevent not only to professional behavioral scientists but also practicing designers. We should also note that, while individuals on higher levels of the socioeconomic ladder are able to buy space and physical mobility, dormitory residents, generally with fewer avenues to control their living environments and to relocate in less crowded places, are thus among the lower standing groups which need to be studied most.

In the current study, I particularly selected multistory dormitories with comparable density but different architectural design as the setting to study the crowding experience. Specifically, I an studying the problem "how do architectural features of high density dormitories affect residents' perception of crowding, and under what conditions can architectural design alleviate the experience of crowding?" Before describing this research, it is important to clarify the strengths and limitations of the choice of the college dormitory as the setting in which to explore the relationship between crowaing and design.

\section{LIMI TATIONS}

The population surveyed in this research is college students living in multistory dormitories. This special subject pool places limits mainly on the generalization of findings; inferences made from this data may not necessarily 
be assumed to hold for other user groups in other types of residential settings. For example, the physical system involved in general apartments and in dormitories is different in many ways; a private bathroom and a kitohen are usually available in the apartment but not in most dormitories. In addition, the dormitory is a short-term residence for at most a couple of years, and dormitory residents are students in a specific life cycle stage. Thus, the first limitation of the research arises in the attempt to generalize the findings to general multi-unit housing, especially to housing for middle- and upper-income groups who are able to buy space and to have control over their environments.

The second limitation is inherent in the characteristics of the physical surroundings. If the crowded condition of the outside environment affects the tolerable degree of inside crowding, as suggested by Carnahan et al. (1974), then our findings from the selected doms of Oregon State University, a low density campus, may not be generalized to multistory dwellings at inner-city locations.

The third limitation is inherent in the scope of the study. While sociologists and planners are generally cono cemed with crowding phenomena in macro-environments, the present research focuses on the experfence of crowding at a microscopic level, 1.e., within the context the multistory dwelling. The dissimilarities between the inside density in a dormitory environment and the outside density in a general city environment limit the generalizability of our findings 
to macro-crowding phenomena. Nontheless, urban crowding can be characterized as an aggregation of micro-crowding phenomena. An understanding of crowding at the psychological level should have implications for dealing with crowding at the societal level.

\section{STRENG'LTS}

Although we are aware of the subsequent limits of our research, several strengths are inherent in it. First of all, the importance of studying crowding at the microcosmic level, where people spend much of their time relating to others on a personal basis and engaging in personally important activities, should be obvious. Crowding effects in a primary environment are argued to be more crucial than in a macrocosmic one where crowding experiences are more transitory in nature (stokols, 1976).

second, the realistic setting ensures that any findings are ecologically valid. Several writers have claimed that the university is the stage the young seek to pursue knowledge, to meet people, to experience personal development, and to quest for identity, and their needs for living are not only a place for sleep and study but also a place that provides for stimulation, socialization, and privacy. Dormitories do function as the physical and social environments for these needs (Chickering, 1967: E.F.L., 1972; Riker \& Lopez, 1961). In fact, one's ability to explore and control the physical and social environments or to regulate 
privacy and interaction with others is the central element of crowding (Altman, 1975; Stokols, 1976). Since the dormitory is a semi-independent social-physical entity which maintains various linkages to the large university community, it is an ideal setting for crowding research. Third, designers must predict the effects of various architectural changes if they are to create optimal environments in which to live. The ability to draw conclusions about causality is important if data is to be used in the design or alteration of the physical setting. Basic to our perspective is the comparison of relatively comparable $11 \mathrm{~V}-$ ing groups in different environments that can be contrasted along specific design variables. In an experimental gense, treatments are the direct result of architectural variation and the assessment of these treatments is conducted in much the same way as in the laboratory. For our attempt to understand the effects of architectural treatments on crowding in a field setting over which we can exert no direct experimental control, it is important that subject variance be kept minimal. Living in an apartment is likely to have more confounding variables such as family size and age affecting the crowding perception. However, by studying a homogeneous student population residing in architecturaliy different dormitories on one college campus, we are able to observe the effects of design variables that moderate the perception.

Fourth, for the purpose of investigating crowding 
perception, the fact that a greater number of contacts and interactions take place in multistory dormitory than other possible settings due to the large absolute number of residents and the usage of common facilities makes the dormitory a good setting in which to observe orowding phenomena.

Finally, the methodology employed in this research, including the research design and multivariate statistics for data analysis, to assess the interrelationships between housing design and crowding could be utilized for research of similar purposes but in different types of high density residences.

ill in all, as Baron and Mandel (1978) pointed out:

A dormitory setting, although not representative of many residential settings, is a true behavior setting in that it provides a temporarily and spatially bounded context for a variety of important behaviors, and that it avoids to a larger degree the artifical and transitory nature of laboratory crowding studies... Vioreover, dormitory studies offer a sufficiently wide but manageable range of variations in properties of persons and in the properties of internal and external architectural structures that an opportunity exists to explore the complex nature of the interactions that occur between social and physical environments (P. 304). 
CHAPTER II

\section{CROWDING THEORIES AND DETERMINANTS}

While there is an abundance of studies examining the consequences of residing in dense environments, a relatively small literature focuses on how the crowding experience occurs and what factors account for the experience. This chapter presents the major theories of crowding as a necessary aid to understand the crowding phenomenon. Since the effects of high density and the ways to alleviate them cannot be understood until the determinants of crowding are accurately delineated, we also investigate the performance of various determinants, emphasizing the effects of physical factors.

\section{THEORIES OF CROWDING}

It has been pointed out that perceptions of crowding indicate a negative feeling state and are not necessarily related to density levels (e.g., Stokols, 1976). Non-density factors such as friendship groups and architectural features have been shown to affect feelings of crowding (Baum \& Valins, 1977). However, in studies varying physical density, people's reports of crowding strongly reflect differences in actual density (e.g., Desor, 1972; Mitchell, 1971; Saegert et al, 1975). The different conditions detemining perceived 
crowding have led many to theorize about how the crowded feeling occurs.

While various crowding theories have been presented (e.g., Altman, 1978; Saegert, 1978; Stokols, 1976) the models of "stimulation overload", "spatial constraint", and "ecological affordance" have dominated present trends of conceptualization about crowding.

Stimulus Overlosd

Beginning with the classical sociologists Wirth (1938) and Simmel (1950) who argued that the intensification of physical and social stimulation involved in typical city life reduced meaningful personal interaction and resulted in superficial urban social relations, several writers have offered stimulus overload explanations of high density living.

Overload, according to Milgram (1971), refers to one's inability to process excessive inputs from the environment which leads one to experience stress or to adapt by screening out unwanted interaction. Specifically, an individual is regarded as having a limited capacity for information processing which is overloaded when bombarded with too much social or physical stimulation. Decrements in information processing, or stimulation overload, is said to occur when this capacity is exceeded, 1.e., where there are too many inputs which come too fast to process.

The impact of overload on human social behavior has 
been reviewed by Fischer (1976) and Zimbardo (1973). Zimbardo indicated that dense urban living diminished the sense of the relative significance of individuals and social responsibility, which would result in the phenomena of anonymity and deindividuation. Similarly, Fischer argued that urbanites adapt to the overloaded city environment by becoming socially withdraw, showing less concern for others and adopting a generally cool and brusque interpersonal style.

However, an overloaded state may involve various types of effects resulting from different stimuli in the city environment. For example, high density experiences are qualitatively different from experiences of other stressors such as noise. Unlike noise, the presence of other people and one's interactions with them are fraught with social and psychological implications for behavior. Many writers thus have adopted variants of the theoretical model of overstimulation; while some stress social stimuli; others stress sensory stimuli.

Social 0verload. Social overload arises from high density conditions when the number of social interactions or expected interactions that impinge on a person is so great that one's attentional capacity is taxed (Saegert, 1978). Not only is the intensity of interactions demanding of attention, but it creates unpredictability in the environment if one has to interact with different people instead of with the same group of people. The unpredictability of other 
people's Intentions and behavior also places high levels of demand for attention and coordination on the person. As a result of overloaded attentional capacity, individuals are likely to develop tendencies and techniques to regulate their levels of social stimulation.

This hypothesis about the effects of social overload has been confirmed by many studies. The restriction of social and moral involvement that Milgram (1971) described was analogous to the social withdrawal and heightened aggression that Calhoun (1962) observed from some of the rats in his laboratory study. Such withdrawal or aggressive behavior can be interpreted as the consequence of attempting to cope with the high levels of social stimulation in highly dense conditions. The domitory studies at the Stony Brook Campus (Baum et al, 1979; Baum et al, 1975; Baum \& Valins, 1977; Valins \& Baum, 1973) comparing responses between residents living in traditional corridor-style dormitories and those living in comparable density (persons per floor) but in suite-stjle dorms are of particular interest for the purposes of the current study; corridor residents felt more crowded, perceived themselves as having too much undesired contact with others, and tended to seek minimally involving social situations. The stony Brook studies confirmed laboratory findings that even with space per person held constant, subjects perceived more interference and a shortage of space when there were large numbers of other people present (Saegert, 1975). In another experiment 
Desor (1972) asked subjects to place miniature figurines into a model room until the room was just short of being crowded; she found that subjects perceived more crowding in a large undivided room than in the same room when it had been partitioned or had more doors. The results can be interpreted to mean that perceived crowding is related to potential quantity of social encounters in addition to space per person.

Sensory Overload. The concept of overload is equally applicable to excessive physical information since the physical environment contains and affects human activities and thus has functional meaning. It consists of human artifactssensory inputs due to lights, sounds, noises, views, and a wide range of sensory cues from the environment itself which is quite apart from the presence of people and actual amount of face-to-face interactions in the environment. It is said that the modern day urban dweller is bombarded with this wide range of sensory stimulation (Altman, 1975; Rapoport, 1977). Unlike their rural or small town counterparts, city residents continuously encounter complex, intense, surprising, and threatening stimuli. Random bursts of noise, hot and crowded mass transport, and air pollution are among the many inputs encountered during daily activities. Urban congestion and visual complexity could overwhelm the individual perceptual capacities.

Using the capacity model of attention to understand the 
effects of urban and environmental stress, Cohen (1978) drew on research concerning the effects of noise and of high densities to demonstrate that physical and social stimulation have similar effects on attentional processes. He argued that in stress-provoking environments, demands on attentional capacity are created by the intensity, unpredictability, and uncontrollability of the stressor, and that those conditions reduce the amount of attention available for peripheral information. Thus, when simultaneous tasks are performed under stressful conditions, attention is focused on relevant cues to the neglect of less relevant ones. This may lead to poor performance on peripheral tasks.

An exploratory study (Saegert, 1973) found a lack of memory for peripheral cues under conditions of high density. Subjects were brought to a New York department store at a time chosen to assure either high or low density. High density subjects had a less detailed and less correct picture of the area in which they were working.

\section{Behavioral Constraint}

Density may not only result in stimulus overload but may restrict freedom and constrain behavior, in effect producing a sense of helplessness, due to restricted behavioral options. The most obvious consequence of limited space is the reduction of freedom of physical movement. It has been hypothesized (Proshansky et al, 1970; Zlutnick \& Altman, 1972) that maintenence of freedom of choice and control is an important 
concern strongly related to an Individual's affective and behavioral responses to the environment. People are disposed to maintain or restore the freedom when it is threatened, and an individual's reaction to the environment is dependent on his success at accomplishing this end. High density is stressful, according to Proshansky et al. (1970), to the extent that it imposes restrictions on behavioral freedom. If one's behavior is not coordinated by effective norms that prevent unpredictable and unwanted interference, there is a high probability that it will be interrupted and his or her goal attainment will be frustrated. As a result, interference with both goal attainment and freedom of choice can produce crowding (Proshansky et al, 1970).

The theoretical position has been applied by stokols (1972) to the interaction of social behaviors and physical spaces. An individual who perceives that his/her goals are thwarted by inadequate space is more likely to feel spatial impingement. Crowding occurs, according to stokols, in a spatially constrained environment where certain types of behavior are excluded, especially where desired activities are inhibited and when more interpersonal coordination is required.

One extension of the perspective emphasizes the importance of personal control of spatial behavior based on a privacy model. According to Altman (1975), crowding arises from a breakdown in self-other boundary regulation. Crowding effects are predicted to arise whenever the individual's 
desired level of privacy is greater than the achieved level. This presumably occurs when privacy regulation mechanisms such as territories fail to provide the desired level of social interaction. When this occurs, no matter how ample the space or few the stimuli in absolute terms, the person will experience crowding.

The perspective of this model derives from Hall's (1959) observation of both animal and human territorial behaviors for defending a geographically defined space against intmusion. Following the concept of defensibility, Hall (1966) and Sommer (1969) theorized that human interactions are characterized by keeping appropriate distances and that stress results when comfortable personal space is violated. Altman (1975) further developed a conceptual model to integrate the concepts of crowding with privacy, personal space, and territory. Privacy was the central construct, and was related to the regulation of interpersonal interaction through a boundary control process involving the use of personal space and territory. Crowding occurred when the control mechanisms did not function well. Accordingly, crowding in the constraint context is viewed as an outcome of lack of behavioral control and freedom of choice. While the overload approach to crowding deals with the effects and consequences of perceptual and cognitive over-stimulation, the constraint approach postulates that the perception of crowding is inversely related 
to the individual's ability to exercise behavioral freedom and control over one's social and physical environments. In Baron and Rodins' (1978) terms: "The conceptualization distinguishes between the impact of density on attentionarousal processes and its impact on response capabilitycontrol processes."

Recently, the interactive effects of stimulus overload and behavioral constraint have also been explored. Saegert (1973) suggested that both the number of others and their proximity were important to crowding. Increasing the number of others leads to increasing informational complexity, resulting in stimulus overload, whereas the increasing proximity of others increases the salience of information and restricts freedom. In the case of placing large numbers of people in relatively small spaces, it would be expected to greatly heighten the possibility that they will experience attentional overload and difficulties of coordination. Saegert et al. (1975) specifically investigated the interaction effects in two studies of public spaces, in which subjects were required to perform tasks calling for understanding of and movement through the environment under different density conditions. The results indicated that subjects exposed to social overload in restricted spaces developed a less detailed and less accurate imago of the environment than did subjects in low density conditions.

In a comparison of high-rise and low-rise public 
housing projects, McCarthy and Saegert (19'79) found that not only was overload highly related to perceived crowding but also there was a strong relationship between both of these factors and the amount of control people felt over the environment. The residents seemed to experience loss of control over semi-public areas in their building when these were used by many other people (high-rise) and also felt that the building was more crowded. Furthermore, residents who more frequently experienced such situations also had less sense of control over the management of the project, identified less with the project as a whole, belonged to fewer organizations, and generally withdrew from social interaction.

Ecological Affordance

The third feature of contemporary crowding theory is based on an ecological perspective which stresses the link between spatial needs and human adaptions in given behavioral settings. The central assumption of the model is that high density is characterized as disruptive to the degree that it is accompanied by a condition of lack of affordances of the environment to the organisms who reside in the environment (Earon \& Vandel, 1978). The affordances of the environment, according to Gibson (1977), are "what it offers an animal, what it provides or furnishes for good or evil (p. 68)" . Eased on the concept of affordance, variants with different emphases have been developed. 
Environmental Fit. This perspective stresses the disruptive impact of density on the functioning of the social environment. As Baron and Mandel (1978) theorized, density is stressful to the extent that it "interferes with the activities and opportunities for control over social contact normally afforded by the types of living setting (p. 311)." They discussed this type of problem in terms of a general lack of congruence between behavior and environments. For example, they suggested that, considering the functional aifordance of different settings, dormitory bedrooms were intended for sleeping and studying, whereas socializing was primarily a property for lounge areas. Under certain conditions of architecturally generated crowding, however, such bedrooms are forced to serve as lounge areas. Baum and Valins (1977) reported that whereas corridor residents interacted with neighbors living on the same floor in their bedrooms as opposed to the common hallway areas, suite residents manifested a strong tendency to prefer the suite lounge for neighbor interactions. It was interpreted that corridor bedrooms "must" provide for social activities since they functioned as a better setting for social control than the hallways.

The inadequate functional affordance underlying socializing in corridor bedrooms is discussed in terms of a lack of fit between intended and actual environmental functions. The lack of environmental fit is argued to produce crowding (Baron \& Mandel, 1978). 
The model can be applied to Altman's (1975) distinction among primary, secondary, and public territories. Primary territories are clearly identifiable in terms of personal control and are occupied on a permanent basis. Secondary territories are semiprivate and less clearly defined in torms of ownership (e.g., apartment hallways). Public territories are temporary and aro generally open settings wi thout identifiable personal patterns of ownership (e.8., parks and streets). Stokols (1976) further suggested that crowding experiences would be different in primary and in secondary environments. Primary environments are places such as homes and offices where an individual spends large amount of time, and engages in a wide range of personally important social contacts; secondary environments are those such as parks and transportation settings where one's social encounters with others are relatively transitory, anonymous, and inconsequential. Since the primary environments function as the places of affordance for socially significant interactions such as sexual encounters, nurturant encounters, play, and so forth, they should influence mood and behavior differently from those of secondary environments.

Adaptive Compatibility. Another ecological perspective was proposed by Stokols (1976) who suggested that disruptions in afforiance were accompanied by a shortage of social roles or physical resources. The theory is derived from the concepts of dominance hierarchy and territorality used by 
Calhoun (1962) and Dubos (1965) to explain animals' abnormal behaviors in high density conditions. In many animal societies, social organization involves a well defined dominance hierarchy and personal jurisdiction over space. As the population increases, the constant violation of the social norms due to the inevitable confrontations and invasions consequently results in aggressive acts and social wi tharawal (Calhoun, 1962).

This ecological analysis has been applied to human density as stressful to the extent that the availability of social roles or physical resources in a behavior setting is so limited as to result in an over-manning condition (Wicker, 1973) or competition for scarce resources (Stokols, 1978). The former stresses that when a setting becomes overmanned, there are more people available than necessary to maintain operations; the latter emphasizes when the ratio of numbers of persons to numbers of resources grows too great, negative feelings may occur. The distinctive features of this model are reflected in its conceptualization of crowding as a resource management problem and its emphasis on the adaptation of group members to environmental limitations. However, information about the impact of this crowding model is accumulating only sporadically. 
Sumary

According to these theories, crowding is a phenomenon of intensive and uncontrollable stimulation resulting from social and/or physical stressors, of less behavioral freedom or control over a spatial and/or socially constrained environment, or of lack of affordance structures in the physical and/or social environments to serve occupants' behavioral needs. Among these variations, some share of common components, and some may be causally interrelated as well. The critical link among these theoretical perspectives is a situational determinant. The physical variable space, plus the intervening psychological constructs of personal control, information capacities, goals, roles, and concern about threat may interact to produce stress in humans, as Schmidt et al (1979) pointed out:

The propositions that crowding is related to a lack of behavioral freedom and control, that it is precipitated by excessive social and visual stimulation, and that it is mediated by a number of personal, cognitive, and time factors are not mutually exclusive viewpoints.

In fact, as Altman (1978) perceived, there is a consensus among the various theories, i.e., the homeostatic/ equilibrium framework from which these theories are derived. The framework presumes that there is an equilibrium underpinning humen functioning; the human organism is constantly striving to maintain a state of equilibrium. An excessive degree of stimulation or efforts to adjust to constraint or affordance of the environment may absorb so much of the adaptive energy of the organism that it becomes unable to 
cope adequately with or adjust to the undesirable situation inherent in the environment. consequently, the feeling of crowdedness occurs due to the failure to cope or adjust.

\section{DETERMINANTS OF CROWDING PERCEFTION}

In order to determine how experiences and consequences of crowded conditions can be altered, it is necessary to assess the parameters of crowding. In this section, various physical, social, and personal determinants of perceived crowding, which are relevant to but may not be directly applied in this study, are examined.

Physical Determinants

While Calhoun's (1962) study of rats in compressed environments is well known for the density effects, he in fact designed a specific structure so as to provide a high degree of defensible space for some male dominants and a low degree for most. In sections of the experimental pen which could be approached by only one ramp, the most dominant males with their harems gathered in relative spatial comfort, and remained the most normal of the whole population. The rest were cramped into the remaining portions of the pen at excessive densities; because density interfered with normal behavioral patterns, they exhibited various abnormal behaviors. The implication of this design leads us to look for physical interventions which may modify the Individual's reactions to inadequate space. Preliminary exploration has 
been made on the following variables:

Room Dimension. Although density is not equal to crowding, it is obviously one of the antecedent conditions that could precipitate feelings of crowding. As we reviewed in rhapter I, although several experimental studies examining the effects of room size on psychological response (e.g., stress) and behavioral reactions (e.g., task performance) found positive effects of high spatial density (e.g., Freedman, 1972; Loo, 1972; Sundstrom, 1975), a great number of studies examining the effects on perceived crowding and Immediate responses found that groups in smaller rooms reported greater crowdedness, confinement, discomfort, and/ or less friendliness than did similar groups in larger rooms (Baum \& Koman, 1976; Epstein \& Karlin, 1975; Evans, 1975; Rohe \& Patterson, 1974; Ross et al, 1973; Saegert, 1975; Sherrod, 1974; Stokols et al, 1973; and Sundstrom, 1975). Building Type. Although the type or the size of building is only a rough measure of density, high inside density is more or less coincident with multi-unit/multistory dwellings. Gillis (1974) found in his analysis of Edmonton census tract data that only bullding type (single family vs. multiple family) showed a significant relationship with welfare payments and juvenile deliquency when income and ethnicity controls were applied. Comparison of living experiences of otherwise similar high- and low-rise apartment residents revealed that builaing bulk correlated positively with anti-social behaviors and crime rate (Newman, 1973; 
Yancey, 1973), and that high-rise tenants reported feeling more crowded, more anonymous, less safe, and less satisfied with their buildings (McCarthy \& Saegert, 1979). McCarthy and Saegert (1979) explained that high-rise residents would experience more social overload due to the absolute number of people and interactions inherent in the high-rise building, which in turn resulted in more perceived crowding. The effect of overload was also found in a dormitory study (Bickman et al, 1973) in which, compared with residents of low-rise dormitories, residents of the high-rise dorm were less willing to help.

Floor Plan. The Stony Brook research program by Baum and colleagues (Baum et al, 1975; Baum et al, 1979; Baum \& Valins, 1977; Valins \& Baum, 1973) using field and laboratory methods has shown that students who lived in dormitory rooms arranged along double-loaded corridors reported experiencing more crowding, unwanted interactions, and less satisfaction than did those living in suites of a few rooms arranged around a common lounge. Similar results were found in a comparison of long-corridor and short-corridor residents (Baum et al, 1978). One explanation is derived from the overload concept: Students who live in larger living groups tend to meet a greater number of different people in the vicinity of their rooms than those living in smaller living groups. In addition, the physical system has consequences for group interaction and friendship formation which in turn mediate the desirability and control of face-to-face contacts, casual 
socializing, and thus the local crowding experience (Baum \& Valins, 1977).

Room Partitioning. The overload perspective of crowding suggests that the presence of partitions may reduce stress since partitions would help cut down on visual exposure, noise, and other sources of stimulation. Partial support for this position has been found. Desor (1972) reported that people placed more stick figures in scalemodel rooms when partitions were present. Another study also found that the presence of a screen reduced feelings of spatial invasion (Baum et al, 1975). However, Stokols et al. (1975) demonstrated that partitions in a crowded waiting area slightly increased feelings of crowdedness and significantly increased behavioral indices of tension. This finding may be interpreted in terms of the behavioral constraint model of crowding (Stokols, 1976); the partitions may be seen as infringments of individual behavioral options.

Room Shape. One's perception of crowding in a space may aiso be affected by many aspects of the enclosure other than the actual physical size of the space. The shape of the enclosure is one of those aspects. In a projective crowding study Desor (1972) found that when people were instructed to place stick figures in an interior scalemodel up to the point at which the room would become crowded, they placed more figures in rectangular models than square ones with the area held constant.

Floor Height. Several investigations have explored 
the effects of floor height in crowding literature. Two studies of public housing (McCarthy \& Saegert, 1979; Mitchell, 1971) found that residents living on higher floors experienced more crowding in the building. Mitchell's interpretation of the finding is that an escape from crowded conditions is easier for those living close to the ground floor. Meanwhile, a study of a women's dormitory (Schiffenbauer et al, 1977) found that residents who lived on higher floors tended to feel that their rooms were larger. rerhaps the higher floors provide broader views of surrounding areas, hence more openness. A recent dormitory study (Mandel et al, 1980) reported that women on higher floors reported their rooms more spacious than those on lower floors, but opposite results were obtained for men.

\section{Visual Complexity and Distraction. Visual effects}

have also been studied in terms of complexity and distraction. A conception of crowding based on the overload model predicts that complicated or disorderly settings create demands on a person's capacity to assimilate information; such settings are expected to produce greater stress than simple, orderly ones. Baum and Davis (1976) using miniature figures found that a high degree of complexity intensified crowding in darker rooms but only for certain activities. Another study examining the effects of furniture density on perceived room size and spaciousness (Imamoglu, 1973) indicated that there was an inverse relationship between perceived room size and 
furniture density, i.e., the empty room was assessed as the largest and the overfurnished as the smallest. It also found that both the empty and overfurnished rooms were perceived as less spacious than a moderately furnished room. Meanwhile, Coss (1973) argued that the use of deliberate distractions in design may be helpful in reduction of stress in high arousal-producing settings. Some evidence was found by Worchel and Teudlie (1976) that the presence of pictures tended to reduce discomfort that accompanied close interpersonal proximity in groups of males. The implication is that the visually complex features of a crowded setting can sometimes provide a diversion from overloaded conditions that would otherwise produce discomfort, but may at other times contribute to overstimulation.

Brightness. The brightness of a room also appears to affect its perceived crowdedness. Both Baum and Davis (1976) and Schiffenbauer et al. (1977) found that well lit or light colored rooms tended to be perceived as larger than comparable darker rooms and the ratings of crowding were lower in lighter rooms.

Heat and Noige. Both heat and noise may be seen as aversive, arousal-producing stimuli which sensitize people to their environments. The hypothesis presumes that people are often more irritable, prone to outbursts of temper, and more negative in their reactions to others under warmer or noisier conditions. However, little direct ovidence has been reported to support the idea that noise and heat intensify 
crowding stress. In a laboratory experiment, Griffitt and Veitch (1971) placed students in a chamber in groups of various size at different conditions of temperature; high social density and heat produced discomfort but did not enhance each other's effects.

As for the effects of noise, Cohen (1978) recentIy hypothesized that environmental stressors such as noise would place some load on information-processing capacity and would result in an overload state when the load demands exceeded the capacity of the individual. This hypothesis is generally supported by a few studies. For example, in a small group of laboratory studies testing how noise sensitized people to their environment it was found that persons who perceived that they had greater control over noise exhibited fewer behavioral aftereffects and performed better on measures of frustration tolerance and attention to detail than individuals who had no perception of control (Freedman et al, 1972; Glass \& Singer, 1972; Loo, 1973). Meanwhile, a group of field studies found that construction noise significantly decreased people's helping behaviors (Page, 1977) and long-term exposure to traffic noise significantly reduced children's reading ability (Cohen et al, 1973). An interesting finding for current study was that Marshall (1972), in her study of the relationship between privacy and environment, found that persons judged their homes as too crowded when their houses did not allow adequate insulation between quiet and noisy activities. 
Fersonal Determinants

In various analyses of spatial behavior, two aspects of individual differences have generally been involved. They are personal characteristics such as gender, age, and ethnicity, and past experiences of density.

Gender. In examinations of brief exposures to high density, a few studies varied gender and room density and measured crowding or discomfort. Several of them (Baum $\hat{x}$ roman, 1976; Freedman et al, 1972; Ross et al, 1973) found that in same-sex groups, males showed greater discomfort in high room density than did females, while one study (saegert, 1974) reported the opposite result for reports of anxiety, and many of them reported no gender differences in crowding, discomfort, or task performance as a function of room density (Eaum \& Greenberg, 1975; Epstein \& Karlin, 1975; Evans, 1975; Paulus et al, 1976; Stokols et al, 1973; Sundstrom, 1978). As for studies of long-term exposure to high density, while Baum et al. (1975) and Valins and Baum (1973) found no gender differences in residents of college dormitories, ivalden, Nelson, and Smith (1981) reported that female students were less disturbed by the crowded conditions of their rooms. In summary, studies of effects of gender have generally found no consistent results.

Age. Age has been found to be related to spatial needs and the overall trend in age data suggests that young children are more susceptible to crowding than are adults (Aiello it Aiello, 1974; Evans, 1978). 
Race/Culture. It has been argued that ethnic heterogeneity is linked to an individual's experience of overload in the city (Milgram, 1971). The ability to adapt to crowded conditions is likely to be different in different ethnic/ cultural groups. In a comparative study, Schmitt (1966) Indicated that the effects of density could be strongly mediated by a local culture which was characterized by social customs, e.g., long-established traditions of tolerance of high density living, and extreme family cohesiveness. Empirical studies have also supported Hall's (1966) observation that "contact cultures" interact more closely than more distant North Americans (Evan \& Howard, 1973; Mitchell, 1971). Cross-cultural speculations have further illustrated that culture provides the referents necessary for an individual to assign meaning to any level of density or to determine how he/she perceives space (Rapoport, 1977) and that some cultural differences in handing crowding derive from established privacy norms which rely on highly regulated interaction patterns coupled with social hierarchies (Altman, 1975).

Past Experience. Another assumption based on the concept of human adaptation holds that people with a history of intense social interaction are less likely to experience crowding at a given level of density than are people with a history of relative isolation. A field study examining the relationship between density and crowding of one's childhood home and privacy preferences (Marshall, 1972) found that perceived crowding during childhood was significantly related 
to not only childhood density measures such as having a room of one's own, living in a single-family dwelling, number of siblings, and amount of open space but also to current privacy preferences for anonymity and reserve. Similarly, Cozby (1973) reported that individuals who grew up in higher density households had larger personal space zones.

Moreover, while Wohlwill and Kohn (1973) found that urban migrants were more likely to report crowding if they had come from a smaller town than if they had come from a larger one, in a short-term laboratory experiment sundstrom (1978) found that an immediately previous exposure to crowding was shown to increase social withdrawal and create greater personal space needs.

Personality. Personality has been examined as an antecedent of crowding. Evans (1975) used regression analysis to examine several personality variables of students, yet none were significant predictors of crowding.

Time. Another approach to adaptation relates a person's toleration for high density to the length of time for which he/she has been exposed. In laboratory research based on brief exposures (about 40 minutes) to high density, Sundstrom (1975) found a decrease over time in crowding and discomfort in both high and low roum density. However, one field study using repeated measures to examine responses to prolonged high density over a period of 21 days found that 
anxiety increased over time (Smith \& Haythom, 1972). Another field study found that residents of a long-corridor dormitory, compared with short-corridor residents, were more competitive and reactive after 1 and 3 weeks of residence; by the end of 7 weeks, however, they had become more withdrawn, were less involved, and exhibited symptoms of helplessness (Baum et al, 1978).

\section{Social Determinants}

Social determinants of crowding may originate from two sources: 1. one of the types of high density may produce aversive conditions, such as close proximity, and 2 . high density may be accompanied by aversive social conditions Independent of the space supply, e.g., social atmosphere and the nature of setting.

Excessive Proximity. People who are friends or view one another positively may interact more closely, while extreme closeness can be used to threaten another. Some researchers have hypothesized that crowding results from excessive interpersonal proximity, citing evidence that personal space invasion produces disconfort (Altman, 1975). Sundstrom (1975) varied spatial density in groups of six males that included three confederates who were either intrusive or nonintrusive. Intrusion produced discomfort in both large and small rooms. Another experiment by Worchell and Teddlie (1976) also varied interpersonal distance in 
groups and found crowding at close proximity since excessive Immediacy generally leads to the loss of interpersonal behavioral freedom and control. In sumary, studies of the effects of excessive proximity appear to confirm the hypothetical model of behavioral constraint.

Social Climate. Researchers have examined the effects of conditions related to cohesion, liking, cooperativeness, and warmth in a group. Freedman et al. (1975) manipulated positive versus negative feedback and room density; results showed that the positive feedback group in high room density had highest scores on "would participate again". A field study also indicated that persons living in larger groups showed less satisfaction with their social life (Baum \& Valins, 1977).

In contrast, several studies failed to find the effects of social atmosphere. Stokols et al. (1973) found that groups working on a competitive task showed higher scores on crowding than did groups who cooperated, but the effect was not intensified in high density. Smith and Haythorn (1972) conducted a 21-day study of men 1solated in groups of two and three in small and large quarters. The compatibility of the group members was also varied, but it had no effects on stress.

Group Size. Some researchers have examined a social overload hypothesis: a larger number of actual or potential interaction partners may tax a person's capacity for processing information. A few studies varied social density 
(1.e., number of people) in a single room for brief periods of time and found that crowding, discomfort, and other forms of stress were greater in larger groups than in small ones (Griffitt \& Veitch, 1971; Saegert, 1975). Studies that varied the size of expected groups also found greater crowding with higher social density (Baum \& Greenberg, 1975; Baum \& Koman, 1976).

Several field studies examined variations in group size that continued over prolonged periods in such settings as dormitory rooms, naval vessels, prisons, and classrooms. Results generally indicate greater stress with larger groups (Baron et al, 1976; Dean et al, 1975; Paulus et al, 1975; Saegert et al, 1975; Sommer \& Becker, 1971; Walden et al, 1981). On the other hand, D'Atri (1975) reported no difference in crowding as a function of group size in prisons, and Smith and Haythorn (1972) reported that two-man groups showed more stress than three-man groups. Generally, most studies in this topic have confirmed the theoretical model of social overload.

Social setting. The nature of the setting is related to the level of social interaction. Mitchell (1971) found that social features of the household such as the number of nonrelatives sharing a dwelling unit were potential sources of crowding stress. A few experimental studies have examined setting variables of a more social nature. Interpersonal distance is greater in more formal settings and when working on less pleasant tasks, and subjects tend to feel more 
crowded when less structure is anticipated (Edney, 1972). Two studies using miniature figures suggested that crowding occurs at lower densities when the task is solitary than when it is social (Desor, 1972; Cohen et al, 1975). However, a similar study found that crowding was higher in high density rooms regardless of the nature of the situation (Cozby, 1973).

\section{Summary}

It appears, and not surprisingly, that the human responses to crowding are very complex. Al though some inconsistent results have been reported in various areas, it is generally recognized that high density, in and of itself, may not necessarily be detrimental to effective human functioning and may not always lead to the experience of being crowded (Freedman, 1979). Whatever relationship may exist, in Lawrence's (1974) terms, "between high density and aberrant human behaviors, or between the social crowding of the individual and aggression", is mediated by such varlables as interpersonal relationships (Mitchell, 1971) and social and physical structure (Loo, 1973). The current view is that physical, social, and personal ractors determine to a large extent the crowding experience at any density level (Stokols et al, 1973). 


\section{CHAPTER III}

\section{DESIGN OF THE RESEARCH}

The research reported here was designed with the dual purposes of producing data that would further the scientist's conceptual understanding of the effects of high density living and information that architects could use in the design process. To make the data relevant to the designer's concerns, several steps were taken: First, the experiments were performed in field rather than in laboratory settings. Often the designer is concerned about how well laboratory research can be generalized to a real world setting. Doing the research in the real world to begin with gives the results an ecological validity that is necessary if the architect is to base decisions on them.

Another feature of this research is that the conceptual variables important to the ocientist are operationalized and discussed in terms of the architectural features over which the designer has control. The operationalization as well as the hypotheses to be described in this research were made to coincide with specific design decisions. This was done in the hope that the results would be useful to architects as well as to behavioral scientists. 


\section{CONCEPTUALIZATION OF THE RESEARCH}

Recent studies have made it clear that it is not density alone but the ways the social and physical environments are structured and organized and the ways an individual perceives the degree of stimulation, constraint, and affordance of the environment which lead to feelings of crowding. As determined in a relative rather than an absolute context, crowding thus is a function of physical, social, and personal variables.

The model in Figure 1 outlines a network of variables associated with the perception of crowding. It includes the physical, social, and personal determinants of crowding; intermediate channels which explain the processing of the effects of determinants through the overload, constraint, and/or aftordance theories; the affective stage, i.e., the degree of perceived crowding; and the behavioral consequences of and reactions to crowding. These responses include control mechanisms in the form of verbal, nonverbal, personal-space, and territorial behaviors; architectural design; and housing policies which may be employed to modify the determinants so as to reduce their impact on the affective and behavioral levels. Thus a feedback loop is introduced.

Although the perception of crowding may be influenced by physical, social, and personal variables, this research is concerned only with alleviating crowding by altering the design of the physical environment. In order to understand 


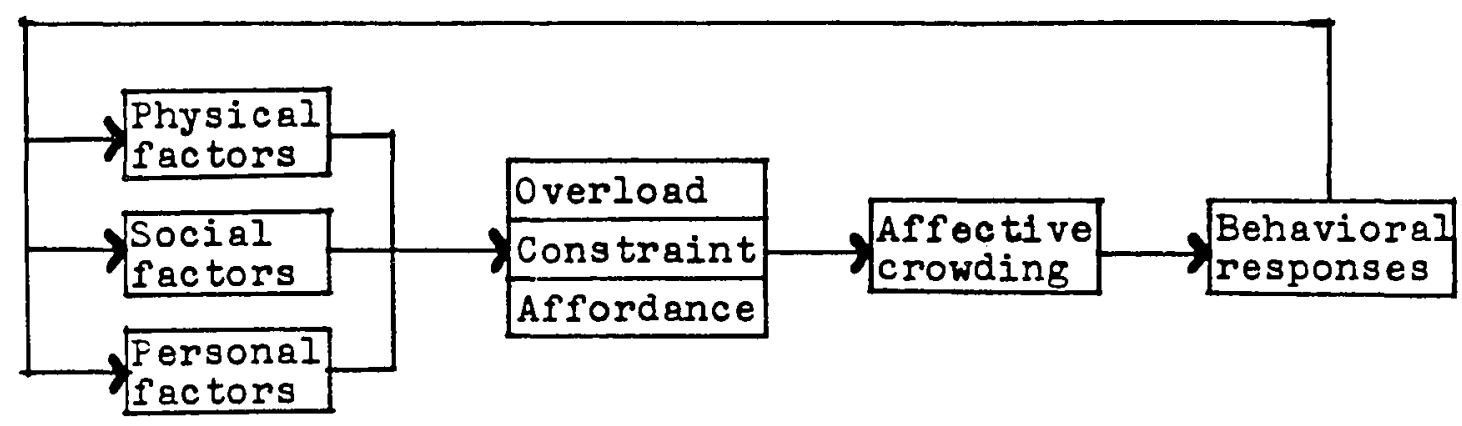

Figure 1. Model of the crowding process

how physical variables, compared with social and personal variables, contributed to perceived crowding, the following hypothesis is first tested in this study:

Hypothesis A: Holding density constant, the physical variables will affect perceived crowding differently from social and personal variables.

is noted in Chapter II, some of the research on the effects of physical, social, and personal determinants is inconsistent, if not contradictory, and may be limited in its potential use because of its laboratory origins. This hypothesis, directed to test the physical, social, and personal parameters of crowding in a selected field setting, may delineate the potential applicability of the reviewed data in real residential settings.

In addition, in the present study although all of the residents live in spaces with comparable density, there may be great variability in how crowded they feel their spaces to be. This variability may be explained by certain physical features inherent in the selected research setting, and the feeling of being crowded may be manipulated by architects or 
residents through the following three physical means available in the setting:

Hypothesis B: Holding density constant, being crowded $c a n$ be reduced if the space can be manipulated to reduce the amount of excessive stimulation.

If Hypothesis $B$ is true, it follows that any architestural features of an enclosed space that reduce the degree to which people therein experience overstimulation, for example, from visual or auditory sources, may reduce the degree to which they are crowded. In other words, the degree of perceived crowding may be reduced in proportion to the reduction in stimulation by means of physical features designed, for example, to reduce or disperse noise or to avoid seeing large numbers of people. Specifically, this study examines the effects of the presence of people and nojse:

B1. Space is perceived as less crowded, if it is designed in such a way that fewer people are seen.

B2. Space is perceived as less crowded as noise is reduced.

Hypothesis $C$. Holding density constant, being crowded can be reduced if the space can be manipulated to reduce the degree of undesired behavioral constraint.

If Hypothesis $C$ is true, it follows that any architectural features of an enclosed space that provide means to reduce the degree of undesired constraint may reduce the degree of perceived crowding. Since territory is a buffer against the invasion of privacy which is a central construct of crowding (Altman, 1975), the degree of perceived crowding 
may be reduced in proportion to the availability of spatial mechanisms such as territory to control interpersonal behav1ors. Specifically, this study examines the effects of territorality:

C1. Space over which a high level of territorial control is executed will be perceived as less crowded.

Hypothesis D: Holding density constant, being crowded $c a n$ be reduced if the space can be manipulated in such a way as to be perceived as more open than it is.

If Hypothesis $D$ is tmue, it follows that any architectural features of an enclosed space that provide means to increase the perceived openness of the space reduce the degree of perceived crowding. In other words, reduction of crowding may accomplished, for example, by employing mirrors, views, and colors that expand the space visually. This study specifically examines the potential of a spacious view:

D1. Space with a more spacious view will be perceived as less crowded.

The above Hypotheses A, B1, B2, C1, and D1 derived from the crowding model are subjected to test in this study.

\section{RESEARCH SETTING}

Three residence halls: Bloss, Finley, and McNary at Oregon State University, Corvallis, Oregon were selected as the research setting. The main floor of each dormitory contains a main lounge, the Head Resident's office and apartment, and various service facilities; the remaining 
floors in each dorm are identical living quarters. As far as the floor plans of living quarters are concerned, McNary Hall was built in 1963 in a conventional corridor format with two double-loaded wings served by a central area including a lounge, an ironing room, a stairway, an elevator shaft, a centralized shared bathroom, and storage areas (Figure 2). Built with a modified corridor design in 1967 , Finley fiall has a service core, with similar facilities but separate common bathrooms at both ends of the core, to serve two shorter wings of double-loaded corridors as well as those living units lining the north and south sides of the core (Figure 3). The most recently constructed hall, Bloss Hall (1972, Figure 4), was also designed in a modified corridor style but fumished with an individual bathroom for every suite instead of common bathrooms in the service core. (A suite is a unit of two rooms with a shared bathroom in between).

The latter two halls, namely, the modified-corridor and the suited-corridor dorms, are seven-story structures located in the same vicinity in the south of the campus, while the 6-story conventional-corridor dorm is located at the east end of the campus. All of them are approximately equally distant from the student union and main library, and have similar surroundings. For example, each has a dining hall next to it and has easy access to open spaces (Appendix A).

All the dorms accommodate students of various class levels and of both sexes. The conventional-corridor dorm 


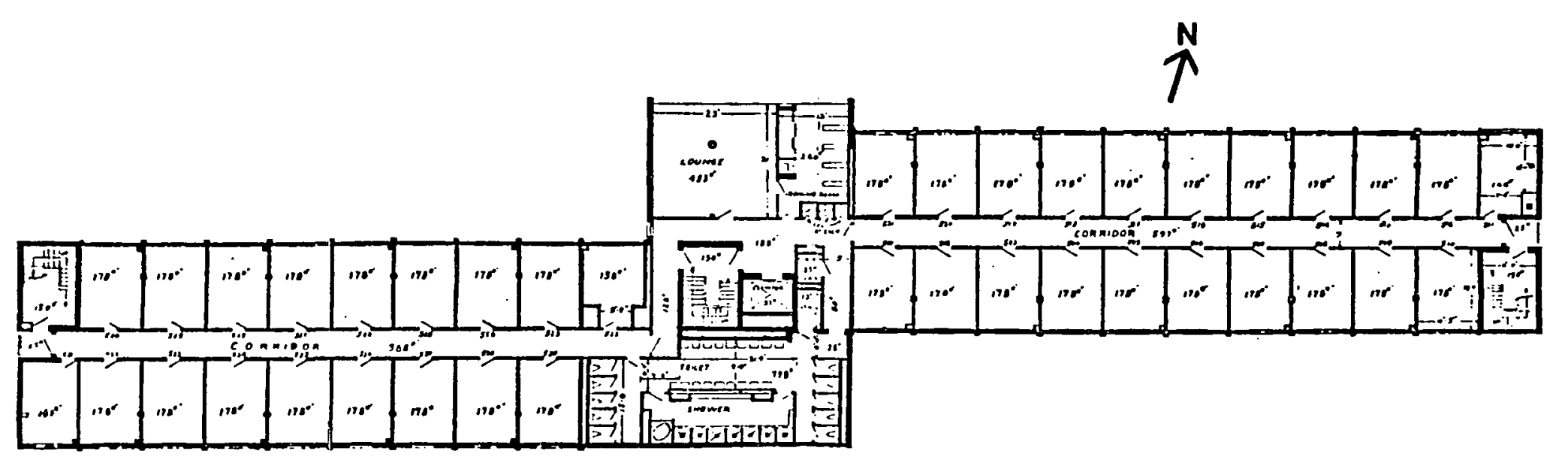

Figure 2. Typical floor plan of Mclvary Hall (Conventional-corridor dormitory) 


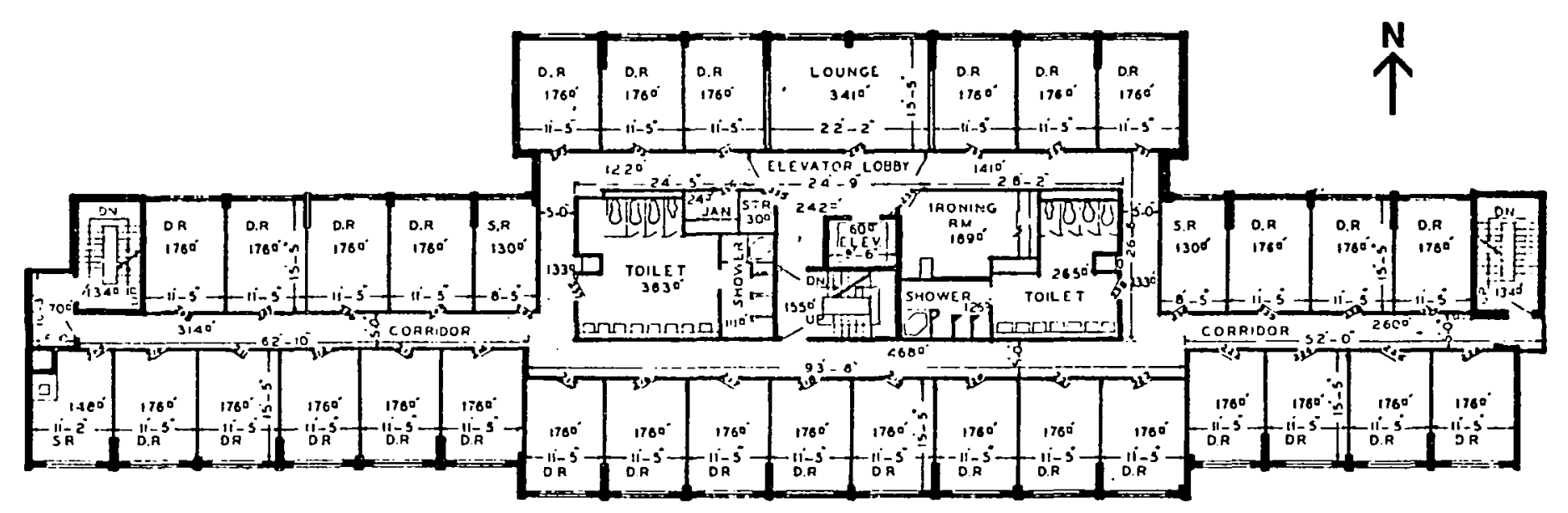

Figure 3. Typical floor plan of Finley Hall (Modified-corridor dormitory) 


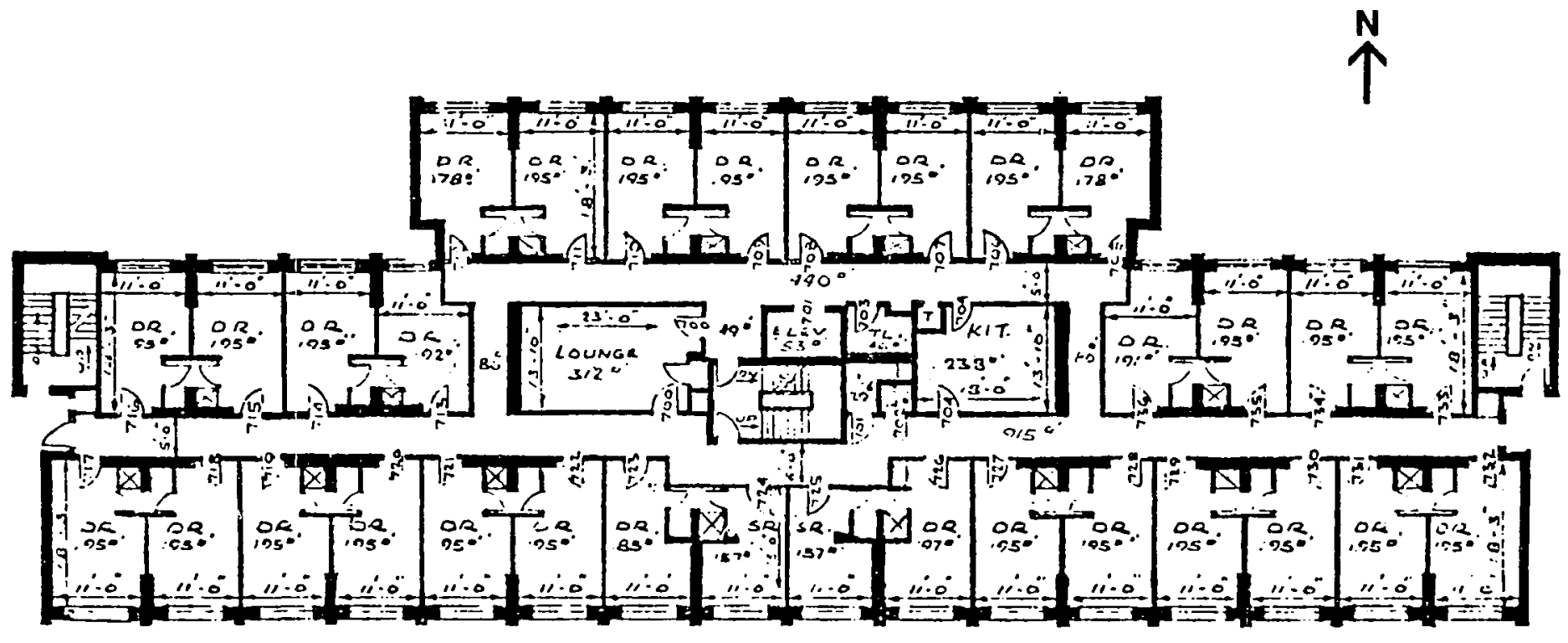

Figure 4. Typical floor plan of bloss hall (Suited-corridor dormitory) 
houses men on the 2nd, 4th, and 6 th floors and women on 3 rd and 5th; the modified-corridor dorm houses men on 2 nd, 4 th, and 6 th, and women on the $3 r d, 5$ th, and 7 th floors; and the suite dormitory is co-ed by suite instead of by floor. The typical floor of the conventional dorm contains 36 double rooms, i.e., rooms designed for double occupancy, and three single rooms; the modified one has 30 doubles and 3 singles; and the suite dorm has 15 double suices and one single suite. In terms of net floor density, each resident is furnished with about $138,151,147$ square feet of space respectively.

As far as the living units are concerned, room fumishing is similar, and every resident has a bed, a wardrobe, a chair, and a desk (Figure 5-a, b, \& c). In typical double rooms of the conventional and modified dorms desks and wardrobes are built-ins; bunk beds are available upon request in all three dorms. The residents can add furniture if they wish, and they often do add an easy chair or a TV set. The rooms are so small, however, that the amount of student-contributed furniture is always small. The density as measured within a double room is about 89 square feet per person in the conventional dorm, 88 in the modified one, and 93 in the suite dorm (including half of the suite bath). Therefore, we consider that residents in all three dormitories are furnished with a comparable amount of space (see Table I for detailed descriptions). 

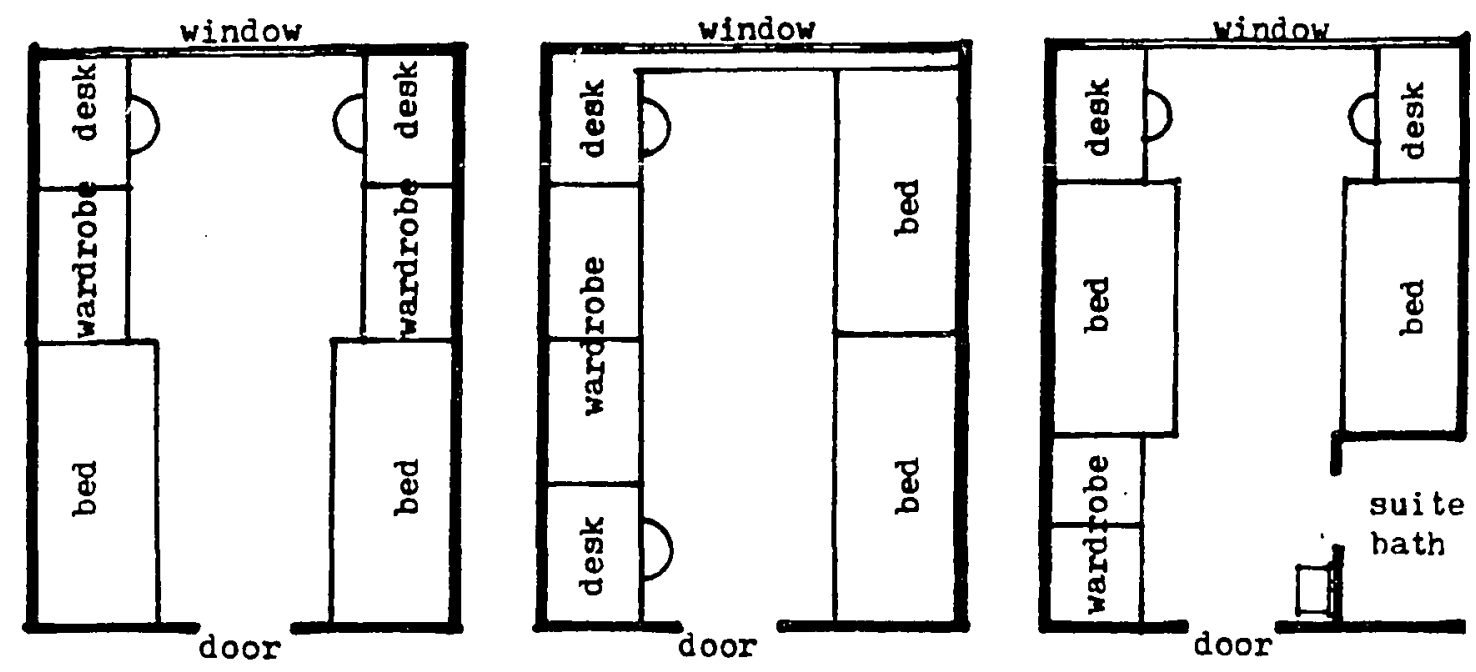

$$
\begin{array}{lrr}
\text { 5-a. McNary } & 5-b . \text { Finley } & \text { 5-c. Bloss } \\
\text { Figure 5. Typical room plans (not to scale) }
\end{array}
$$

TABLE I

COMPARISONS OF BUILDING CHARACTERISTICS

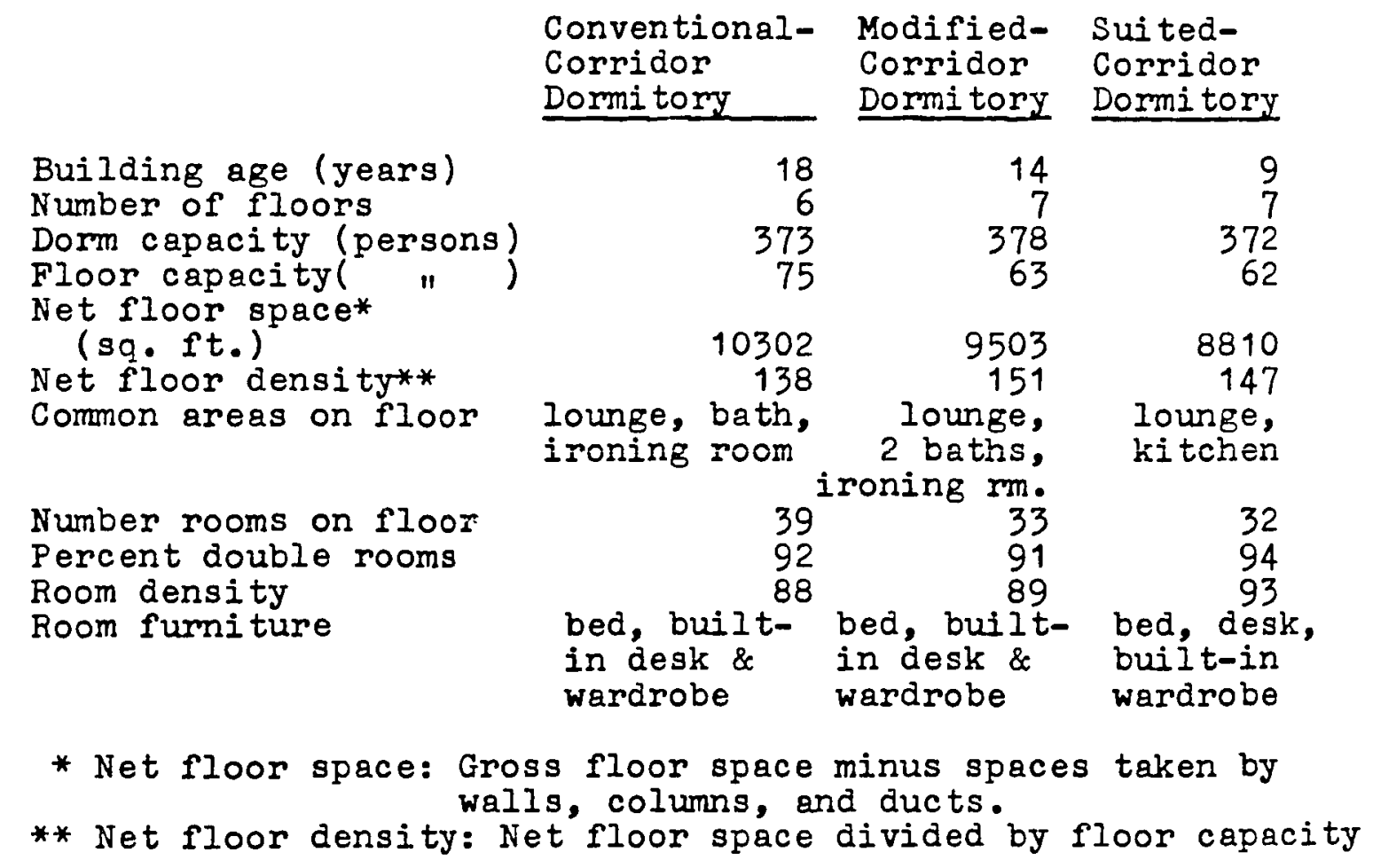


STUDY DESIGN AND HYPOTHESES

The present research consists of three studies. While the first study explores the relationship between the perceived crowdedness and relevant physical, social, and personal conditions in the dormitories, the second and the third studies are specifically designed to assess the effects of physical variations in the design of the dormitory floors and rooms, respectively, on perceived crowding. The central assumptions underlying the research are that the physical environment is a vital determinant of crowding and the categorization of physical elements should provide a basis for developing design guidelines.

Study I: Effects of Fhysical, Social, and Personal Factors

Based on our preceding discussion, the experience of crowding is a function of physical, social, and personal determinants. While there are considerable methodological difficulties in determining the effects of a physical variable independently of other correlated factors, past studies have indicated that the physical structure of an environment can impose absolute limits on human functioning which in turn mediate personal cognitive-perceptual experience toward potential behavioral constraint. In addition, the physical systems have consequences for group interaction and friendship formation which in turn mediate desired level of social stimulation. In other words, there may be an indirect 
relation between physical factors and perceived crowding. Thus, we predict that:

1. Holding density constant, the physical determinants will be significantly different from social and personal determinants in affecting perceived crowding.

The dependent variable for this hypothesis is perceived crowding. Crowding, as an individual's motivational response to the social and physical conditions of the environment, could mean different things to different people in different situations. Thus, crowding perceptions of the individual room, floor, and dorm where respondents resided were measured, and composite crowding scales were created and used as dependent variables so as to capture the possible variations in crowding meaning. As for the independent variables involved in the hypothesis, verjous physical features, personal characteristics, and social dimensions of dormitory living were also measured. All sampled residents of the three dorms were used as subjects in this study as well as in the following study on crowding effects of floor variation.

\section{Study II: Effects of Floor Variation}

In order to test the hypothesis that, holding density constant, space with fewer people present will be perceived as less crowded, a study examining the effects of different physical features of the floor layout on crowding perception was constructed. The floor was chosen because it is the place in which many interactions take place; floor residents share the 
lounge, hallway, elevator lobby, and community bathroom. In addition, each floor has its own social/governmental organization. Since floor residents frequently interact, they are considered to be a living group.

While corridors lead all residents to common spaces and facilities, it is in the corridors themselves where residents frequently encounter persons whose intentions are unknown or whose values may be in conflict with their own, and sometimes meet people when interaction is not wanted. Thus any device that helps control the presence of people in the corridor would reduce the level of stimulation or interaction. The design features specifically examined in the study were the presence of short corridors, access to exits, and dispersion of centralized activities. Three independent hypotheses were designed to test these items.

Effect of Corridor Length. In an unpartitioned space, people can perceive all the other people who are present. Imposing a partition or a barrier in the space may result in a net reduction in the information level, thus leading to less crowding. In addition, studies have indicated that it is easier to control interaction with others in small as opposed to large living groups. In the present study, the central service area of the traditional-corridor dorm divides the floor into two sections, while the service cores in the moaified-corridor and suited-corridor dorms function as barriers dividing the floor into four visually discontinuous and relatively small living sections. Residents who live 
along the short corridors in the modified and suite dorms are likely to receive a smaller amount of stimulation or encounter fewer interactions than those who live along the long corridors in the conventional dormitory. Thus, we predict that:

2. Floors will be perceived as less crowded by persons living in shorter corridors.

The dependent variable involved in the hypothesis is perceived crowding of the floor; the independent variable is length of the corridor.

Effect of Floor Height. Another way to reduce the number of people present in corridors is by providing accessible exits. In our study, there is a stairway located at each end of every dormitory in addition to the centrally located elevator and stairway. People living on lower floors, especially those who live near the ends of the dorms, are likely to use the side-stairways to get in or out of the building. Compared with people on higher floors, the lower floor residents are likely to encounter people less frequently in the corridor due to the possibility of escape from the corridor and due to the dispersed location of activity nodes (stairways). On the contrary, people on higher iloors are likely to make a trip first to the centraliy located elevator in order to get in and out. The stress arising from actual or perceived encounters in the corridor may be enhanced when escape from the overloaded condition is not immediately available. Thus we predict that: 
3. Floors at lower levels will be perceived as less crowded than identical floors at upper levels.

The dependent variable of the hypothesis is perceived crowding of the floor; and the independent variable is floor height.

Effects of Eathroom Iocation. Dispersing geographical locations of activity nodes leads to dispersed activities which may in turn lower the intensity of stimulation and reduce the need to coordinate one's behavior with others. This assumption involving the combined effects of theories of behavioral constraint and stimulus overload is examined by comparing the different bathroom distribution patterns in three selected dorms. The floor design of the conventionalcorridor style with the centrally located bathroom requires that residents encounter each other in the corridor and bathroom and coordinate their behaviors in both settings. Thus, the highest degree of perceived crowding is expected to be found in the conventional-corridor dorm. On the other hand, the suite style design that disperses the bathroom activities in individual suites thus reduces the encounters and interactions taking place outside resident's room to minimum. Thus we predict that:

4. Floors with a less centralized bathroom pattern will be perceived as less crowded.

The dependent variable of the hypothesis is, again, perceived crowding of the floor; and the independent variable is bathroom location. 
Study III: Effects of Room Variation

In order to test the notions that persons with larger territories, with a more spacious view or with less exposure to noise will perceive their spaces as less crowded, this study examines the effects of different architectural features, namely, desk location, window orientation, and room location on perceptions of the resident's room as crowded. Effect of Desk Location. Crowding stress has been theorized to result from the invasion of an individual's privacy, and territory is a buffer against the invasion of privacy (Altman, 1975). In most of the typical double rooms of the modified-corridor dorm and in some of the cases of the suited-corridor one, furniture is arranged in such a way that one person's desk is near the door and the other's is near the window. To the person whose working/studying area is by door, the in-and-out movements of the other person as well as visitors are likely to load to a constant stress due to constant demand for defending one's territory and maintaining privacy. On the contrary, the person whose desk is near the window is likely to have a higher degree of control over his or her territory. Thus, we predict that:

5. Rooms of double occupancy will be perceived as more crowded by the occupants whose desks are closer to door.

The dependent variable involved in the hypothesis is perceived crowding of the room, and the independent variable is desk location. 
Effect of Window Orientation. Another physical element affecting perceived crowding concerns the openness of the room that residents perceive, since it is well noted that the visual perception of space is not only determined by the absolute size of the space. In this research setting, the modified-corridor and suited-corridor dorms were built in parallel on the site with a one-story dining hall in between, and each of them has one side facing the other dorm and the other side facing open spaces. Since those who have a view toward open spaces are likely to perceive a higher degree of openness than those who have blocked views, we predict that:

6. Rooms with a blocked view will be perceived as more crowded than those with an open view.

The dependent variable of the hypothesis is perceived crowding of the roam, the independent variable is window orientation.

Effect of Room location. As noted in Chapter II, noise may be seen as an arousal-producing stimulus which sensitizes people to their environment. It may produce stress and may intensify the stress produced by other aversive conditions. On each floor of the modified- and suitedcorridor dorms some rooms are located in the central section, as opposed to rooms located in the two wings, directly facing the service core. The core area, as we noted earlier, contains spaces for various community activities. It not only serves as a circulation node but also as a gathering 
spot for social and service activities. Under these circumstances, residents in the central section are likely to receive constant noise from the operation of elevator, from the passers-by, and from various activities that take place in the community lounge and bathrooms. Since those who reside in the central section are likely to receive larger amount of noise, we predict that:

7. Rooms facing community areas will be perceived as more crowded than identical rooms in wings.

The dependent variable in this case is, again, perceived crowding of the room, and the independent variable is room location.

Since the architectural layout or the conventionalcorridor dormitory does not include variations in terms of desk location (by door vs. by window), window orientation (with spacious view vs. blocked view), and room location (in core vs. in wing) as the other two dorms do, only the residents of the latter two dorms--the modiried and the suited--were selected as subjects for study III.

\section{METHODOLOGY DESIGN}

\section{Survey Methods}

In consideration of economies of time, energy, and budget, a self-administered questionnaire was used for data collection in this research. Background information for developing the questionnaire, such as issues of residents' 
living conditions in the dormitories, were first gathered through informal interviews with the University officials of the Student Housing Office and Head Residents of the three dorms. A field inventory was then conducted to observe residents' activity patterns at various spaces in the dormitory and to collect a number of physical indices of the built environment.

After the approval of the questionnaire by the University (Appendix B), a pre-test was carried out on the questionnaire design, and necessary changes were made. For the final survey, two copies of the questionnaire were slipped under the doors of sampled double rooms on the same evening in the second half of spring term, 1980. Since most of tenants moved in prior to or at the beginning of the term, we assumed that the novel effects of a new residence would have disappeared after residents had lived there for at least two months. Accompanying the questionnaire (Appendix C) was a cover letter explaining the purposes of the survey and the instruction to return the completed form. Tenants were given ten days to complete and return the questionnaire. A reminder was sent to them a week after the questionnaire was distributed.

Sampling and Subjects

A random sample of one hundred and eighty-nine residents living in typical double rooms of the dormitories was used in our research. Typical double rooms were employed 
as the subject nool because the research was designed mainly to examine the effects of architectural variation while the size of space was controlled. Eased on the number of individual rooms on each floor, a random sampling technique was applied to every floor of each dorm to insure that a representative proportion of subjects was drawn from all floors.

In order to rule out the possible effects of density anc cultural differences on crowding, responses from double rooms with only a single resident and rooms occupied by foreign students were screened out. As a result, the usable return rate was approximately one-third. The major sampling problem we encountered in this research was self selection in that students vere allowed to request placement in a particular dormitory. The individual preference of selecting different living environments may thus be a potential variable confounding the results of our hypothesis testing. In order to examine the influence of other possible confoundinE, factors, a Chi-square test was done to compare the characteristics of residents of the three dorms. As shown in Table II, all residents have a relatively homogeneous background with respect to gender, length of residence, credits taken, ethnicity, and socioeconomic status of the family, since the test revealed that the three dorms did not differ significantly on these variables. The only significant demographic difference among the groups was in average age $\left(\underline{x}^{2}(4,188)=24.40, \mathrm{p}<.01\right)$. A larger proportion of younger people lived in the conventional- 
TABLE II

COMPARISONS OF SAMPLE CHARACTERISTICS

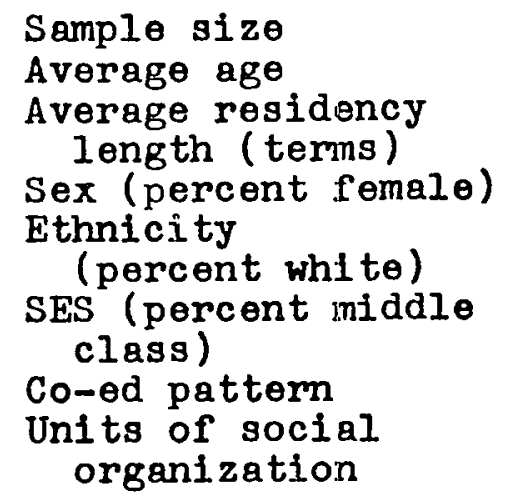

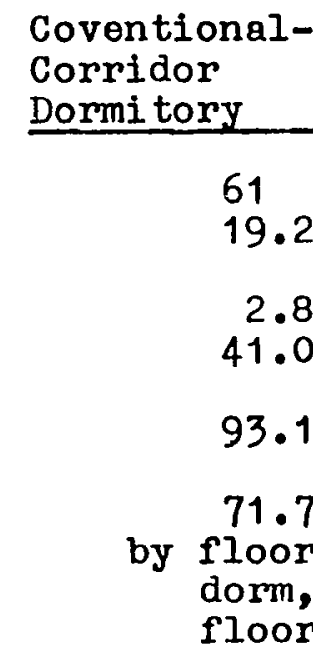

Modified-
Corridor
Dormitory

62

19.9

2.8

93.1

2.9

45.2

95.1

85.2

by floor

dorm,

suited-

Corridor

Dormi tory

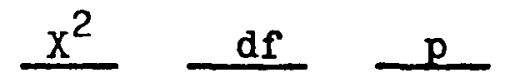

66

$\begin{array}{llll}66.6 & 24.40 & 4,188 & .0001\end{array}$

3.0

37.9

1.15

.70

4,189

n.s.

93.8

.21

n.8.

84.8

by suite

3.54

2,184

n.s.

floor 
corridor dorm, suggesting that effects attributed in the analyses of hypotheses to differences in architecturel desigr could be due to differences in residents' age. This issue was therefore dealt with by taking the effect of age on crowding into account in the hypothesis which tested the explanatory power of physical, social, and personal determinants of crowding perception.

Operational Design of Questionnaire and Variables

The development of the fifty-four-item questionnaire was centered on the three dimensions of crowding determinants: physical, social, and personal. It covered information about residents' personal backgrounds in addition to questions about their experiences and perceptions of various settings in the dormitory. Both open- and closed-ended questions were used and were sequenced in such a way as to avoid having sensitive questions (e.g., ethnicity) appear in the early part of the questionnaire. The data were then coded and processed on the computer at Portland State University. Specifically, the questions contained several sections:

Personal Items. A section of questions was included to obtain factual information about demographic and schooling data. These items dealt with categorical determination of sex, ethnicity, year of school, socioeconomic status of family, etc. For example, Table III shows the measuring categories and distribution pattern of ethnicity. Information conceming age, length of residency, credit load, and past living conditions were collected on interval scales (Table IV). 
TABLE III

FREQUENCY DISTRIBUTION OF ETHNICITY

\begin{tabular}{lrc} 
Categories & Persons & $\%$ \\
\hline Causasian/White & 173 & 94 \\
American Indian/Alaskan native & 3 & 1.6 \\
Black/Afro-American & 0 & 0 \\
Chicano Mexican-American & 2 & 1.1 \\
Pacific Islander/Asian-American & 6 & 3.3 \\
Total (excluding missing information) & 184 & 100
\end{tabular}

Physical Items. Physical variables used in hypothesis testing were operationalized as follows:

Corridor length was measured on a dichotomous scale, i.e., long versus short. The long corridors were those in the conventional dorm, and the short ones were those in the modified and suite dorms.

Floor height ranged from 2 to 7 (the first floor is not a living quarter).

Room location was measured on a dichotomous scale, i.e., rooms located near core areas versus rooms in wings.

Bathroom location was measured on a nominal scale ranging from floors with dispersed buite bating as in the suite dorm, floors with two central baths (dualistic pattern) as in the modified dorm, to floors with one central bath (centralized petterm) as in the conventional dorm.

Desk location was measured on a dichotomous scale, i.e., 
persons with desk located by the door versus those with desk by the window.

Window orientation was measured on a dichotomous scale, i.e., rooms with windows facing open spaces versus rooms with windows facing each other.

Noise level through room partitions was assessed by the question, "how often do you hear noise through the walls of your room?" and rated on a five-point scale ranging from "almost never" to "very often".

Social Items. Another section contained a series of questions rated on five-point bipolar scales to investigate areas of (1) social climate among floor residents, (2) involvement in neighboring behaviors, (3) participation in formal floor and dormitory activities, and (4) privacy from neighbors and roommates, as shown in Table IV. Sample items include:

There is a feeling of unity and cohesion among floor residents. (strongly disagree-strongly agree)

How often do you and your nelghbors exchange or borrow things such as books and tools from one enother? (never- often)

How extensively have you been involved in social, athletic, or governmental activities of this floor? (nevar- very involved)

How much privacy would you say that you have from your roommate? (none- very much)

Intermediate Behavioral Items. The presence of people in corridors was assumed as an intermediate variable between floor height, the independent variable, and perceived floor crowding, the dependent variable; and the noise was assumed 
to be an intermediate variable between room location, the independent variable, and perceived room crowding, the dependent variable. The number of people seen in hallway and bothersome noise were assessed by the following two questions measured on 5-point scales:

How many people in the hallway do you usually see when you walk through 1t? (none-quite a few)

How of ten does the noise you hear bother your sleeping or studying? (almost never- very often)

In addition, a typical room plan and a floor plan were included in the questionnaire to obtain information about the residents' perceptions of their cognitive territories in the room and on the floor. Tenants were asked to shade the area that they considered their territory; the territorial variables were measured as the proportion of shaded area to the space of the whole room or floor.

Perception of Crowding Items. The major dependent variable in the present research was perceived crowdedness. As we noted earlier, crowding experience involves not only physical and social conditions but also personal judgement. People may experience crowding when their goals are blocked by the mere presence of other people even if there is sufficient physical space for all (Stokols, 1976), and they may feel uncrowded even when sharing a restricted amount of space (Freedman, 1975). This makes one question whether terms such as crowding are defined in the same way by the subjects and by the researcher, i.e., whether there is a consensus regarding the key dimensions of crowding. Two steps were 
TABLE IV

SUMMARY OF MEASUREMENT DESCRIPTIONS

\begin{tabular}{|c|c|c|}
\hline Items & Measurement Description & $\begin{array}{l}\text { Interpretation } \\
\text { of High Score }\end{array}$ \\
\hline \multicolumn{3}{|c|}{ Personal/Demographic Dimension } \\
\hline $\begin{array}{l}\text { Demographic } \\
\text { data }\end{array}$ & $\begin{array}{l}\text { Age } \\
\text { Socioeconomic status } \\
\text { Gender } \\
\text { Ethnicity }\end{array}$ & $\begin{array}{l}\text { Older } \\
\text { Lower } \\
\text { Male } \\
\text { White }\end{array}$ \\
\hline Schooling & $\begin{array}{l}\text { Credit load } \\
\text { Year of school } \\
\text { Dorm residency length }\end{array}$ & $\begin{array}{l}\text { Higher } \\
\text { Graduate student } \\
\text { Longer }\end{array}$ \\
\hline $\begin{array}{l}\text { Past } \\
\text { spatial } \\
\text { experience }\end{array}$ & $\begin{array}{l}\text { Dwelling type } \\
\text { Number persons sharing room } \\
\text { Degree perceived crowding } \\
\text { in childhood home }\end{array}$ & $\begin{array}{l}\text { Large apartment } \\
\text { building } \\
\text { Room shared with } \\
3 \text { or more people } \\
\text { Not crowded } \\
\text { at all }\end{array}$ \\
\hline
\end{tabular}

Social/Behavioral Dimension

\begin{tabular}{|c|c|c|}
\hline $\begin{array}{l}\text { Social } \\
\text { climate on } \\
\text { floor }\end{array}$ & $\begin{array}{l}\text { Degrees of perceived unity } \\
\text { \& cohesion, of perceived } \\
\text { ease in making friends, of } \\
\text { perceived friendly places } \\
\text { Degree of perceived } \\
\text { acquaintance }\end{array}$ & $\begin{array}{l}\text { Strongly } \\
\text { disagree }\end{array}$ \\
\hline $\begin{array}{l}\text { Neighboring } \\
\text { involvement }\end{array}$ & $\begin{array}{l}\text { Frequency of doing things } \\
\text { together and of borrowing/ } \\
\text { exchanging things }\end{array}$ & Never \\
\hline $\begin{array}{l}\text { Organiza- } \\
\text { tional par- } \\
\text { ticipation }\end{array}$ & $\begin{array}{l}\text { Intensities of participation } \\
\text { in formal social/athletic/ } \\
\text { governmental activities of } \\
\text { floor and dorm }\end{array}$ & Never \\
\hline Privacy & $\begin{array}{l}\text { Degrees of perceived privacy } \\
\text { from roommate and from } \\
\text { neighbors }\end{array}$ & None \\
\hline $\begin{array}{l}\text { Territori- } \\
\text { ality }\end{array}$ & $\begin{array}{l}\text { Proportions of cognitive } \\
\text { territory in room and on } \\
\text { floor }\end{array}$ & Larger size \\
\hline $\begin{array}{l}\text { Number } \\
\text { people in } \\
\text { hallway }\end{array}$ & $\begin{array}{l}\text { Number of people seen in } \\
\text { the hallwey }\end{array}$ & None \\
\hline
\end{tabular}


TABLE IV (continued)

\begin{tabular}{|c|c|c|}
\hline I tems & Measurement Description & $\begin{array}{l}\text { Interpretation } \\
\text { of High Score }\end{array}$ \\
\hline $\begin{array}{l}\text { Bothersome } \\
\text { noise }\end{array}$ & $\begin{array}{l}\text { Frequency of perceived } \\
\text { bothersome noise in room }\end{array}$ & Never \\
\hline \multicolumn{3}{|c|}{ Physical/Design Dimension } \\
\hline $\begin{array}{l}\text { Corridor } \\
\text { length }\end{array}$ & $\begin{array}{l}\text { Long corridors vs. short } \\
\text { corridors }\end{array}$ & Short \\
\hline $\begin{array}{l}\text { Floor } \\
\text { height }\end{array}$ & $\begin{array}{l}\text { Floor level on which } \\
\text { resident lives }\end{array}$ & Higher \\
\hline $\begin{array}{l}\text { Room } \\
\text { location }\end{array}$ & Core group vs. wing group & Wing \\
\hline $\begin{array}{l}\text { Bathroom } \\
\text { location }\end{array}$ & $\begin{array}{l}\text { Dispersed, dualistic, and } \\
\text { centralized patterns }\end{array}$ & Centralized \\
\hline $\begin{array}{l}\text { Desk } \\
\text { location }\end{array}$ & $\begin{array}{l}\text { Desk by the door vs. by } \\
\text { the window }\end{array}$ & By the door \\
\hline $\begin{array}{l}\text { Window } \\
\text { orientation }\end{array}$ & Open view vs. blocked view & Open view \\
\hline Noise level & $\begin{array}{l}\text { Frequency of noise through } \\
\text { walls }\end{array}$ & Never \\
\hline \multicolumn{3}{|c|}{ Crowding Dimension } \\
\hline $\begin{array}{l}\text { Room } \\
\text { crowding }\end{array}$ & $\begin{array}{l}\text { Degrees of perceived size, } \\
\text { of perceived spaciousness, } \\
\text { \& of perceived crowdedness }\end{array}$ & $\begin{array}{l}\text { Large } \\
\text { Spacious } \\
\text { Uncrowded }\end{array}$ \\
\hline $\begin{array}{l}\text { Floor } \\
\text { crowding }\end{array}$ & $\begin{array}{l}\text { Degrees of perceived size, } \\
\text { of perceived spaciousness, } \\
\text { \& of perceived crowdedness }\end{array}$ & $\begin{array}{l}\text { Empty } \\
\text { Spacious } \\
\text { Uncrowded }\end{array}$ \\
\hline $\begin{array}{l}\text { Dorm } \\
\text { crowding }\end{array}$ & $\begin{array}{l}\text { Degree of perceived } \\
\text { crowdedness }\end{array}$ & $\begin{array}{l}\text { Not crowded at } \\
\text { all }\end{array}$ \\
\hline
\end{tabular}

taken to deal with the issue.

First, the crowding variable consisted of several

items rather than one. These were designed to measure the 
respondents' perception of crowding at three levels--the room, the floor, and the dormitory. The question pertaining to perceived crowding within the room was: "How adequate do you feel the space in your room is?", and perception was measured by three items on five-point bipolar rating scales, namely, "small-large", "cramped-spacious", and "crowdeduncrowded". Similarly, the perceived crowding of the floor was measured by the items "full-empty", "cramped-spacious", and "crowded-uncrowded". The question pertaining to perceived crowding in the dormitory as a whole was: "How crowded do you feel living in this dorm?", measured on a five-point rating scale ranging from "very crowded" to "not crowded at al1".

Construction of Crowding Indices

In dealing with the issue of defining crowding, composite crowding indices rather than individual crowding items were used as dependent variables. Principal component analysis was used as the major tool to build the indices. Based on subprograms of Statistical Package for the Social Science (SPSS), a principal component analysis with a varimax rotation procedure was carried out with all seven crowding measures, resulting in two factors. All items relating to room crowding heavily loaded on one factor and the remaining four items on the other (Table V, see Appendix D for the correlation matrix).

Room Crowding Index. To use principal component 
analysis in building a composite index, the variables involved should have relatively high loadings on a single factor. Since all items relating to room crowding had high loadings on one factor, it was possible to build a composite room crowding scale by either employing the factor scores or suming the raw scores of the three items. The latter method, which has been commonly used in psychological research, was employed because the differences in factor score coefficients among the three items of room crowding were small (see Table V) and because factor scores would be more appropriate if there were true interval data rather than the present data in which most variables were measured on five-point scales.

In addition, a reliability analysis (Table VI) with item-total correlations was carried out. As shown in Table VI, the differences in mean value among the three items were small, the alpha was high, and the item-total correlations were high. Therefore, the raw scores of the three items were assigned by an equal weight and were summed to build the composite room crowding index. Floor Crowding Index. Using the same procedure, a composite crowding index was constructed for the three hypotheses involved in Study II designed to test the effects of floor height and physical variation of floor design among dormitories. Table V showed that the three items measuring floor crowding were loaded heavily on one factor and varied little in factor score coefficients (Table V); the reliability 


\section{TABLE V}

VARIMAX ROTATED FACTOR MATRIX WITH FACTOR SCORE COEFFICIENTS OF OVERALL PERCEIVED CROWDING

$\begin{array}{lll}\text { Instrument Items } & \text { Factor } 1 & \text { Factor } 2 \\ \text { Room: Small- large } & .206(-.096) & .840(.400) \\ \text { Cramped- spacious } & .247(-.083) & .872(.408) \\ \text { Crowded- uncrowded } & .167(-.119) & .858(.419) \\ \text { Floor: Full- empty } & .575(.233) & .194(-.030) \\ \text { Cramped- spacious } & .859(.346) & .299(-.040) \\ \text { Crowded- uncrowded } & .880(.385) & .175(-.110) \\ \text { Dorm: Very Crowded-not } & .802(.363) & .108(-.129) \\ \text { crowded at all } & & \end{array}$

analysis showed small mean differences, a high alpha, and high item-total correlations among the three items (Table VI). Thus, the composite floor crowding index was built by summing the raw scores of all items measuring floor crowding.

Dwelling Crowding Index. For the purpose of understanding how physical, social, and personal determinants affect perceived crowding in the dormitories, a composite dwelling crowding scale was constructed. Since the item measuring perceived dorm crowdedness and the three items measuring perceived floor crowding were heavily loaded on a single factor and their factor score coefficients varied little (Table V), and since there were small mean differences, a high alpha, and high item-total correlations (Table VI), the dwelling crowding index was built by summing the raw scores of the four items. 
TABLE VI

REIIABILITY ANALYSES FOR ROOM, FLOOR, AND DWELLING CROWDING

\begin{tabular}{|c|c|c|c|c|}
\hline Items & $\overline{\mathrm{X}}$ & S.D. & & $\begin{array}{l}\text { Item-Tot } \\
\text { Correlet }\end{array}$ \\
\hline \multicolumn{5}{|l|}{ Room Crowding } \\
\hline Small-large & 2.29 & .99 & & .71 \\
\hline Cramped-spacious & 2.41 & .93 & & .79 \\
\hline Crowded-uncrowded & 2.64 & 1.03 & & .71 \\
\hline $\begin{array}{l}\text { * Reliability } \\
* * \mathrm{~N}=179\end{array}$ & coefficient: & Alpha = & .86 & \\
\hline \multicolumn{5}{|l|}{ Floor Crowding } \\
\hline Empty-full & 2.49 & .92 & & .47 \\
\hline Cramped-spacious & 2.92 & .85 & & .74 \\
\hline Crowded-uncrowded & 3.04 & .98 & & .69 \\
\hline $\begin{array}{l}* \text { Reliability } \\
* * \mathrm{~N}=177\end{array}$ & coefficient: & Alphe = & .78 & \\
\hline \multicolumn{5}{|l|}{ Dwelling Crowding } \\
\hline Enpty-full & 2.49 & .92 & & .42 \\
\hline Cramped-spacious & 2.93 & .85 & & .79 \\
\hline Crowded-uncrowded & 3.03 & .96 & & .76 \\
\hline $\begin{array}{l}\text { Very crowded-not } \\
\text { crowded at all (do) }\end{array}$ & $\mathrm{mm})$ & 1.20 & & .60 \\
\hline $\begin{array}{l}\text { * Reliability } \\
* * \mathrm{~N}=176\end{array}$ & coefficient: & Alpha = & .81 & \\
\hline
\end{tabular}

Statistical Design

Various subprograms in the SPSS Package were employed for statistical testing. Several criteria were used as rationales for choosing. each statistical test, such as the manner in which the sample was drawn, the nature of the population, and the levels of measurement of the variables involved. Multiple linear regression (MIR) and analysis of variance 
(ANOVA) were the major tools for hypotheses testing. Also, principal component analysis (PC) and Poarson's correlation analysis were used to reduce the number of variables inserted in the equations of regression analysis so that the problem of collinearity among independent variables could be avoided. MIR is a statistical technique through which one can analyze the relationship between a dependent variable and a set of independent variables. Through MLR we can obtain a prediction equation that indicates how much of the variation in perceived crowding is accounted for by the juint and separate influences of a set of independent variables, and obtain statistics that indicate the relative importance of each variable. MLR allows us to control for confounding factors in order to evaluate the contribution of a specific variable or set of variables. Specifically, to test Hypothesis 1 we assessed the crowding effects of the physical environment after the effects of social and personal factors were taken into account. Analysis of variance was employed to test hypotheses 2 to 7. It was performed to examine the significant differences between mean perceived crowding scores for two or three semple groups who experienced different physical conditions. Also, Pearson's $\underline{r}$ was used to examine the interrelationships between dependent, intermediate, and independent variables. In analyzing the correlation, 
an $\underline{\underline{r}}$ between \pm .15 to \pm .25 was considered to indicate a relationahip worthy of further exploration and a coefficient exceeding \pm .25 was considered significant. While the details of statistical design for hypothesis testing are elaborated along with the analysis of data presented in the following chapter, a preview of the overali design framework for the research is sumarized in Table VII. 
SUMMARY OF HYPOTHESES, VARIABLES, AND STATISTICAL DESIGN

\begin{tabular}{|c|c|c|c|}
\hline Hypotheses & Variables* & $\begin{array}{l}\text { Level of } \\
\text { Measure? }\end{array}$ & Statistics \\
\hline Study I & $\begin{array}{l}Y-\text { Perceived room \& } \\
\text { dwelling crowding }\end{array}$ & 0 & \\
\hline $\begin{array}{l}\text { 1a. Phyoical determinants will be signifi- } \\
\text { cantly different from social \& personal } \\
\text { determinants in affecting room crowding. }\end{array}$ & $\begin{array}{l}\text { X- } 5 \text { physical, } 4 \\
\text { personal, \& } 3 \\
\text { social predictors }\end{array}$ & $D, 0, I$ & $\begin{array}{l}\text { Pearson CORR, } \\
\text { PC, \& } \\
\text { SImple MLR }\end{array}$ \\
\hline $\begin{array}{l}\text { 1b. Physical determinants will be signifi- } \\
\text { cantly different from social \& personal } \\
\text { determinants in affecting dwelling } \\
\text { crowding. }\end{array}$ & $\begin{array}{l}X-4 \text { physical, } 4 \\
\text { personal, \& } 3 \\
\text { social predictors }\end{array}$ & $D, 0, I$ & $\begin{array}{l}\text { Pearson CORR, } \\
\text { PC, \& } \\
\text { Simple MLR }\end{array}$ \\
\hline Study II & $\begin{array}{l}\text { Y- Perceived floor } \\
\text { crowding }\end{array}$ & 0 & \\
\hline $\begin{array}{l}\text { 2. Floors will be perceived as less } \\
\text { crowded by persons living in shorter } \\
\text { corridors. }\end{array}$ & $\begin{array}{l}\text { X- Corridor length } \\
\text { XY - Number people } \\
\text { seen in hallway }\end{array}$ & $\begin{array}{l}\mathrm{D} \\
0\end{array}$ & $\begin{array}{l}\text { 1-way ANOVA, } \\
\text { Peargon CORR }\end{array}$ \\
\hline $\begin{array}{l}\text { 3. Floors on lower levels will be } \\
\text { perceived as less crowded than those } \\
\text { on upper levels. }\end{array}$ & $\begin{array}{l}\text { X- Floor height } \\
\text { XY- Number people } \\
\text { seen in hallway }\end{array}$ & I & $\begin{array}{l}\text { 1-way ANOVA, } \\
\text { Pearson CORR }\end{array}$ \\
\hline $\begin{array}{l}\text { 4. Floors with a less centralized bathroom } \\
\text { patterm will be perceived as less crowded }\end{array}$ & $\mathrm{X}$ - Bathroom location & $\mathbf{N}$ & $\begin{array}{l}\text { 1-way ANOVA, } \\
\text { w/ Contragts }\end{array}$ \\
\hline Study III & $\begin{array}{l}\text { Y- Perceived room } \\
\text { crowding }\end{array}$ & 0 & \\
\hline $\begin{array}{l}\text { 5. Rooms will be perceived as more crowded } \\
\text { by persons whose desks are closer to door }\end{array}$ & $\begin{aligned} X-\text { Desk location } \\
X Y-\text { Room territory }\end{aligned}$ & $\begin{array}{l}\text { D } \\
I\end{array}$ & $\begin{array}{l}\text { 1-way ANOVA, } \\
\text { Peargon CORR }\end{array}$ \\
\hline $\begin{array}{l}\text { 6. Rooms with a blocked view wili be } \\
\text { perceived as more crowded than those } \\
\text { with an open view. }\end{array}$ & $\begin{array}{l}\mathrm{X} \text { - Window orientation } \\
\text { Desk location } \\
\text { Floor height }\end{array}$ & $\begin{array}{l}\text { D } \\
\text { D } \\
\text { I }\end{array}$ & \begin{tabular}{|l|} 
1-way ANOVA, \\
3-way ANOVA
\end{tabular} \\
\hline $\begin{array}{l}\text { 7. fooms facing community areas will be } \\
\text { perceived as more crowded than those } \\
\text { in wings. }\end{array}$ & $\begin{array}{l}X-\text { Room location } \\
X Y-\text { Bothersome noise }\end{array}$ & $\begin{array}{l}\text { D } \\
0\end{array}$ & $\begin{array}{l}\text { 1-way ANOVA, } \\
\text { Pearson CORh }\end{array}$ \\
\hline
\end{tabular}


CHAP TER IV

\section{ANALYSIS OF THE DATA}

The purpose of this chapter is to present the results of statistical investigation of the research data relevant to the three specifically designed studies: the first examines the relationships between perceived crowding and its physical, social, and personal determinants; the second assesses the effects of different physical conditions on the perception of crowding on the floor of the dorm; and the third assesses the effects of different physical conditions on perceived crowding within the room.

\section{ANALYSIS OF STUDY I}

Subjects involved in this study were sampled residents of all three dormitories $(N=189)$, and the hypothesis to be tested was:

$$
\begin{array}{ll}
\text { Hypothesis 1. Holding density constant, physical } \\
\text { determinants will be significantly } \\
\text { different from social and personal } \\
\text { determinants in affecting perceived } \\
\text { crowding. }
\end{array}
$$

As shown in Table $\bar{V}$, the results of principal component analysis of all seven crowding measures showed that room crowding measures heavily loaded on one factor and floor and dorm measures on another factor, implying that perceptions of crowding may differ from one setting to another within the 
domitory. The individual's daily activities take place both within and outside the living units, which correspond to the primary and secondary territories of Altman (1975), and each place varies in its social and physical functions. According to Baron and Mandel's (1978) hypothesis regarding the effect of affordance in specific environments reviewed in Chapter II, crowding experiences in the two settings are likely to be different.

Therefore, it appears important to test Hypothesis 1 using crowding as the dependent variable at both the room and dwelling levels since different physical, social, and personal factors may be associated with crowding in each of the two distinctive spheres. The following two sub-hypotheses were tested:

1a. Physical determinants will be significantly different from social and personal determinants in affecting perceived room crowding.

1b. Physical determinants will be significantly different from social and personal determinants in affecting perceived dwelling crowding.

Regression analyses were employed to assess the two hypotheses, in which the constructed composite scales of perceived room crowding and dwelling crowding were used as criterion variebles, and several physical, social, and personal variables were used as predictors in the two regression equations. Preceding the analyses, three groups (i.e., physical, social, \& personal) of potential crowding determinants were first selected based on their theoretical connections with crowding. In order to measure important 
aspects of the three dimensions of crowding and to avoid the problem of collinearity, only a small number of crowding predictors to be used in the MLR were then selected through correlation or principal component analysis of the three groups of hypothetical crowding determinants.

Correlation and Principal Component Analyses of Crowding Determinants

Selection of Physical Determinants. Because two separate regression equations were employed to assess room crowding and dwelling crowding, two sets of physical factors were selected as crowding predictors to be used in the equations. As far as room crowding is concerned, theoretical connections between the dependent crowding variable and the independent variables of desk location, window orientation, and iusisg level have been presented in Chapter III. In addition, floor height has been found to affect perceived room size (Mandel et al, 1980; Schiffenbauer et al, 1977) and crowding experience (McCarthy \& Saegert, 1979; Mitchell, 1971). In addition, we assume that use of facilities in community baths or a suite bath may result in competition or a need for coordination which is a central construct of crowding (stokols, 1978). Therefore, these five variables: desk location, window orientation, noise level, bathroom patterns, and floor height, were all considered to potentially affect the perception of room crowding.

In order to avoid the problem of collinearity, all physical variables involved in this research were inter- 
correlated (Table VIII). Since none of the correlation coefficients among these five variables was over .25, all five items were selected as predictors to be used in the regression equation.

As far as dwelling crowding is concerned, the theoretical connections between the dependent crowding variable and the independent variables of bathroom patterns, floor height, and corridor length have been discussed in Chapter III. We assume that room location in the core area as opposed to the wing is likely to be related to the frequency of encountering or interacting with others, which in turn affects perceived dwelling crowding. In addition, the intensity of noise received in one's room may reflect the level of activities taking place outside the room, which may in turn affect the perception of dwelling crowding. Therefore, these five variables: bathroom patterns, floor height, corridor length, room location, and noise level were all expected to affect perceived dwelling crowding. Checking the correlation coefficients among these five variables in Table VIII, we found corridor length significantIy correlating with room location ( $\underline{r}=.37, \underline{p}<.01$ ), noise level $(\underline{\underline{r}}=.29, \underline{\mathrm{p}}<.01)$ and bathroom patterns $(\underline{\underline{r}}=.51, \underline{\mathrm{p}}<$ .01). As a result, we selected room location, noise level, bathroom patterns, and floor height but eliminated corridor length as the predictors to be used in the regression equation for perceived dwelling crowding; the effects of corridor length were examined in Study II. 
TABLE VIII

INTERCORRELATIONS AMONG PHYSICAL VARIABLES

\begin{tabular}{|c|c|c|c|c|c|c|c|c|}
\hline \multicolumn{2}{|c|}{ Items } & & 1 & 2 & 3 & 4 & 5 & 6 \\
\hline 1. & $\begin{array}{l}\text { Desk } \\
\text { location }\end{array}$ & $\begin{array}{l}r= \\
N= \\
p=\end{array}$ & $\begin{array}{l}= \\
= \\
=\end{array}$ & & & & & \\
\hline 2. & $\begin{array}{l}\text { Window } \\
\text { orientation }\end{array}$ & $\begin{array}{l}\mathbf{r}= \\
\mathbf{N}= \\
\mathbf{p}=\end{array}$ & $\begin{array}{r}=-.01 \\
=\quad 89 \\
=\quad .45\end{array}$ & & & & & \\
\hline 3. & $\begin{array}{l}\text { Noise level } \\
\text { througn } \\
\text { walls }\end{array}$ & $\begin{array}{l}\mathbf{r}= \\
\mathrm{N}= \\
\mathrm{p}=\end{array}$ & $\begin{array}{l}=.01 \\
=\quad 89 \\
=\quad .47\end{array}$ & $\begin{array}{l}-.16^{*} \\
189 \\
.01\end{array}$ & & & & \\
\hline 4. & $\begin{array}{l}\text { Bathroom } \\
\text { patterns }\end{array}$ & $\begin{array}{l}\mathbf{r}= \\
\mathbf{N}= \\
\mathbf{p}=\end{array}$ & $\begin{array}{r}=-.16 \\
=\quad 89 \\
=\quad .07\end{array}$ & $\begin{array}{r}-.03 \\
189 \\
.35\end{array}$ & $\begin{array}{l}.10 \\
189 \\
.09\end{array}$ & & & \\
\hline 5. & $\begin{array}{l}\text { Floor } \\
\text { height }\end{array}$ & $\begin{array}{l}r= \\
N= \\
p=\end{array}$ & $\begin{array}{l}=.04 \\
=\quad 89 \\
=.37\end{array}$ & $\begin{array}{l}.02 \\
189 \\
.38\end{array}$ & $\begin{array}{r}-.11 \\
189 \\
.08\end{array}$ & $\begin{array}{l}.19^{*} \\
189 \\
.00\end{array}$ & & \\
\hline 6. & $\begin{array}{l}\text { Corridor } \\
\text { length }\end{array}$ & $\begin{array}{l}r= \\
N= \\
p=\end{array}$ & $\begin{array}{rr}= & -.11 \\
= & 89 \\
= & .16\end{array}$ & $\begin{array}{r}-.03 \\
189 \\
.33\end{array}$ & $\begin{array}{l}.29^{*} \\
189 \\
.00\end{array}$ & $\begin{array}{l}.51^{*} \\
189 \\
.00\end{array}$ & $\begin{array}{l}.09 \\
189 \\
.10\end{array}$ & \\
\hline 7. & $\begin{array}{l}\text { Room } \\
\text { location }\end{array}$ & $\begin{array}{l}r= \\
N= \\
p=\end{array}$ & $\begin{array}{l}=.02 \\
=\quad 88 \\
=\quad .41\end{array}$ & $\begin{array}{r}-.04 \\
185 \\
.28\end{array}$ & $\begin{array}{l}.00 \\
185 \\
.49\end{array}$ & $\begin{array}{l}-.13^{*} \\
185 \\
.05\end{array}$ & $\begin{array}{r}-.09 \\
185 \\
.12\end{array}$ & $\begin{array}{r}-.37^{*} \\
185 \\
.00\end{array}$ \\
\hline
\end{tabular}

Selection of Social Determinants. Past literature has revealed that the occurance of perceived crowding is arfected by social conditions such as interpersonal proximity and social climate, as reviewed in Chapter II. Based on these conditions, eleven variables pertaining to the social dimenaton of crowding were initially selected from our questionnaire items. In order to rule out the problem of 
collinearity among the social factors to be placed in the regression equation, all eleven items were included in a principal component analysis followed by the varimax rotation procedure, resulting in three composite factors (Table IX).

To represent the three orthogonal factors, only those items with the highest factor loading on each factor were selected for the study. For Factors 1 and 2--the feeling of cohesion and unity among floormates and the intensity of participation in organized floor activities--the same items were selected as predictors to be used in both regression equations. Because the study dealt with crowding perception in two settings, i.e., within the room and within the dwelling, the content of the items dictated that the item with the highest loading on Factor 3--the degree of privacy from roommate--be used only for assessing room crowding, while the item with the second highest loading on Factor 3-the degree of privacy from neighbors-be used as a predictor in assessing dwelling crowding.

Selection of Personal Determinants. Based on connections between crowding and its personal determinants derived from the literature reviewed in Chapter II, demographic items such as age, sex, ethnicity, and residency length and items assessing past living experience such as past dwelling type, past roommate number, and past perceived crowding were initially selected as potential personal determinants of crowding. The variable of credit load was also included; it was expected that a heavy credit load might sensitize subjects to crowded 
TABLE IX

VARIMAX ROTATED FACTOR MATRIX OF

PERSONAL AND SOCIAL VARIABLES **

Personal Items

1. Age

2. $\operatorname{sex}$

3. Ethnicity

4. SES

5. Length of

6. Credit load

7. Past dwelling type

8. Past roommate number

9. Past perceived crowding

Social Items

1. Degree of ease in making friends on floor

2. Degree of cohesion among floormates

3. Degree of feeling floor is a friendiy place

4. Degree of acquaintance among floormates

5. Frequency of doing things with neighoors

6. Frequency of exchanging things with neighbors

7. Intensity of participation in floor activities

8. Intensity of participation in dormitory activities

9. Degree of privacy from neighbors

10. Degree of privacy from roommate

11. Degree of getting along well with roommate

$$
\begin{aligned}
& \text { Factor Factor Factor Factor } \\
& \frac{1}{.760^{*}} \frac{2}{.015} \frac{3}{.173} \frac{4}{.239} \\
& \begin{array}{llll}
-.094 & -.195 & .191 & .505
\end{array} \\
& \begin{array}{llll}
.064 & .135 & -.130 & .814^{*}
\end{array} \\
& \begin{array}{llll}
-.333 & .242 & .240 & -.330
\end{array} \\
& \begin{array}{llll}
.673 & -.104 & -.102 & -.231
\end{array} \\
& \begin{array}{llll}
-.305 & -.022 & -.757^{*} & .102
\end{array} \\
& \begin{array}{llll}
-.380 & .517 \quad .670 \quad .144
\end{array} \\
& \begin{array}{llll}
-.038 & .775 & -.012 & -.096
\end{array} \\
& \begin{array}{llll}
.077 & -.812^{*} & -.072 & -.036
\end{array}
\end{aligned}
$$

\begin{tabular}{|c|c|c|}
\hline 1 & 2 & 3 \\
\hline .747 & .218 & .015 \\
\hline $.860^{*}$ & .191 & .003 \\
\hline .839 & .190 & .078 \\
\hline .687 & .163 & .041 \\
\hline .372 & .654 & -.065 \\
\hline .243 & .675 & -.055 \\
\hline .258 & $.829^{*}$ & .064 \\
\hline .053 & .784 & .098 \\
\hline-.008 & -.240 & $.718^{*}$ \\
\hline .034 & .047 & $.810^{*}$ \\
\hline .062 & .198 & .606 \\
\hline
\end{tabular}

Factor Factor Factor

* Items selected for regression analyses * See Appendix $E$ for correlation matrix 
conditions because those students carrying a heavy credit load were assumed to have less time and energy for handing social interactions.

A principal component analysis with varimax rotation procedure was carried out on these nine personal variables and resulted in four factors as shown in Table IX. As a consequence, the four items with the highest factor loading were used 8 s predictors in the regression equations, namely: age, ethnicity, credit load, and past perceived crowding.

Regression Analysis of Room Crowding

To understand how the selected physical, social, and personal predictors affect perceived crowding in individual rooms, a simple regression analysis was carried out. As shown in Table $X$, the $F$ ratios for the overall regression equation and for individual regression coefficients (B) were not statistically significant at the .05 level. The insignificant overall $F$ indicated that there was no significant linear relationship between room crowding and the selected sets of independent predictors, and the insignificant Fs for individual Bs indicated that none of the selected predictors had significant linear relationships with room crowding. In all, the results failed to support the hypothesis that physical determinants would be significantly different from social and personal ones in affecting perceived room crowding. other information obtained through regression analysis includes the proportion of the variance of the criterion 
TABLE X

OVERALL EXPLANATORY POWER OF PREDICTORS ON PERCEIVED ROOM CROWDING

\begin{tabular}{|c|c|c|c|c|c|c|}
\hline Predictors & Multiple R & $\mathrm{R}^{2}$ & $\mathrm{R}^{2}$ Change & $\begin{array}{c}\text { Standardized } \\
\text { Beta }\end{array}$ & (B) & $p$ \\
\hline \multicolumn{7}{|l|}{ Physical Variables } \\
\hline Floor height & .053 & .003 & .003 & -.049 & .150 & n.s. \\
\hline Desk location & .367 & .004 & .001 & .038 & .098 & n.8. \\
\hline Window orientation & .096 & .010 & .006 & .139 & 1.248 & n.8. \\
\hline Noise level. through walls & .141 & .021 & .011 & -.000 & .000 & n.s. \\
\hline Bathroom pattern & .176 & .032 & .011 & .080 & .290 & n.s. \\
\hline Social Variables & & $R^{2}$ & $=.031$ & & & \\
\hline $\begin{array}{l}\text { Degree of cohesion } \\
\text { among flcormates }\end{array}$ & .185 & .035 & .003 & .058 & .185 & n.s. \\
\hline $\begin{array}{l}\text { Intensity of participation } \\
\text { in floor activities }\end{array}$ & .257 & .067 & .032 & -.156 & 1.333 & n.s. \\
\hline $\begin{array}{l}\text { Degreo of privacy } \\
\text { from roomrnate }\end{array}$ & .337 & $\begin{array}{r}115 \\
\mathrm{R}^{2}\end{array}$ & $\frac{.048}{=.083}$ & -.209 & 2.418 & n.s. \\
\hline \multicolumn{7}{|l|}{ Personal Variables } \\
\hline Age & .340 & .133 & .002 & -.049 & .115 & n.s. \\
\hline Ethnicity & .365 & .134 & .018 & .138 & 1.249 & n.s. \\
\hline Credit load & .372 & .138 & .004 & .075 & .343 & n.s. \\
\hline Past perceived crowding & .375 & $\begin{array}{r}140 \\
\mathrm{R}^{2}\end{array}$ & $=.002$ & -.048 & .145 & n.s. \\
\hline
\end{tabular}

$F=.844, d \mathfrak{I}=12,62, p>.05$ 
variable that is accounted by the predictor variables. $\underline{\mathrm{R}}^{2}$ is an estimate of that proportion; the higher the percentage the greater the proportion of total variance accounted for by the inclusion of each predictor variable in the regression procedure. Additional information is obtained by examining the standardized beta weights; an approximation of the relative importance of a variable in predicting the criterion is indicated by the relative size of its beta weight.

In the equation predicting perceived crowding in the room using only the physical set of variables, $3.1 \%$ of the total variation in crowding was explained. Once the social variables were added, the percentage increased to $11.3 \%$. A second increase occurred when the personal items were taken into account. At this stage, the proportion of variance increased to $14.0 \%$. In other words, $3.1 \%$ of total variance was accounted for by the set of five physical environment items, $8.3 \%$ of total variance by the set of three items representing social features, and $2.6 \%$ by the set of four personal characteristics. These results indicate that the social dimension was the most effective, the physical dimension was less, and the personal dimension was the least effective in predicting room erowding.

Examining the beta weights of individual predictors, al though none of the predictors had a significant effect on room crowding, we found that privacy from the roommate was the most effective emong the selected predictors in explaining the variance of room crowding; persons who had a 
higher degree of privacy from their roommates tended to feel less crowded in the room. In addition, variables such as window orientation, intensity of participation in floor activities, and ethnicity were found to be relatively important in their effect on room crowding. It appeared that persons having an open view through their window felt less crowded than those having a blocked view, that persons more frequently participating in floor activities felt less crowded, and that whites felt less crowded than nonwhites The nonwhites in the sample ( $6 \%$ of total) consisted of $18 \%$ Chicano/Yexican-Imerican, $27 \%$ American Indian/Alaskan native, and 55\% Facific Islander/isian-imerican.

Regression Analysis of Dwelling Crowding

In order to understand how the selected physical, social, and personal preciictors affect perceived crowding in individual dormitory, a simple regression analysis was carried out. As shown in Table XI, the $\underline{F}$ ratios for the overall equation and the individual B's were not statistically significant at the .05 level, which indicated that there was no significant linear relationship between dwelling crowding and the selected sets of independent predictors and that none of the selected predictors had a significant linear relationship with dwelling crowding. In all, the results failed to support the hypothesis that physical determinants would be significantly different from social and personal ones in affecting perceived dwelling crowding. 


\section{TABLE XI}

OVERALI EXPLANATORY POWER OF PREDICTORS ON PERCEIVED DWELLING CROWDING

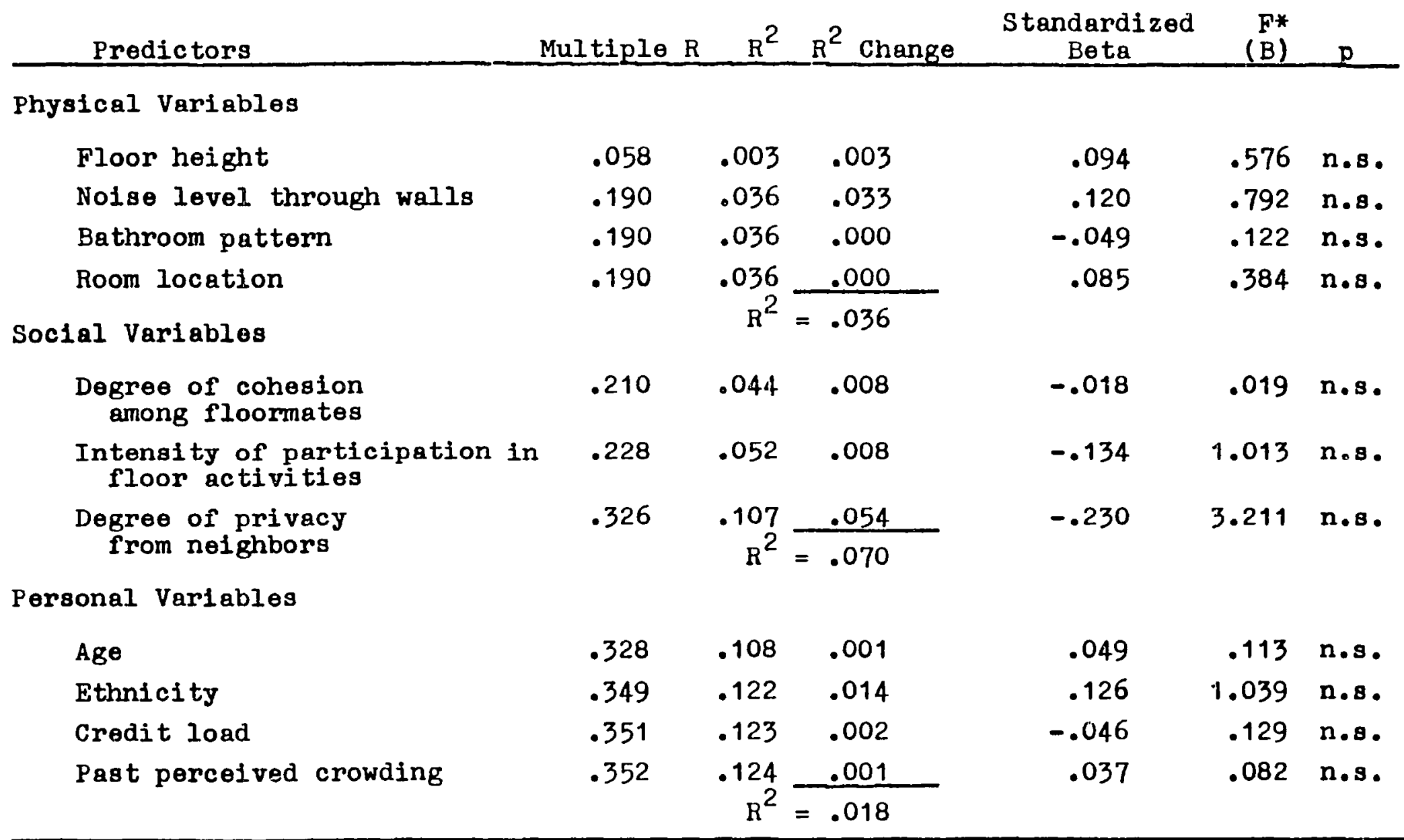

$F=.812, d f=11,63, p>.05$ 
Table XI also indicated that, in the equation predicting percelved dwelling crowding using only the physical set of variables, $3.6 \%$ of the total variation in crowding was explained. Once the social variables were added, the percentage increased to $10.7 \%$. A slight increase up to $12.4 \%$ occured when personal variables were taken into account. In other words, $3.6 \%$ of the total variance was accounted for by the set of four variables in the physical dimension, $7.0 \%$ of total variance was explained by the set of three variables in the social dimension, and only $1.8 \%$ was b\% the set of four variables in the personal dimension. The results indicated that the social dimension was the most effective, the physical dimension was less, and the personal dimension was the least effective in predicting the perceived dwelling crowding.

Examining the beta weights of individual variables, al though none of the predictors had a significant effect on dwelling crowding, we found that privacy from neighbors was the most effective emong the selected predictors in explaining the variance of dwelling crowding; persons who had a higher level of privacy from neighbors tended to foel less crowded in the building. In addition, variables such as frequency of noise, intensity of participating in floor activities, and ethnicity were relatively important in their explanatory power on dwelling crowding. It appeared that persons felt less crowded in the bullding when they participated in floor activities more frequently, when they received noise less frequently, and when they were white. 
Summary

Correlation and principal component analyses were done on groups of physical, social, and personal variables selected on the basis of their theoretical and empirical connections with perceived crowding at both room and dwelling levels, so that two sets of crowding predictors were selected and used in the regression equations. Two simple regression analyses were then done on perceived room and dwelling crowding, and the results of both analyses failed to support Hypothesis 1 that physical determinants were significantly different from social and personal determinants in affecting perceived crowding.

Although there was no significant relationship between perceived crowding and the selected sets of predictors, the social determinants as a whole were consistently found to be the most effective, the physical determinants were less effective, and the personal ones were the least effective in predicting both perceived room and dwelling crowding.

As far as individual variables were concerned, al though none of the selected predictors had a significant effect on either perceived room and dwelling crowding, privacy appeared to be the most effective among the selected variables in predicting perceived crowding; persons having a higher degree of privacy were found to feel less crowded in both room and dwelling. In addition, intensity of participation in floor activities and ethnicity were found to be relatively important in affecting both room and dwelling crowding. 
ANALYSIS OF STUDY II

As in Study I, the sampled residents from the three dorms were used as subjects for this study $(\mathrm{N}=189)$. To test the effects of variations in the physical design of the dormitory floors on perceived floor crowding, analysis of variance was employed as the major analytical tool, in which selected physical elements were the categorical independent variables while the composite index of floor crowding was the criterion variable. The analyses of the three hypotheses involved in this study are reported below.

Variance and Correlation Analyses of the Effect of Corridor Length

Hypothesis 2: Floors will be perceived as less crowded by persons living in shorter corridors.

The assumption underlying the hypothesis was that residents living in long corridors were likely to encounter and interact with more different people than those clustered in short corridors, and thus would perceive a higher degree of floor crowding. A one-way ANOVA (Table XII) was carried out comparing the crowding scores of residents of long corridors (the conventional-corridor dorm) to those of residents of short corridors (the modified- and suitedcorridor dorms). The results showed that residents living along long corridors reported more crowding (indicated by lower mean scores) than those along short corridors, and that the difference was statistically significant $(\underline{F}(1,175)$ $=8.56, \mathrm{p}(.01)$, supporting the hypothesis. 
TASiLE XII

ANALYSIS OF VARIANCE: FLOOR CROWDILG BY CORRIDOR LENGTH, FLOOR HEIGHT, AND BATHROOM LOCATION

\begin{tabular}{|c|c|c|c|c|c|c|c|c|}
\hline Source of Variance & $\overline{\mathrm{X}}^{*}$ & S.D. & S.S. & $N$ & $D \cdot F$. & M.S. & $F$ & $\mathrm{P}$ \\
\hline \multicolumn{9}{|l|}{ Corridor Length } \\
\hline $\begin{array}{l}\text { Long } \\
\text { Short }\end{array}$ & $\begin{array}{l}8.80 \\
7.74 \\
\end{array}$ & $\begin{array}{l}2.31 \\
2.15 \\
\end{array}$ & $\begin{array}{r}627.15 \\
263.12 \\
\end{array}$ & $\begin{array}{r}119 \\
58 \\
\end{array}$ & & & & \\
\hline Within groups & 8.45 & 2.26 & 890.28 & 177 & 175 & 5.09 & & \\
\hline Between groups & & & 43.56 & & 1 & 43.56 & 8.56 & .004 \\
\hline
\end{tabular}

Floor Levels

\begin{tabular}{|c|c|c|c|c|c|c|c|c|}
\hline $\begin{array}{l}2 \text { nd } \\
3 \text { rd } \\
4 \text { th } \\
5 \text { th } \\
6 \text { th } \\
7 \text { th } \\
\end{array}$ & $\begin{array}{l}7.89 \\
8.84 \\
8.32 \\
8.58 \\
8.55 \\
8.65 \\
\end{array}$ & $\begin{array}{l}2.42 \\
2.25 \\
2.34 \\
2.69 \\
2.12 \\
1.73 \\
\end{array}$ & $\begin{array}{r}199.54 \\
152.19 \\
131.44 \\
232.06 \\
144.18 \\
56.55 \\
\end{array}$ & $\begin{array}{l}35 \\
31 \\
25 \\
33 \\
33 \\
20 \\
\end{array}$ & & & & \\
\hline Within groups & 8.45 & 2.31 & 915.97 & 177 & 171 & 5.38 & & \\
\hline Between groups & & & 17.87 & & 5 & 3.58 & .67 & .649 \\
\hline $\begin{array}{l}\text { Dispersea } \\
\text { Dualistic } \\
\text { Centralized } \\
\end{array}$ & $\begin{array}{l}9.10 \\
8.46 \\
7.74 \\
\end{array}$ & $\begin{array}{l}2.38 \\
2.19 \\
2.15 \\
\end{array}$ & $\begin{array}{l}351.43 \\
263.93 \\
263.12 \\
\end{array}$ & $\begin{array}{l}63 \\
56 \\
58 \\
\end{array}$ & & & & \\
\hline Within groups & 8.45 & 2.25 & 878.48 & 177 & 174 & 5.05 & & \\
\hline Between Eroups & & & 55.36 & & 2 & 27.68 & 5.48 & .005 \\
\hline
\end{tabular}

* The crowcine score was rated in the direction that the higher the value, the less the degree of perceived crowdodness. 
A correlation analysis was done to further assess the relationship of corridor length with number of people seen in the hallway (Table XIII). With the number of people seen measured on a scale ranging from 1 representing "quite a few" to 5 representing "none" and the corridor length coded as 0 for "long corridors" and 1 for "short corridors", a high positive correlation would indicate support for the hypothesis that short-corridor residents see fewer people than do long-corridor residents. The result of the correlation was: $\underline{r}(188)=.10, \underline{p}>.05$. Although the $\underline{r}$ was in the direction of the prediction, it was not statistically significant at the .05 level. The findil.gs suggest that the feeling of being crowded in long-corridor floors is not mediated by the number of people seen in the hallway.

Variance and Correlation Analyses of the Effect of Floor Height

Hypothesis 3: Floors on the lower levels will be perceived as less crowded than floors on the upper levels.

The assumption underlying the hypothesis was that residents living on lower floors were likely to have fewer social encounters and interactions in the hallways than those on higher floors due to the easier in-and-out access associated with lower floors, and thus that they would perceive a lower degree of floor crowding. A one-way ANOVA was done to compare the crowding scores rated by residents living on different floors (Table XII). The results indicated that 
TABLE XIII

CORRELATIONS BETWEEN CORRIDOR IENGTH, FLOOR HEIGHT, NUMBER OF PEOPLE SEEN IN HALLWAY, AND PERCEIVED FLOOR CROWDING

\begin{tabular}{|c|c|c|c|c|c|}
\hline & Items & & 1 & 2 & 3 \\
\hline 1. & $\begin{array}{l}\text { Corridor } \\
\text { length }\end{array}$ & $\begin{array}{l}r= \\
N= \\
p=\end{array}$ & & & \\
\hline 2 & $\begin{array}{l}\text { Floor } \\
\text { height }\end{array}$ & $\begin{array}{l}r= \\
N= \\
p=\end{array}$ & $\begin{array}{l}.09 \\
189 \\
.10\end{array}$ & & \\
\hline 3. & $\begin{array}{l}\text { Numer of } \\
\text { people seen } \\
\text { in hallway }\end{array}$ & $\begin{array}{l}r= \\
N= \\
p=\end{array}$ & $\begin{array}{l}.10 \\
188 \\
.09\end{array}$ & $\begin{array}{l}.14^{*} \\
188 \\
.03\end{array}$ & \\
\hline 4. & $\begin{array}{l}\text { Ferceived } \\
\text { floor } \\
\text { crowding }\end{array}$ & $\begin{array}{l}r= \\
N= \\
p=\end{array}$ & $\begin{array}{l}.22^{*} \\
177 \\
.00 \\
\end{array}$ & $\begin{array}{l}.07 \\
177 \\
.17 \\
\end{array}$ & $\begin{array}{l}.12 * \\
177 \\
.05 \\
\end{array}$ \\
\hline
\end{tabular}

no significant difference was found among different floors $(\underline{F}(5,171)=.667, \underline{p}>.05)$.

A correlation analysis was then done as the second step to assess the relationships of the hypothetical intermediate variable, the number of people seen in the hallway, with floor height and perceived floor crowding (Table XIII). The correlation between the number of people seen and floor crowding was: $\underline{r}(177)=.12, \underline{p}=.05$. With the number of people seen measured from 1 representing "quite a few" to 5 representing "none" and the crowding index constructed with higher scores for lower degrees of perceived crowding, a high and positive $\underline{r}$ would indicate support for our prediction, i.e., the fewer people seen in the hallway, the less the perceived floor crowding. The moderate 
magnitude and the positive sign of the $\underline{r}$ showed some relationship between the two rariables in the predicted direction.

Meanwhile, the result of correlation between floor height and the number of people seen was: $\underline{r}(188)=.14$, $\underline{p}<.05$. With floor height numbered from 2 to 7 , a high and negative correlation would indicate support for the prediction, i.e., the lower the floors, the fewer the people seen in the hellway. The $\underline{r}=.14$, while significant at the .05 level, was in the opposite direction of our prediction. Thus, the rejection of Hypothesis 3 that lower floors are perceived as less crowded can be partially explained by the inaccurate assumption about relationship between the number of people seen in the hallway and floor height.

\section{Variance Analysis of the Effect of Bathroom Location}

Hypothesis 4: Floors with a less centralized bathroom pattern will be perceived as less crowded.

The assumption underlying the hypothesis was that the floors designed with dispersed suite bathrooms were likely to result in fewer people appearing/interacting in the hallway or bathrooms, and thus that their residents would feel less crowded than those living on floors with community bathrooms. A one-way ANOVA was done (Table XII) to compare the crowding scores among the three types of floors designed with different bathroom locational pattems, i.e., dispersed, dualistic, and centralized. 
The result $(\underline{F}(2,174)=5.48, \underline{p}<.01)$ indicated that residents using suite baths reported the lowest degree of perceived floor crowding and those sharing the centralized community bath with all other floomates reported the highest degree of crowding, and that the differences among the three groups were statistically significant in support the hypo thesis.

Since the dorm with dispersed bathroom location is also the dorm with short corridors, corridor length may perform as a confounding factor. That is, effects attributed in the above analysis to differences in bathroom location could be in part due to differences in corricor length. In order to clarify the assumption, two a priori contrasts were done. The first compared floor crowding between the suited-corridor dorm (Group 1) and the modified-corridor dorm (Group 2); both dorms had short corridors but the former had individual suite baths and the latter had shared community baths. The second cortrast compared the modified-corridor dorm (Group 2) and the conventional-corridor dorm (Group 3); both dorms had community baths but the former had short corridors and the latter had long corridors.

Table XIV showed the contrast coefficient matrix and the results of the two contrasts, i.e., Group 1 versus Group 2 and Group 2 versus Group 3. The small $t$ values and large $p$ magnitudes resulting from both contrasts indicated no significant differences in group means between Groups 1 and 
2 and between Groups 2 and 3, al though the difference botween Groups 2 and 3 approached significance. In other words, when the length of corridor was controlled as in Contrast 1. no crowding effects of bathroom location were found; an only marginally significant effect of corridor length was found when the bathroom location was controlled.

TABLE XIV

CONTRAST COEFFICIENT MATRIX AND T STATISTICS: FLOOR CROWDING CONTROLLING CORRIDOR LENGTH AND BATHROOM LOCATION

\begin{tabular}{|c|c|c|c|c|c|c|c|}
\hline & Coeffi & eient & Matrix & & Statj & tics & \\
\hline & & Group & & & POC & ed Varj & $\cos$ \\
\hline & 1 & 2 & 3 & Value & $t$ & d.f. & $\mathrm{p}$ \\
\hline Contrast 1 & 1.0 & -1.0 & 0 & .63 & 1.53 & 174.0 & .13 \\
\hline Contrast 2 & 0 & 1.0 & -1.0 & .72 & 1.72 & 174.0 & .09 \\
\hline
\end{tabular}

Summary

of the three hypotheses testing the effects of physical variation on floor crowding through ANOVA, two were found to be statistically significant at the .01 level to support the hypotheses that residents Ifving on floors with dispersed bathrooms and in short corridors reported less crowding. Subsequent contrast analyses, on the other hand, found no gignificant difference in floor crowding between the two dorms comparable in corridor length but not in bathroom location and between the two dorms comparable in bathroom location but 
not in corridor length.

Meanwhile, the hypothesis testing the effect of floor height on crowding was rejected at the .05 level. The subsequent correlation analysis examining the role of number of people seen in the hallway in the context of floor height and crowding indicated that fewer people were seen in the hallway of lower floors, which indicated that the assumption underlying the hypothesis was wrong. The overall response of all subjects on perceived floor crowding $(\bar{X}=8.45$, median 9 , see Table XII) indicated that students generally felt their floor was a crowded space.

\section{ANALYSIS OF STUDY III}

The sampled residents of the modified- and suitedcorridor dorms were included in this study $(N=128)$. To test the effects of variation in the physical design of the rooms themselves on perceived crowding, analysis of variance was employed as the major analytical tool. Selected physical elements associated with room variation were the categorical independent variables while the composite room crowding index was the criterion variable. The analyses of the three hypotheses involved in this study are reported below.

Variance and Correlation Analyses of the Effect of Desk Location

Hypothesis 5: Rooms will be perceived as more crowded by occupants whose desks are closer to door. 
The assumption underlying the hypothesis was that residents whose desks were near the door would be likely to have a smaller territory and thus would feel more crowded than those whose desks were by the window. An ANOVA was done comparing the crowding scores between the by-door and by-window groups. As illustrated in Table XV, although the by-door group did report a higher degree of perceived crowding than the by-window group (for the by-door group: $\bar{X}(41)=7.54$, by-window group: $\bar{X}(42)=7.74)$, the difference was not statistically significant $(\underline{F}(1,81)=.12$, $p>.05)$.

Since we assumed that the by-door group had smalier territories and thus felt more crowded in the room, a correlation analysis then was done to assess the relationships between desk location, room territory, and room crowding (Table XVI). The correlation between desk location and room territory was: $\underline{r}(78)=.01, \underline{p}>.05$, and between room

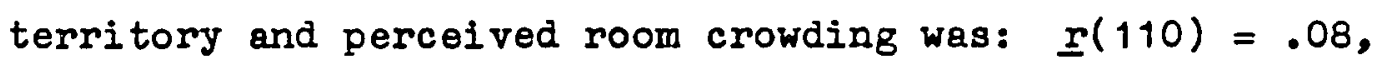
p $>.05$. Room territory was measured on a 10-point scale ranging from 0.0 to 1.0 representing the proportion of the room covered by an individual's cognitive territory and the desk location was coded as 0 for "by-window" and 1 for "bydoor". A high negative correlation between desk location and room territory would indicate support for our prediction. However, the correlation was in the opposite direction from the prediction and too small to be significant. The index of room crowding was constructed so that a 


\section{TAELEE XV}

ANALYSIS OF VARIAINCE: ROOM CROWDING EY DESK LOCATION, WINDOW ORI ENT TATION, ANY ROOH LOCATION

\begin{tabular}{|c|c|c|c|c|c|c|c|c|}
\hline ¿ource of Variance & $\overline{\mathrm{X}}^{*}$ & $S \cdot D \cdot$ & S.S. & $\mathbb{N}$ & $D \cdot F$ & M.S. & $F^{\prime}$ & $\mathrm{p}$ \\
\hline \multicolumn{9}{|l|}{ Desk Location } \\
\hline $\begin{array}{l}\text { By window } \\
\text { By cooor } \\
\end{array}$ & $\begin{array}{l}7.74 \\
7.54 \\
\end{array}$ & $\begin{array}{l}2.98 \\
2.27 \\
\end{array}$ & $\begin{array}{l}364.12 \\
200.20 \\
\end{array}$ & $\begin{array}{r}42 \\
41 \\
\end{array}$ & & & & \\
\hline Within groups & 7.64 & 2.65 & 570.31 & 83 & 81 & 7.04 & & \\
\hline Between groups & & & .84 & & 1 & .84 & .12 & .730 \\
\hline \multicolumn{9}{|l|}{ Window Orientation } \\
\hline $\begin{array}{l}\text { Blocked view } \\
\text { open view }\end{array}$ & $\begin{array}{l}7.46 \\
7.94 \\
\end{array}$ & $\begin{array}{l}2.45 \\
2.70 \\
\end{array}$ & $\begin{array}{l}348.64 \\
445.74 \\
\end{array}$ & $\begin{array}{l}59 \\
62 \\
\end{array}$ & & & & \\
\hline Within Eroups & $7 \cdot 70$ & 2.58 & 794.39 & 121 & 119 & 6.68 & & \\
\hline Between Eroups & & & 6.90 & & 1 & 6.90 & 1.03 & .311 \\
\hline \multicolumn{9}{|l|}{ Room Location } \\
\hline $\begin{array}{l}\text { Core area } \\
\text { Wing }\end{array}$ & $\begin{array}{l}7.34 \\
7.06 \\
\end{array}$ & $\begin{array}{l}2.76 \\
2.52 \\
\end{array}$ & $\begin{array}{l}282.55 \\
509.51 \\
\end{array}$ & $\begin{array}{l}38 \\
81 \\
\end{array}$ & & & & \\
\hline Within groups & 7.70 & 2.60 & 792.06 & 119 & 117 & 6.77 & & \\
\hline Between groups & & & 7.05 & & 1 & 7.05 & 1.04 & .310 \\
\hline
\end{tabular}

* 'the higher the value of crowding score, the lower the degree of perceived crowdedness. 
TABLE XVI

CORRELATIONS BETWEEN LOCATIONS OF DESK AND ROOM, TERRITORY, NOISE, AND MEASURES OF ROOM CROWDING

\begin{tabular}{|c|c|c|c|c|c|}
\hline Items & & 1 & 2 & 3 & 4 \\
\hline $\begin{array}{l}\text { 1. Desk } \\
\text { location }\end{array}$ & $\begin{array}{l}\mathrm{r}= \\
\mathrm{N}= \\
\mathrm{p}=\end{array}$ & & & & \\
\hline $\begin{array}{l}\text { 2. Room } \\
\text { territory }\end{array}$ & $\begin{array}{l}r= \\
N= \\
p=\end{array}$ & $\begin{array}{r}.01 \\
78 \\
.48\end{array}$ & & & \\
\hline $\begin{array}{l}\text { 3. Room } \\
\text { location }\end{array}$ & $\begin{array}{l}r= \\
N= \\
p=\end{array}$ & $\begin{array}{r}.02 \\
87 \\
.44\end{array}$ & $\begin{array}{l}.05 \\
114 \\
.32\end{array}$ & & \\
\hline $\begin{array}{l}\text { 4. Frequency of } \\
\text { bothersome } \\
\text { noise }\end{array}$ & $\begin{array}{l}\mathrm{r}= \\
\mathrm{N}= \\
\mathrm{p}=\end{array}$ & $\begin{array}{c}-.20^{*} \\
88 \\
.03\end{array}$ & $\begin{array}{r}-.04 \\
116 \\
.32\end{array}$ & $\begin{array}{r}.10 \\
126 \\
.13\end{array}$ & \\
\hline $\begin{array}{l}\text { 5. Room: } \\
\text { cramped- } \\
\text { spacious }\end{array}$ & $\begin{array}{l}r= \\
N= \\
p=\end{array}$ & $\begin{array}{r}-.03 \\
83 \\
.39\end{array}$ & $\begin{array}{l}.09 \\
110 \\
.18\end{array}$ & $\begin{array}{l}.05 \\
119 \\
.28\end{array}$ & $\begin{array}{l}.16 * \\
121 \\
.04\end{array}$ \\
\hline $\begin{array}{l}\text { 6. Room: } \\
\text { small- } \\
\text { large }\end{array}$ & $\begin{array}{l}r= \\
N= \\
p=\end{array}$ & $\begin{array}{r}-.04 \\
84 \\
.38\end{array}$ & $\begin{array}{r}.02 \\
110 \\
.44\end{array}$ & $\begin{array}{l}.06 \\
120 \\
.25\end{array}$ & $\begin{array}{l}.22^{* *} \\
122 \\
.01\end{array}$ \\
\hline $\begin{array}{l}\text { 7. Room: } \\
\text { crowded- } \\
\text { uncrowded }\end{array}$ & $\begin{array}{l}r= \\
N= \\
p=\end{array}$ & $\begin{array}{r}-.08 \\
86 \\
.24\end{array}$ & $\begin{array}{l}.17^{*} \\
114 \\
.03\end{array}$ & $\begin{array}{l}.15^{*} \\
123 \\
.05\end{array}$ & $\begin{array}{r}.11 \\
125 \\
.11\end{array}$ \\
\hline $\begin{array}{l}\text { 8. Perceived room } \\
\text { crowding }\end{array}$ & $\begin{array}{l}r= \\
N= \\
p=\end{array}$ & $\begin{array}{r}-.04 \\
83 \\
.37\end{array}$ & $\begin{array}{l}.08 \\
110 \\
.20\end{array}$ & $\begin{array}{l}.09 \\
119 \\
.16\end{array}$ & $\begin{array}{l}.18 * \\
121 \\
.03\end{array}$ \\
\hline
\end{tabular}

$* p \leqslant .05$

** $\mathrm{p}<.01$

high score indicated low perceived crowding; a high positive correlation between room territory and crowding would indicate support for our prediction. Although the relationship was in the predicted direction, it was not significant. However, territory was significantly related to one of the items that constructed the crowding index, 1.e.. the "crowded-uncrowded" item; the larger the personal territory in room, the less 
the perceived crowding $(\underline{r}(114)=.17, \mathrm{p}<.05)$.

Variance Analyses of the Effect of Window Orientation

Hypothesis 6: Rooms with a blocked view will be perceived as more crowded than those with an open view.

The assumption underlying the hypothesis was that rooms with windows oriented to an open view were likely to be perceived as less constrained and thus less crowded than those with windows oriented to a blocked view. A one-way ANOVA was done to compare the crowding scores between the two groups. As illustrated in Table XV, al though residents having an open view reported a lower degree of perceived room crowding than those having a blocked view (for the open view group: $\bar{X}(62)=7.94$, blocked-view group: $\bar{X}(59)=7.46)$, the difference was not statistically significant $(\underline{F}(1,119)=$ $1.03, \mathrm{p}>.05$ )。

Since the openness of the view obtained from window might also relate to floor height (1.e., the higher the floor, the broader the view) and desk location (i.e., the by-window group had better access to the view) in addition to window orientation, a 3-way ANOVA was done to examine the Individual and interaction effects of window orientation, floor height, and desk location. As shown in Table XVII, only the interactive effect of floor height and window orientation was found to be statistically significant. In other words, only the interaction of floor height and window orientation contributed to the variance in perceived 
TABLE XVII

3-WAY ANALYSIS OF VARIANCE: ROOM CROWDING BY WINDOW ORIENTATION, FLOOR HEI GHT, AND DESK LOCATION

\begin{tabular}{|c|c|c|c|c|c|}
\hline Source of Variance & $\underline{S . S .}$ & $d f$ & M.S. & $\mathbf{F}$ & $p$ \\
\hline Main Effects & 6.81 & 3 & 2.27 & .32 & .81 \\
\hline $\begin{array}{l}\text { 1. Window } \\
\text { orientation }\end{array}$ & 5.00 & 1 & 4.99 & .71 & .40 \\
\hline $\begin{array}{l}\text { 2. Floor } \\
\text { height }\end{array}$ & 1.40 & 1 & 1.40 & .20 & .66 \\
\hline $\begin{array}{l}\text { 3. Desk } \\
\text { location }\end{array}$ & $: 87$ & 1 & .87 & .12 & .73 \\
\hline 2-Way Interactions & 36.03 & 3 & 12.01 & 1.71 & .17 \\
\hline $1 \times 2$ & 31.27 & 1 & 31.27 & 4.44 & .04 \\
\hline $1 \times 3$ & 4.43 & 1 & 4.43 & .63 & .43 \\
\hline $2 \times 3$ & .20 & 1 & 1.20 & .03 & .87 \\
\hline 3-Way Interaction & .05 & 1 & .05 & .01 & .93 \\
\hline $1 \times 2 \times 3$ & .05 & 1 & .05 & .01 & .93 \\
\hline Explained & 42.89 & 7 & 6.13 & .87 & .53 \\
\hline
\end{tabular}

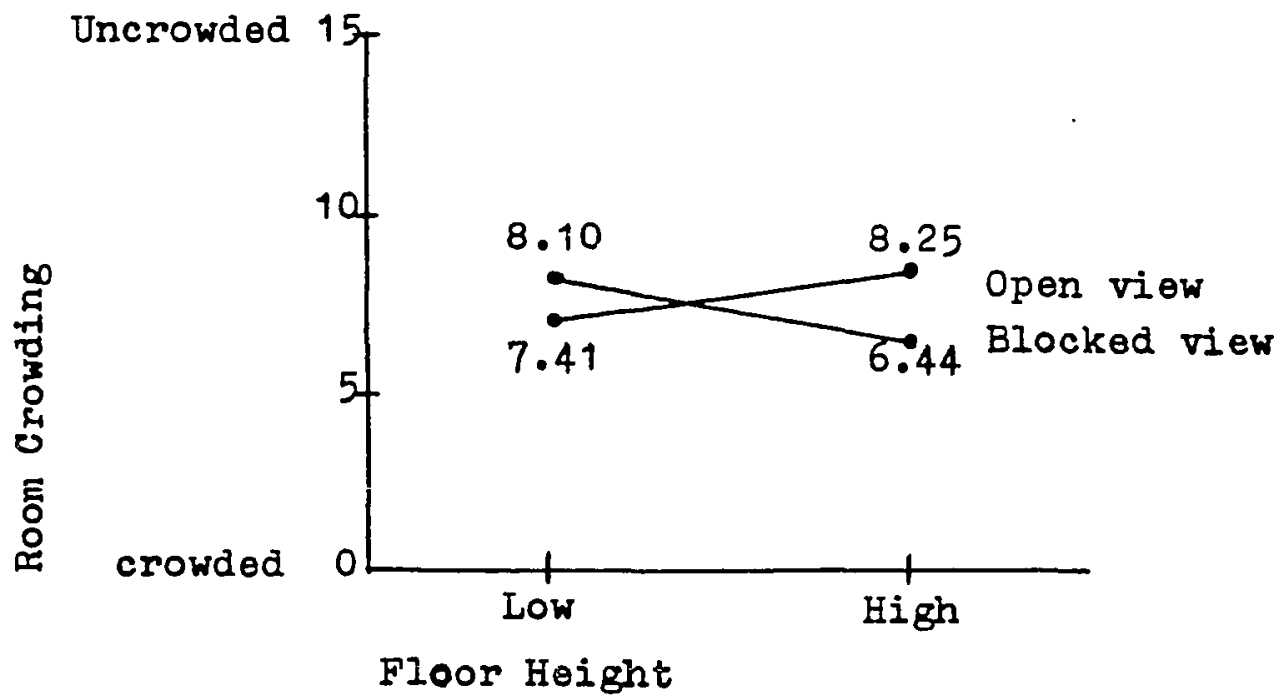

Figure 6. Cell means for floor height by window orientation 
crowding. Figure 6 reports the cell means for floor height by window orientation. The results indicated that subjects felt the least crowded if they lived on higher floors and had an open view through their windows. However, subjects who felt the most crowded were not those who lived in lower floors with a blocked view but those lived on higher floors with a blocked view.

Variance and Correlation Analyses of the Effect of Room Location

Hypothesis 7: Rooms facing community areas will be perceived as more crowded than rooms in wings.

The assumption underlying the hypothesis was that residents living in the wings would perceive a lower degree of room crowding because they were likely to be bothered by noise less frequently than those living at the centrally located comminty cores. A one-way ANOVA was done to compare the crowding scores between the two groups. As reported in Table XV, al though the wing residents reported a lower degree of crowding than the core residents (for the wing group: $\bar{X}(81)=7.86$, core. group: $\bar{X}(38)=7.34)$, the difference was not statistically significant $(\underline{F}(1,117)=$ $1.04, p>.05)$.

Since the frequency of noise that bothered the residents was hypothesized as an intermediate variable, a correlation analysis was then done to further assess the relationships between room location, frequency of bothersome noise, and room crowding (Table XVI). The result for noise 
with room location was: $\underline{r}(120)=.10, \underline{p}>.05$, for noise with room crowding was: $\underline{I}(121)=.18, \underline{p}>.05$. Frequency of bothersome noise was measured on a scale from 1 representing "very often" to 5 representing "almost never" and room location was coded as 0 for core group and 1 for wing group. Although the positive sign of both correlations was in the direction of our prediction, only the $\underline{r}$ of noise with room crowding was statistically significant at the .05 level. In other words, while those who were frequently bothered by noise did perceive higher degree of room crowding, they were not necessarily located at wings. However, Table XVI also showed that the core group reported to feel more "crowded" than the wing group based on one of the three basic crowding measures: Crowded-uncrowded $(\underline{r}(123)=.15, \underline{p}<.05)$.

\section{Summary}

of the three hypotheses tested by one-way ANOVA in this study, despite some indications that the difference in room location, desk location, and window orientation affected perceived room crowding in the direction predicted, none of them were found to be statistically significant. That is, the hypotheses about the effects of three selected physical features on room crowding were rejected. While adifional efforts were made by using Poarson's correlation or 3-way ANOVA, we found that the frequency of bothersome noise was significantly correlated with the room crowding index and that room location and territory were significant- 
Iy correlated with the item "crowded-uncrowded", and that subjects living on bigher floors and having an open view felt less crowded, all at the .05 level. Moreover, the overall response of all subjects on room crowding indicated that residents generally felt crowded in their rooms $(X=7.70$, median 9, Table XV). 
CHAFTTER V

CONCLUSIOIV

This dissertation addresses the following research questions: How do physical features of high density college dormitories affect residents' perceptions of crowding, and what kinds of design strategies are available for alleviating the perceived crowding if it is judged to be undesirable? The central assumptions underlying the research are that the physical environment is a vital crowding determinant and that the identification of physical variables should provide a basis for developing design guidelines. Recent studies have made it clear that it is not density alone but the ways the social and physical environments are structured and organized and the ways an individual perceives the degree of stimulation and the degree to which the environment constrains or affords desired behavior which lead to feelings of crowding. Crowding thus is a function of physical, social, and personal variations rather than absolute level of density.

Using this framework three studies were formulated to examine the relationship between perceived crowding and physical features associated with different settings in the dormitories. First examined were selected physical variables which, along with selected social and personal vari- 
ables, may contribute to perceived crowding both in dormitory dwellings and rooms. Comparisons were then made to determine if crowding differences existeà between groups living on floors with varied corridor length, floor height, and bathroom location, and between groups living in rooms with varied desk location, room location, and window orientation.

As noted in Chapter I, because the physical system of dormitories is different from the system of general apartments in many ways, e.g., a kitchen and private bathrooms are usually available in an apartment unit but not, in a dormitory unit, the generalization of findings from this dormitory research is limited. However, results might apply to institutional buildings such as hospital and nursing homes, where the physical system is similar to that in dormitories. For example, institutional buildings and dormitories are often built with numerous identical units double-loaded along central corridors leading to stairways and elevator shafts; shared public spaces such as bathrooms and kitchens are generally present in both types of buildings.

Despite the limitation in generalizing the findings, this research has several strengths. First of all, basic to its perspective is the comparison of one user population living in comparable high density environments yet in buildings that can be contrasted on specific design 
variables. This perspective is valuable because the attempt to predict the effects of design variables on perceived crowding in a natural setting over which we can exert no direct experimental control requires that subject variance between environments be kept minimal. In contrast, studying those living in apartments is likely to involve more confounding variables such as self-selection and differences in family size and age which might affect crowding perception. Ey studying a homogeneous student population residing in architecturally different dormitories in one college campus, the effects of design variables that may indirectly moderate the perception can be observed.

Second, for the purpose of investigating crowding perceptions, the fact that a greater number of contacts and interactions take place in a multistory domitory than other possible settings due to the large absolute number of residents and the usage of common facilities makes the dormitory a good setting in which to observe crowding phenomena. Third, the methodology employed in this research, including the research design and multivariate statistics used for data analysis, may be transferred to crowding research conducted in other types of high density environments. Specifically, the use of regression analyses aimed at comparing the relative contribution of physical, social, and personal factors on perceived crowding at different levels is a technique that has been little used in crowding research. 
Finally, the importance of studying crowding in a primary environment, where people spend much of their time relating to others on a personal basis and engaging in personally important activities, should be obvious. Crowding effects in a primary environment are argued to be more crucial than in a secondary one where crowaing experiences are more transitory in nature (Stokols, 1976).

\section{DISCUSSION}

The research was designed with the dual purposes of producing data that architects could use in the design process and information that would further the scientist's conceptual understanding of the relationship between physical environment and crowding perception. As noted in Chapter III, three general hypotheses were employed to examine the usefulness of selected physical, social, and personal crowding determinants and the two major crowding theories, i.e., the models of stimulus overload and behavioral constraint were reviewed. Specifically, these hypotheses are:

A. Holding density constant, physical determinants will be significantly different from social and personal ones in affecting perceived crowding.

B. Holding density constant, being crowded can be reduced if the space can be manipulated to reduce the amount of stimulus overload.

C. Holding density constant, being crowded can be reduced if the space can be manipulated to reduce the degree of behavioral constraint.

Based on these general hypotheses, specific hypotheses were 
developed and tested in three studies. Although testing the theoretical model of ecological affordance is not covered in this research, the connections of the model and research findings are elaborated in the discussion.

Determinants of Room and Dwelling Crowding

The results of regression analyses in study I indicated that there was no overall significant relationship between selected physical, social, and personal predictors and perceived crowding at either the room or dwelling levels, and that none of the selected predictors was significantly related to either room or dwelling crowding. While neither regression analysis supported the hypothesis that the physical dimension was the most significantly related to perceived crowding, the magnitude of $\underline{\mathrm{R}}^{2}$ illustrated that the social dimension was the most important in predicting both room and dwelling crowding, that the physical dimension was less important, and that the personal dimension was the least important.

In addition, individual beta weights indicated that, among the selected physical, social, and personal determinants, ethnicity was the most important predictor in the personal dimension, and privacy was the most important one in the social dimension, as well as in the entire set of predictors. However, according to Altman (1975), crowding occurs when privacy is invaded, and privacy is a reciprocal of crowding. Therefore, it would be more sensible for 
this study to think of privacy as an additional outcome measure of environmental conditions rather than as a crowding predictor.

As far as the reasons why no significant relationship has been found between perceived crowaing and the selected predictors are concerned, there is the problem of selfselection. The fact that students could request placement in a particular residence might have had a confounding influence on the effects of selected predictors. For example, people who are sensitive to crowding choose an uncrowded residence to live in and those who are not sensitive do not perceive their residences as crowded. Or, the preferences for certain aspects of the chosen residence may result in a positive attitude toward all aspects of the living environment, which may in turn reduce the variability in crowding scores.

Acknowledging that self-selection is almost always an issue for studies conducted in natural settings, it is suggested that future research should look into economic, social, and physical reasons why particular residences are selected so as to have a better assessment of the magnitude of possible confounding effects.

\section{Overlogd and Floor Crowding}

Overload, as noted in Chapter II, refers to one's inability to process excessive social or physical stimulation due to one's limited capacity for information 
processing (Vilgram, 1971). Study II was designed to examine the overload theory. The study hypothesized that, holding density constant, being crowded can be reduced if public spaces on the floor can be manipulated to reduce the amount of social stimulation.

It was assumed that a larger number of residents sharing common spaces and facilities in the dormitories would result in a higher frequency of social encounters. For example, when residents living in the conventionalcorridor dorm wish to use the community bath which is centrally located, they have to leave their rooms and walk through the hallway to get there. Because about 70 other floormates also use the facility, the likelihood that others would be in the bathroom and hallway is relatively high. Since they are likely to encounter others more frequently, according to Milgram's (1971) assumption of overload, they would reach an overloaded state more often than would residents of modified- and suite-corridor dorms.

Comparing the perceived floor crowding among those living in dormitories with comparable physical densities but different bathroom locations, it was found that residents living on floors with a centrally located community bath reported feeling the most crowded, those living on floors with two separately located common baths felt less crowded, and those on floors with individual suite baths felt the least crowded. The acceptance of the hypothesis that residents sharing more centralized community baths 
perceive more floor crowding suggests the theoretical linkage between social overload and perceived crowding.

Since the distribution of activities, i.e., centralization or decentralization, influence the degree of social density around the activity locations which in turn affects perceived crowding, the data suggest future research should examine the potency of activity nodes (e.g., community bathrooms, lounges, and elevators) as crowding determinants. Study II also hypothesized that floors with longer corridors would tend to create a higher degree of overload due to a larger number of people using the corridors, and thus would be perceived as more crowded. Comparing perceived floor crowaing between those living along long corriciors and those along short corridors, it was found that long-corridor residents perceived their floors as more crowded than short-corridor residents did. The data has corroborated the findings of the Stony Erook Research Program (Eaum et al, 1975; Eaum \& Valins, 1977; Eaum et al, 1979; Valins * Eaum, 1973) that corridor residents felt their dormitory was more crowded than did suite residents, and finding of Eaum et al (1978) that long-corridor resi- 1 dents felt that their dorm was more crowded than did shortcorridor residents.

However, a correlation analysis of this study's results assessing the relationship of corridor length with number of people seen in the corridors found no significant difference between number of people who appeared in long and in short 
corridors. While the finding did not support the assumption that a larger number of encounters occurred in longer corridors, other factors associated with corridor length have been suspected to mediate the social stimulation which resulted in a higher degree of perceived crowding in longer corridors. Since long-corridor residents were found to complain of too many people in the dorms they did not really know (Eaum et al, 1978), it is suspected in this study that they were more apt to meet with large numbers of unfamiliar people living in the long corridors than are short-corridor residents who are more likely to encounter the same group of people living in the short corridors, although no significant difference in the "quantity" of encounters between the two groups was detected. Also, it might be assumed that, compared with short-corridor residents, long-corridor ones who interact with a larger number of unfamiliar people are less able to predict the behaviors of other people, which taxes their attentional capacity, and thus they are more easily brought to an overloaded state. In other words, long-corridor residents are in this way also likely to perceive more crowding.

In addition, this study assumed that lower floor residents would see fewer people in the hallway because they had better ability by using stairs as well as the elevator to escape from the floor, and thus would feel less crowded than higher floor residents. The differences in perceived floor crowding among those living on different 
floors, however, were not statistically significant. This result is not in keeping with the findings of McCarthy and Saegert (1978) and Mitchell (1971) that higher floor residents feel more crowded in the building. In fact, it was found that fewer people were seen in the hallway by those living on higher floors. That more people appear in the hallway of lower floors may imply a preference for in-and-out activities due to the easier assessibility, and the preference may be a confounding variable influencing the crowding scores.

Overload, Constraint, and Noom Crowding

While study II examined perceived crowding in spaces overloaded by social stimulation, the noise as a physical stimulus was used to examine the overload model in study III. This study predicted that residents living in rooms by the core areas where most people and activities congregated would be more likely over-taxed by noise, in terms of their attentional capacity, than resicients living in wings. is a consequence, it was expected that core-area residents would feel more crowded than wing residents. While an analysis of variance in crowcing scores revealed no significant difference in the overall crowding scores between the core and wing groups, correlation of room location and one item from the crowaing index, i.e., "crowded- uncrowded", did indicate that the core residents felt more crowded in their rooms then did the wing 
residents. Noreover, the data showed that those who were frequently bothered by noise did perceive a higher degree of room crowding, which supported Cohen's (1978) speculation that the effects of noise would be to function as a stressor of attentional processes.

Study III also examined the model of behavioral constraint which has theorized that a perception of crowding arises when the regulation mechanisms controlling spatial behaviors, such as territorality, fail to provide the desired level of social interaction (AItman, 1975). This study hypothesized that, holding density constant, being crowced can be reduced if the space can be manipulated to reduce the degree of behavioral constraint the space is perceived to have.

The ability to gain freedom from constraint or to gain control over one's immediate environment has been shown to have a variety of important effects on behavior. For example, Baron et al (1976), studying the variation of social density in dormitory rooms, indicated that the larger a person's perceived territory, the less cramped the room was perceived to be. This study assumed that a person whose desk was close to the door would have a smaller territory and thus perceive a higher degree of crowding than his/ her roommate whose desk was close to window. However, in Study III it was found that no significant relationships between desk location and the room crowding index were found. Nevertheless, subsequent correlation analyses of 
desk location, territory size, and crowding measures, while indicating no significant correlation between desk location and territory size, did indicate a significant though relatively small correlation $(\underline{r}=.17)$ between territory size and one of the three items making up the room crowding index, i.e., "crowded- uncrowded." The finding that people who perceived they had a larger territory felt less "crowded" in their rooms is consistent with the findings of Earon et al (1976), and suggests the theoretical linkage of behavioral constraint and perceived crowding. Study III also assumed that people living in rooms with an open view obtained from the window would perceive themselves to be less crowded than did those in rooms with $a$ blocked view. Contrary to the hypothesis, an analysis of variance of crowding scores detected no significant difference in room crowding between residents having an open view and those having a blocked view.

In another dormitory study, Schiffenbauer et al (1977) reported that ratings of room size were inversely related to floor level. It was argued that the higher up one is, the more visually expanded is the environment; people in the room can see further when they look out of the window, and this perceptual expansion makes them feel and act as if the room wero larger than it actualiy is (Schiffenbauer, 1979). Further analysis in the current study, while it found no significant effect of floor height, found that the interactive effects of height and view on room crowding were 
significant in such a way that residents living on higher floors and having an open view f'elt the least crowded and those living on higher floors and having a blocked view felt the most crowded. It is probably because people reporting the least crowding are tiose who in fact own the best view by living not only with an open view but also on hizher floors, and because people reporting the most crowding are those who not only face the visual constraint (a blocked view) but who are less able to free themselves from the constraint by leaving the dorms.

Summary

Three general hypotheses were examined in this research. The first hypothesis assessed relationships between perceived crowding and selected crowcing determinants. The results indicated that there was no overall significant relationship between perceived crowding and selected physical, social, and personal determinants and that none of the selected determinants was significantly related to perceived crowing by itself.

The second and third hypotheses examined the usefulness of the two theoretical models of stimulus overload and behavioral constraint. As far as the overload approach was concerned, it assumed that floors with a more centralized bathroom pattern, with Ionger corrizors, or on higher levels tended to demand more social encounters, thus would be more likely to lead to a state of overload. Although 
this study found no significant difference in floor crowding between higher and lower floor residents, the acceptance of the hypotheses that residents sharing more centralized community bath(s) or residing along longer corridors perceived more crowding suggests there may be a theoretical linkage of overload and perceived crowding.

The finding that residents who share more centralized bathroom facilities perceived more floor crowding might also be explained by a third theoretical model of "ecological affordance" which emphasizes the competition of group members for the limited existing environmental resources. Although this study did not compare the adequency of bathroom and other shared facilities among the dorms, it is likely that those who share a centralized public community bath perceive less adequate bathroom facilities available than those privileged to use a semi-private suite bath. In other words, different social densities created by varied groupings of residents around shared resources may lead to different perceptions of the degree of resource affordance present, which in this particular case functions as an intermediate channel of overload and therefore of perceived crowding.

Noreover, although this research found no significant difference in perceived crowding between residents living in wings and in cores, it found that perceived crowding had a small yet significant correlation with frequency of bothersome noise $(\underline{r}=-.20)$ in such a direction that those who 
were more of ten bothered by noise perceived more room crowding. Since frequency of noise could stimulate people to an overload condition, the finding further suggests the relevance of a model of stimulus overload for explaining perceived crowding.

The usefulness of the behavioral constraint theory was examined in the analysis of relationships among desk location, perceived territory, and perceived crowding in individuals' rooms. Smaller room territory was found to have a small yet significant correlation with the "crowded" rating on the crowdedness index item, "crowded- uncrowded". This result was thus consistent with the model of behavioral constraint in explaining perceived crowding.

Although there was an indication that smaller room territory correlated with a higher degree of room crowding, desk location was not found to correlate significantly with either room territory or room crowding. As noted earlier, the research hypothesized that any physical features of space that reduce the degree to which people therein experience behavioral constraint may reduce the degree of perceived crowding. Since the data did not show that physical features affected room territory and crowding, there is no indication whether change in the physical environment would actually manipulate the intermediate process of constraint. In other words, the relationship of physical environment to behavioral constraint is still not supported in this research. 
Overall, the data of this research suggest that between the two theoretical approaches tested, the overload model held up the most consistently.

\section{INFLIC ATIONS}

Implications for Design Fractice

lost crowding studies of residential environments have employed extreme groups for comparison, e.g., residents who live in high-rise versus those in small dwellings, or those who live in domitory rooms arranged along a traaitional double-loaded corridor versus those in contemporary suites of a few rooms arranged around a common lounge. Generally, the results suggest that high-rise or corridor residents experience more crowding stress than do low-rise or suite residents respectively. Since the provision of corridor-style multi-unit dwellings to college residents commonly has economic causes, the current study employed only corridor-style structures comparable in size and varied in design for the comparison. While the small variability in our research setting may partially explain why some of the results were insignificant, this study is more useful for designers who must design corridor structures within comparable economic constraints.

Fast crowding studies in high-rise or corridor-style housing have demonstrated that the greater the number of tenants in a building, or the mora dwelling units on a corridor, or the more people who must use a common service 
area, the less likely residents are to know each other well and the more frequently uncontrollable encounters and interactions with others are likely to occur (Baum \& Valins, 1977; Eaum et al, 1978; HcCarthy \& Saegert, 1979). The present study, considered in light of the underlying architectural manipulation, suggests that, when the size of the official social group on each floor remains constant, perceived crowding can be reduced by breaking up long corridors and decreasing the number of people served by a common facility or space. The latter measure can be accomplished by increasing the number of and geographically dispersing the activity nodes. Such practices would decrease undesired encounters and make environments more controllable and predictable. To break up long corridors into short ones may in fact formulate smaller residential groups which, as suggested by Eaum and Valins (1977), in turn may reduce perceived crowding.

The data of this study also suggest that the degree of perceived crowding can be reduced by building acoustically insulated partitions, walls, and floor slabs, since noise was found significantly to correlate with one of the measures of perceived room crowding. Fast studies have demonstrated that other architectural manipulations may also increase the perceived size of a space as well as increase the perceived or actual behavioral control and freedom when actual spatial livitations are unavoidable (e.g., Schiffenbauer, 1977; Sommer, 1969). To the extent that 
ciesizners can predict where people will be least able to avoid prolonged exposure to high density, they can take steps to design such settings in ways that enable occupants to reduce the behavioral interferences, privacy infringements, and overstimulation often associated with conditions of Iimited space. It is possible that the breakup of long corridors, the decrease in the number of people served by common facilities, and the incorporation of ample soundproofing materials into partitions would be more beneficial to people living in dormitory or low income housing than the provision of additional square-footage per unit. That is to say, designers should consider residents' social needs rather than merely physical needs in their design process. Such a design process should involve establishing design policies and work programs that will allow dormitory residents to work with designers and should implement planning options that will allow the individual to exercise more control over his/her living environment.

In other words, past studies as well as the current study suggest two quite different ways architects can go about designing livable high density housing. First, they can try to design their spaces in such a way that they are perceived as larger than they are. Second, they can provide residents with the ability to control the environment so that it is responsive to residents' needs. Often architects think of the buildings they create as static entities. They ignore the fact that the building space is also a life 
space for the people who live there. Although the building itself may be static, the activities that it encloses certainly are not. If a high density environment is to be sucessful, the architect must provide some ways for the inhabitants to manage their space so that it conforms to their needs. One of the best things the architect $c a n$ do is to provide variety and flexibility in space design; for example, providing portable partitions and furniture, instead of built-ins, would allow residents to facilitate their territorial control.

In all, this postoccupancy study adds information for evaluating the performance of existing multi-story dormitories and for programming the spatial needs of future high density student housing. Knowledge gained from this study will help college housing designers and administrators to improve the design strategies and policies to which students may be receptive.

Implications for Future Research

The experience from this research also suggests the need for additional empirical research in studying crowding perception. This research was designed to examine the relationships between selected variables and perceived crowding inside the university dormitories in a small town. While the inside environment was perceived as "crowded" (see Tables XII and XV), the effects from the outside environment, if any were not addressed. Since the density 
condition of an outside environment is argued to affect the tolerable degree of inside crowding (Carnahan et al, 1974), future research could broaden the scope of this study by taking possible effects of outside density into account. Hore specifically, residents in an urban university campus and small town university campus can be used as the subjects so as to test whether there are significant difference of perceived crowding between the small town environment and the big city environment, and whether the ability to escape from a situation of high inside density to a low outside density would affect perceived crowding in the inside environment.

Since the main purpose of this research was to predict the effects of design variables on perceived crowding, the effects of social and personal variables were only addressed to a limited extent. Researchers who are interested in the social and personal effects could develop these dimensions in depth. Using "gender" as an example, al though all three dorms in this study were co-ed, two of them were co-ed by floor and one had mixed gender on floors (co-ed by suite). The data indicated that, while residents in all dorms generally perceived the floor was a crowded space, the dorm with lowest perceived crowding was the one with mixed gender on floors. Since whether a living group is co-ed may affect crowding perception, it could also be a confounding variable influencing the effects of physical variables on crowding. Thus, future research could examine, 
in a physically similar condition, whether there is a significant difference of perceived crowding between a singlegender and a co-ed living group.

In adaition, certain methodological modifications in terms of what was measured in the dependent variable and how it was measured are suggested for future research. While this research was specifically designed to examine the effects of physical design on "perceived" crowding, crowding, as a complex phenomenon, can be measured in different ways through different means. Since crowding is a psychological state frequently accompanied by coping responses, researchers who are interested in a broad aspect of crowding can construct a crowding measure based on, for example, not only self-reported data but also behavior-observational data. In example of this type of methodology is used in a cooperative work of Eaum, Harpin, and Valins (1975), in which we see a mix of strategies with elements from self-reports and observations of crowding responses in field or quasi-experimental settings. Wore specifically, it could be used in future research to examine many facets of density and its consequences, such as perceptions, verbal and nonverbal behaviors, performances on problem-solving tasks, and group involvments.

Another concem that arises from the findings is the relationship between the dependent measures of perceived size (small- large), spaciousness (cramped-spacious), and crowdedness (crowded- uncrowded) of a space, while these 
items, at either room or floor level, were highly correlated with each other (see Appendix D), they did not correlate with all other variables simultaneously. For example, room location and territory have some relationship with perceived room crowdedness but not with perceived room size and spaciousness (see Table XVI). One study (Schiffenbauer et al, 1977) also reported that light affected room crowdedness but not perceived size while useable space and floor height affected perceived size but not crowdedness. These findings suggest that perception of limited physical space might not always translate into identical feelings of crowdedness. Thus, the relationship of perceived crowding and perceived size could be addressed as a study subject in future research. For example, a researcher could test whether there would be any systematic differences between the two and, if any, how each of them relates to social, personal, and physical determinants.

\section{COINEUSION}

It is clear that the occurrence of perceived crowding is due partially to the physical entity and partially to the perceptions of observers who impose personal and social values on the environment, and that the user's perceived environment and its positive and negative qualities may differ from the designer's. Given the complexity of crowding-environment relationships, it is both necessary and desirable to have a good deal of collaboration among 
professionals in civerse fields. Decause practitioners of environmental design and behavioral researchers have very different orientations to the resolution of high density issues, interdisciplinary communication can often be quite difficult. Only through these cooperative efforts, however, will we be able to solve problems concerning residential crowding and design. It is my hope that from these efforts will come the knowledge pool upon which housing designers and policy makers can draw programs aimed to maximize building performance and user satisfaction. 


\section{A SELECTED BIBLIOGRAPHY}

Aiello, John R. and T.D. Aiello 1974. "The Development of Personal Space: Proxemic Behavior of Children 6 through 16," Human Ecology, 2, 177-189.

Alexander, Christopher 1974, "The City as a Mechanism for Sustaining Human Contact," in John Helmer and Neil A. Eddington (Eds.), Urbanman: The Psychology of Urban Survival, New York: Free Press, 239-274.

Altman, Irwin 1978. "Crowding: Historical and Contemporary Trends in Crowding Research," in Andrew Baum and Y.M. Epstein (Eds.), Human Response to Crowding, Hillsdale, N.J.: Lawrence Erlbaum Associates, 3-30.

Altman, Irwin 1975. The Environment and Social Behavior, Monterey, Cal.: Wadsworth.

Baron, Reuben M. and David R. Mandel 1978. "Toward an Ecological Model of Density Effects in Dormitory Settings," in Andrew Baum and Y.M. Epstein (Eds.), Human Response to Crowding, Hillsdale, N.J.: Lawrence Erlbaum Associates, 303-324.

Baron, R.M., D.R. Mandel, C.A. Adams, and L.M. Griffen 1976. "Effects of Social Density in University Residential Environments," Joumal of Personality and Social Psyciology, $34: 3,434-446$.

Baron, Reuben and Judith Rodin 1978. "Personal Control as a Mediator of Crowding," in Andrew Baum, J.E. Singer, and $\mathrm{S}$. Valins (Eds.), Advances in Environmental Psychology, V. 1, Hillsdale, N.J.: Lawrence Erlbaum Associates.

Baum, Andrew, John R. Aiello, and Lisa E. Calesnick 1978. "Crowding and Personal Control: Sociel Density and the Development of Learned Helplessness," Journal of Personality and Social Psychology, 36:9, 1000-1011.

Baum, Andrew and Glenn E. Davis 1976. "Spatial and Social Aspects of Crowding Perception," Environment and Behavior, 8:4, 527-544.

Baum, A., G.E. Davis, and S. Valins 1979. "Generating Behavioral Data for the Design Process," in J.R. Aiello 
and A. Boum (Eds.), Residential Crowding and Design, New York: Plenum Press, 175-196.

Baum, A. and C.I. Greenberg 1975. "Waiting for a Crowd: The Behavioral and Perceptual Effects of Anticipated Crowding," Journal of Personality and Social Psycio108X, $32: 4,671-679$.

Baum, A., R.E. Herpin, and S. Valing 1975. "The Role of Group Phenomena in the Experience of Crowding," Environment and Behavior, $7: 2,185-198$.

Baum, A. and S. Koman 1976. "Differential Response to Anticipated Crowding: Psychological Effects of Social and Spatial Density," Joumal of Fersonality and Social Psychology, $34: 3,526-536$.

Baum, Andrew and Stuart Valins 1977. Architectural and Social Behavior: Psychological studies of Social Density, Hillsdale, N.J.: Lawrence Erlbaum Associates.

Bickman, L., A. Teger, T. Gabriele, C. McLaughlin, M. Berger, and E. Sunaday 1973. "Dormitory Density and Helping Behavior," Environment and Behavior, 5:4, 465-490.

Calhoun, J.B. 1962. "Population Density and Social Patholo8y," Scientific American, 206, 139-148.

Carnahan, D., W. Gove, and O.R. Galle 1974. "Urbanization, Population Density, and Overcrowding," Social Forces $53,62-72$.

Chermayeff, Serge and Christopher Alexander 1963. Community and Privacy: Toward a New Architecture of Humanism, Garden City, N.Y.: Doubleday.

Chickering, A.W. 1967. "College Residences and Student Development," Educational Record, 48 .

Christian, J., V. Flyger, and D. Davis 1960. "Factors in the Mass Mortality of a Herd of Sika Deer Cervus Nippon," Chesapeake Science, 1, 79-95.

Cohen, J.L., D.C. Glass, and J.E. Singer 1973. "Apartment Noise, Auditory Discrimination, and Reading Ability in Children," Journal of Experimental Social Psychology. $9,407-422$.

Cohen, J.L., B. Sladen, and B. Bennett 1975. "The Effects of Situational Variables on Judgements of Crowding," Sociometry, 38:2, 273-281.

Cohen, S. 1978. "Environmental Load and the Allocation of 
Attention," in A. Baum and S. Valins (Eds.), Advances in Environmental Psychology, V. 1, Hillsdale, N.J.: Lawrence Erlbaum Associates.

Colton, Kent W. 1980. "Housing Finance in the 1980s: Economic Factors Indicate Future Directions," Journal of Housing, January, 15-21.

Coss, R. 1973. "The Cut off Hypothesis: Its Relevance to the Design of Public Space," Man-Environment Systems, 3, 417-440.

Cox, V.C., P.B. Paulus, G. McCain, and J.K. Schkade 1979. "Field Research on the Effects of Crowding in Prisons and on Offshore Drilling Platforms," in J.R. Aiello and A. Baum (Eds.), Residential Crowding and Design, New York: Plenum Press, 95-106

Cozby, P.C. 1973. "Effects of Density, Activity, and Personality on Environmental Preferences," Journal of Research in Personality, 7, 45-60.

Cranz, G. and T.I. Schumacher 1977. "The Impact of HighRise Housing on Older Residents," in D.J. Conway (Ed.), Human Response to Tal I Buildings, Stroudsburg, Pen.: Dowden, Hutchinson, \& Ross.

D'Atri, D.A. 1975. "Psychophysiological kesoonses to Crowding," Environment and Eehavior, 7, 237-252.

Deân, L.M., W.M. Pugh, and E. Gunderson 1975. "Spatial and Perceptual Components of Crowding: Effects on Health and Satisfaction," Environment and Behavior, 7:2.

Desor, J. 1972. "Toward a Psychological Theory of Crowding," Journal of Personality and Social Psychology, 21.

Dubos, Rene 1965. Man Adapting, New Haven, Conn.: Yale University Press.

Edney, J.J. 1972. "Place and Space: The Effects of Experience with a Physical Locale," Journal of Experimental Social Psychology, 8, 124-135.

Educational Facilities La'uoratories 1972. Student HousingA Report, New York: E. F. I.

Ehrlich, Paul and Anne Ehrlich 1970. Population, Resource, Environment: Issues in Human Ecology, San Francisco: W. H. Freeman.

Epstein, Y.M. and R.A. Karlin 1975. "Effects of Acute Experimental Crowding," Joumal of Applied Social 
Psychology, 4, 34-53.

Esser, A.H. 1973. "Experiences of Crowding: Illustration of a Paradigm for Man-Environment Relations," Representative Research in Social Psychology, 4, $207-218$.

Evans, Gary W. 1975. Behavioral and Psychological Consequences of Crowding in Humans, unpublished doctoral dissertation, University of Massachusetts.

Evans, Gary W. 1978. "Crowding and the Development Process," in A. Baum and Y.M. Epstein (Eds.), Human Response to Crowding, Hillsdale, N.J.: Lawrence Erlbaum Associates, 117-140.

Evans, G.W. and R.B. Howard 1973. "Personal Space," Psychological Bulletin, $80,334-344$.

Fanning, D.M. 1967. "Families in Flats," British Medical Journal, $4,382-386$.

Fischer, C. 1976. The Urban Experience, New York: Harcourt.

Freedman, Jonathan L. 1975. Crowding and Behavior, New York: Viking Press.

Freedman, J.I. 1979. "Current Status of Work on Crowding and Suggestions for Housing Design," in R. Aiello and A. Baum (Eds.), Residential Crowding and Design, New York: Plenum Press, 167-174.

Freedman, J.L., S. Heshka, and A. Levy 1975. "Population Density and Pathology: Is There a Relationship?" Journal of Experimental Social Psychology, 11, 539-552.

Freedman, J.L., S. Klevansky, P. Ehrlich 1971. "The Effect of Crowding on Human Task Performance," Journal of Applied Social Psychology, 1, 7-25.

Freedman, J.L., A.S. Levy, R.W. Buchanan, and J. Price 1972. "Crowding and Human Aggressiveness," Journal of Experimental Social Psychology, 8, 528-548.

Galle, Omer R. and Walter R. Gove 1979. "Crowding and Behavior in Chicago, 1940-1970," in R. Aiello and A. Baum (Eds.), Residential Crowding and Design, New York: Plenum Press, 23-40.

Galle, O.R., W.R. Gove, and J.M. McPherson 1972. "Population Density and Pathology: What are the Relationships for man?" Science, 176, 23-30.

Gibson, J.J. 1977. "Theory of Affordances," in R.E. Shaw 
and $\mathrm{J}$. Bransford (Eds.), Perceiving, Acting, and Knowing: Toward an Ecological Psychology, Hillsdale, N.J.: Lawrence Erlbaum Associates.

Gillis, A.R. 1974. "Population Density and Social Pathology: The Case of Building Type, Social Allowance, and Juvenile Delinquency," Social Forces, 53, 306-314.

Glass, D.C. and J.E. Singer 1972. Urban Stress, New York: Academic Press.

Green, C.M. 1965. The Rise of Urban America, New York: Harper and Row.

Griffitt, W. and R. Veitch 1971. "Hot and Crowded: Influence of Population Density and Temperature on Interpersonal Affective Behavior," Journal of Personality and Social Psychology, $17: \overline{1}, 92-98$.

Hall, Edward T. 1966. The Hidden Dimension, New York: Doubleday.

Hal1, Edward T. 1959, The Silent Language, New York: Doubleday.

Hawley, A. 1972. "Population Density and the City," Demography, 9.

Hayward, S.C. and S.S. Franklin 1974. "Perceived OpennessEnclosure of Architectural Space," Environment and Behavior, 6, 37-52.

Holahan, Charles J. and Brian L. Wilcox 1979. "Environmental Satisfaction in High- and Low-Rise Residential Settings: A Lewinian Perspective," in J.R. Aiello and A. Baum (Eds.), Residential Crowding and Design, New York: Plenum Press, 127-140.

Howard, E. 1965. Garden Cities of Tomorrow, Cambridge, Mass: MIT Press. Originally published in 1898.

Imamoglu, V. 1973. "The Effect of Furniture Density on the Subjectiva Evaluation of Spaciousness and Estimation of Size of Rooms," in Rikard Kuller (Ed.), Architectrieal Psychology, Stroudsburg, Penn.: Dowden, Hutchinson, and Ross.

Jacubs, Jane 1961. The Death and Life of Great American Cities, New York: Random House.

Jenson, Rolf 1966. High Density Living, New York: Frederic Praeger. 
Lantz, H.R. 1953. "Population Density and Psychiatric Diagnosis," Sociology and Social Research, 37, 322-326.

Lawrence, J.E. 1974. "Science and Sentiment: Overview of Research on Crowding and Human Behavior," Psychological Bulletin, 81:10, 712-720.

Le Corbusier 1933. The Radiant City, New York: Orion.

Lee, Terence R. 1968. "Urban Neighborhood as a SocioSpatial Schema," Human Relations, 21, 241-267.

Loo, C. M. 1972. "The Effect of Spatial Density on tine Social Behavior of Children," Journal of Applied Social Psychology, 2: 4, 372-381.

Loo, C. M. 1973. "Important Issues in Researching the Effects of Crowding on Humans," Representative Research in Social Psychology, 4: i, 219-2 27 .

Lynch, Kevin 1965. "The City as Environment," Scientific American, 213:3, 209-215.

Mandel, D. R., R. M. Baron, and J. D. Fisher 1980. "Room Utilization and Dimensions of Density: Effects of Height and View," Environment and Behavior, 12:3, 308-319.

Marans, Robert W. and John D. Wellman 1976. "Optimizing Urban Density" in Pierre Laconte (Ed), The Environment of Human settlements, V. 1. 167-176.

Marshall, Nancy J. 19\%2. "Privacy and Environment," Human Ecology, $1: 2,93-110$.

McCain, G., V. Cox, and P. Paulus 1976. "The Relationship Between Illness Complaints and Degree of Crowding in a Prison Environment," Environment and Behavior, 8:2, 283-290.

McCarthy, Dennis P. and Susan Saegert 1979. "Residential Density, Social Overload, and Social Withdrawal," in J.R. Aiello, and A. Baum (Eds.), Residential Crowding and Design, New York: Plenum Press, 55-76.

Milgram, Stanley 1970. "The Experience of Living in Cities," Science, 167, 1461-1468.

Mitchell, R. 1971. "Some Social Implications of Higher Density Housing," American Sociological Review, 36, 18-29.

Mumford, Lewis 1956. From the Ground Up, New York: Harcourt Brace Jovanovich. 
Newman, 0scar 1973. Defensible Space: Crime Prevention through Urban Design, New York: Macmillan.

Page, R.A. 1977. "Noise and Helping Behavior," Environment and Behavior, 9:3, 311-334.

Paulus, P.B., A.B. Annis, J.J. Seta, J.K. Schkade, and R.W. Matthews 1976. "Density Does Affect Task Performance," Joumal of Personality and Social Psychology, 34, 248-253.

Paulus, P.B., V. Cox, G. McCain, and J. Chandler 1975. "Some Effects of Crowding in a Prison Environment," Joumal of Applied Social Psychology, 5:1, 86-91.

Plant, J.S. 1930. "Some Psychiatric Aspects of Crowding Living Conditions," American Journal of Psychiatry, $9: 5,849-860$.

Proshansky, H.M., W.H. Ittelson, and L.G. Rivlin 1970. Environmental Psycholory: Man in His Physical Setting, New York: Holt, Rinehart, and Winston.

Rapoport, Amos 1977. Human Aspects of Urban Form, Oxford: Pergamon Press.

Rapoport, Amos 1975. "Toward a Redefinition of Density," Environment and Behavior, $7: 2,133-158$.

Ricker, Harold C. and Frank G. Lopez 1961. College Students Live Here, New York: Educational Facilities Laboratories.

Rodin, Judith 1976. "Crowding, Perceived Choice, and Responses to Controllable and Uncontrollable Outcomes," Joumal of Experimental Social Psychology, 12, 564-578.

Rohe, W., and A.H. Patterson 1974. "The Effects of Varied Levels of Resources and Density on Behavior in a Day Care Center," in D.H. Carson (Ed.), EDRA 5: ManEnvironment Interactions, Milwalkee, Wis.: Environmental Design Research Association.

Ross, M., B. Layton, B. Erickson, and J. Schopler 1973. "Affect, Facial Regard, and Reactions to Crowding," Journal of Personality and Social Psychology, 28:1, $69-76$.

Saegert, Susan, 1973. "Crowding: Cognitive Overload and Behavioral Constraint," in Wolfgang Preiser (Ed.), Environmental Design Research, VII, Stroudsberg, Penn.: Dowden, Hutchinson, and Ross. 
Saegert, Susan 1975. Effects of Spatial and Social Density on Arousal, Mood, and Social Orientation, Dissertation Ábstracts International, V. 35, 7, 3649.

Saegert, Susan 1978. "High Density Environments: Their Personal and Social Consequences," in A. Baum and Y. M. Epstein (Eds), Human Response to Crowding, Hillsdale, N. J.: Lawrence Erlbaum Associates.

Saegert, S., E. Mackintosh, S. West 197j. "Two Studies of Crowding in Urban Public Spaces," Environment and Behavior, $7: 2,159-184$.

Safdie, Moshe 1970. Beyond Habitat, Cambridge, Mass: MIT.

Schiffenbquer, Allen 1979. "Design for High-Density Living," in J.R. Aiello and A. Baum (Eds.), Residential Crowding and Design, New York: Plenum Press, 229-240.

Schiffenbauer, A.I., J.E. Brown, P.L. Perry, L.K. Shutack, and A.M. Zanzola 1977. "The Relationship between Density and Crowding: Some Architectural Modifiers," Environment and Behavior, 9, 3-14.

Schmidt, D.E., R.D. Goldman, and N.R. Feimer 1979. "Perception of Crowding: Predicting at the Residence, Neighborhood, and City Level," Environment and Behavior, $11: 1,105-130$.

Schmitt, R.C. 1966. "Density, Health, and Social Disorganization," Journal of the American Institute of Planners, $32,38-40$.

Sherrod, Drury R. 1974. "Crowding, Perceived Control, and Behavioral Aftereffects," Journal of Applied Social Psychology, 4:2, 171-186.

Simel, George 1950. The Sociology of George Simmel, edited by K.H. Wolff, New York: The Free Press.

Smith, S and W.W. Haythom 1972. "Effects of Compatability, Crowding, Group Size, and Leadership Seniority on Stress, Anxiety, Hostility, and Annoyance in Isolated Groups," Journal of Personality and Social Psychology, $22: 1,67-69$.

Soleri, P. 1969. Arcology: The City in the Image of Men, Cambridge, Mass.: MIT Press.

Sommer, Robert 1969. Personal Space, Englewood Cliffs, N.J.: Prentice-Hall.

Sommer, R. and F.D. Becker 1971. "Room Density and User 
Satisfaction," Environment and Behavior, 3, 412-417.

Stokols, Daniel 1972a. "On the Distinction between Density and Crowding: Some Implications for Future Research," Psychological Review, 79:3, 275-278.

Stokols, Daniel 1972b. "A Social-Psychological Model of Human Crowding Phenomena," Journal of the American Institude of Planners, $38,72-83$.

Stokols, Daniel 1973. "The Relation between Micro and Macro Crowding Phenomena: Some Implications for Environmental Research and Design," Man-Environment Systems, 3 .

Stokols, Daniel 1976. "The Experience of Crowding in Primary and Secondary Environments," Environment and Behavior, $8: 1,49-86$.

Stokols, Daniel 1978. "A Typology of Crowding Experiences," in A. Baum, and Y.M. Epstein (Eds.), Human Response to Crowding. Hillsdale, N.J.: Lawrence Erlbaum Associates, 219-258.

Stokols, D., M. Rall, B. Pinner, and J. Schopler 1973. "Physical, Social, and Personal Determinants of Perception of Crowding," Environment and Behavior, 5:1, 87-117.

Stokols, D., T.E. Smith, and J.J. Proster 1975. "Partitioning and Perceived Crowaing in a Public Place," American Behavioral Scientist, 18:6, 792-814.

Sundstrom, Eric 1978. "Crowding as a Sequential Process: Review of Research on the Effects of Population Density on Humans," in A. Baum, and Y.M. Epstein (Eds.), Human Response to Crowding, Hillsdale, N.J.: Lewrence Erlbaum Associates, 32-116.

Sundstrom, Eric 1975. "An Experimental Study of Crowding: Effects of Room Size, Intrusion, and Goal-Blocking on Nonverbal Behaviors, Self-Disclosure, and Self-Reported Stress," Journal of Personality and Social Psychology, $32: 4,645-654$.

Valins, Stuart and Andrew Baum 1973. "Residential Group Size, Social Interaction, and Crowding," Environment and Behavior, 5:4, 421-440.

Verbrugge, L.H. and R.B. Taylor 1980. "Consequences of Population Density and Size," Urban Affairs Quarterly.

$16: 2$.

Walden, T.A., P.A. Nelson, and D.E. Smith 1981. "Crowding, Privacy, and Coping," Environment and Behavior, 13:2, 205-224. 
Wicker, A. 1973. "Undermanning Theory and Research: Implications for the Study of Psychological and Behavioral Effects of Excess Populations," Representative Research in Social Psychology, 4, 185-206.

Wirth, Louis 1938. "Urbanism as a Way of Life," American Journal of Sociologr, $44,1-24$.

Wirth, Louis 1969. "Human Ecology," in R. Sennett (Ed.), Clessic Essays on the Cultures of Cities, New York: Appleton-Century-Croft. Originally published in 1945.

Wohlwill, J. and I. Kohn 1973. "The Environment as Experienced by the Migrant: An Adaptation-Level View," Representative Research in Social Psychology, 4, 135164.

Worchel, S and C. Teddlie 1975. "The Experience of Crowding: A Two-Factor Theory," Journal of Personality and Social Psychology, 34:1, 30-40.

Wright, Frank L. 1958. The Living City, New York: Horizon Press.

Yancey, William L. 1973. "Architecture, Interaction, and Social Control: The Case of a Large-Scale Public Housing Project," in J. Helmer and N.A. Eddington (Eds.), Urbanman: The Psychology of Urban Survival, New York: Macmilian, 107-122.

Zimbardo, Philip G. 1973. "The Human Choice: Individuation, Reason and Order Vs. Deindividuation, Impulse and Chaos," in J. Helmer and N.A. Eddington (Eds.), Urbanman: The Psychology of Urban Survival, New York: Niacmillan, 196-238.

Zlutnick, S and I. Altman 1972. "Crowding and Human Behavior," in J. Wohlwill and D. Carson (Eds.), Environment and Social Sciences: Perspectives and Applications, Washington, D.C.: American Psychological Association, 44-60. 


\section{APPENDIX A}

LOCATIONS OF SELECTED DORMITORIES IN OREGON STATE CAMPUS

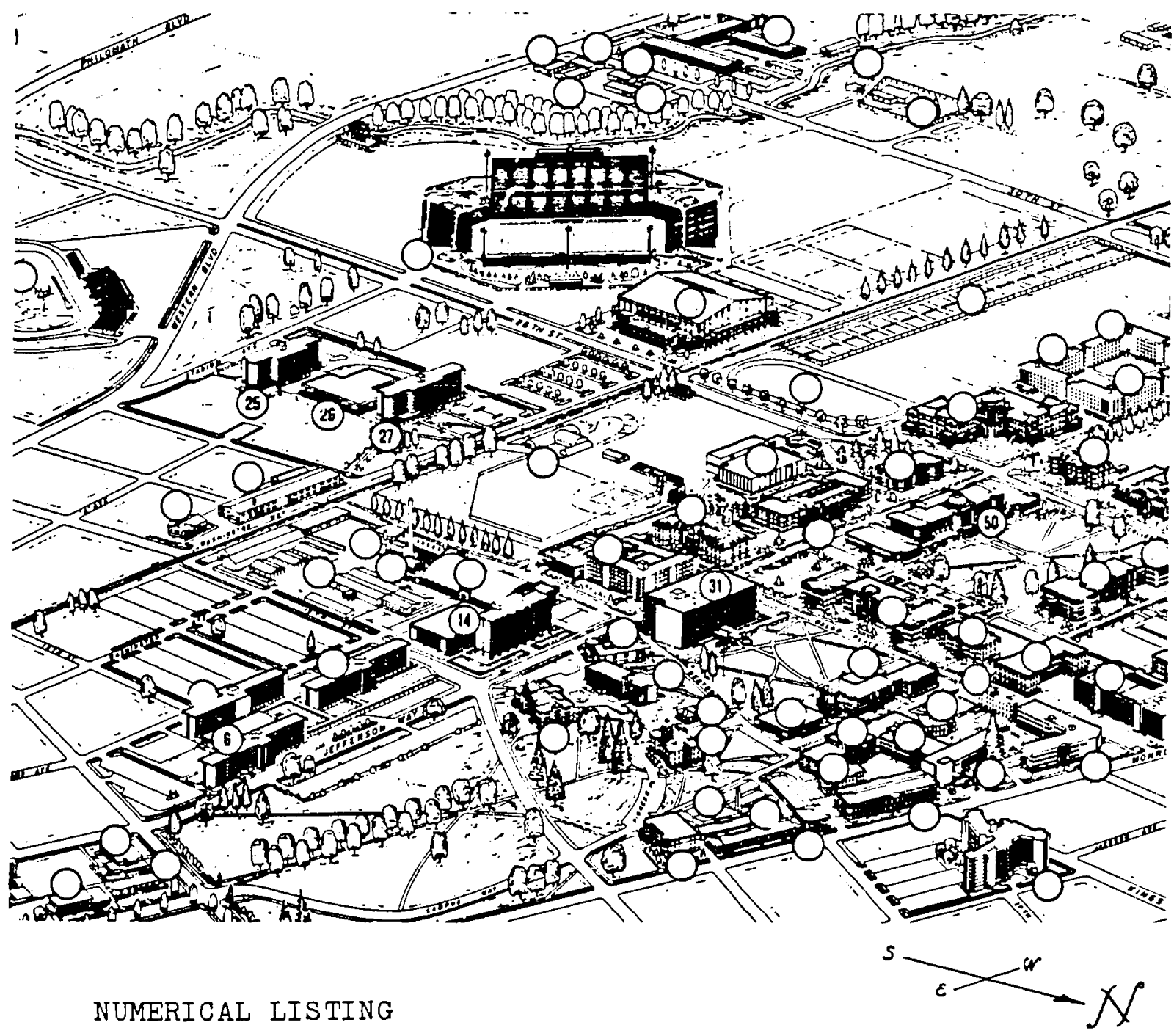

6 McNary $\mathrm{Hall}$

14 Administrative Services Building

25 Bloss Hall

26 Arnold Dining $\mathrm{Hall}$

27 Finley $\mathrm{Hall}$

31 Kerr (main) Library

50 Memorial (student) Union Euilding 


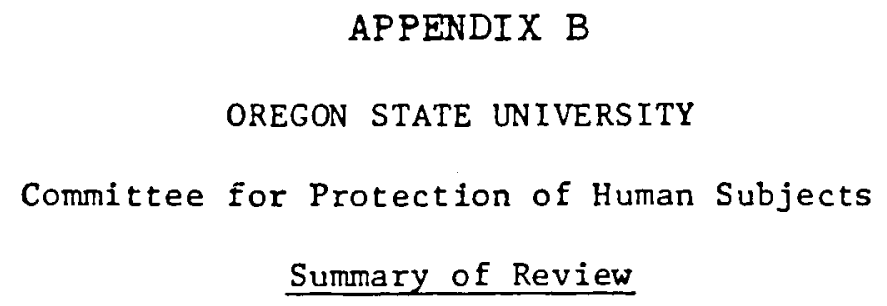

Summary of Review

TITLE: Architectural Impacts on Crowding Perception

PROGRAM DIRECTOR:___ Nancy Chapman (Edward T. Huang)

RECOMENDATION :

XX Approva1

Provisional Approval

Disapproval

No Action

REMARKS :

Since the names of the students are not needed, recommend deleting

the name blank from the questionnaire.

Date: March 24, 1980

cc: Committee Chairman

mep

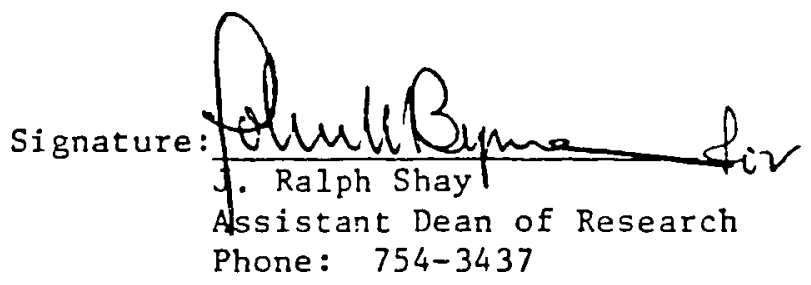




\author{
APPENDIX C \\ LETTER TO STUDENT PARTICIPANTS AND \\ SELF-ADMINISTERED QUESTIONNAIRE
}

LETTER TO STUDENT PARTICIPANTS

Hello,

The following questionnaire survey aims to understand how the building design of this dormitory services your needs. Primarily, your feelings concerning the adequacy of spaces in your room and the floor where you live are investigated. The result from your inputs and opinions on this study should help improve the quality of student housing for you and other students.

Your response to questionnaire will be scored by a computer, and will be held strictly confidential. Printing your name at the top page of questionnaire is optional.

I am interested in the total response of men and women in the various dormitories sampled, and am not analyzing individual scores. You will notice that I have pre-marked your room number at the top page of the questionnaire. The purpose of coding the number is to identify the location of your room within the floor plan of the building.

When you have completed the questionnaire, please drop it in the box placed on the reception counter at the Head Resident Office. I will pick it up at 7:00 PM on the 17 th of April. Your immediate response shall be fully appreciated.

You will determine the success of this study, and I want to thank you in advance for taking time from your busy schedule to participate in this project. If you have any questions regarding the study, please contact me at 1-2250642 .

Sincerely,

Ed Tieh-Yeu Huang Graduate Program in

Urban Studies and Planning

Portland State University 
SELF-ADMINISTERED QUESTIONNAIRE

(Data codes reported in parenthesis)

\section{Suilding name:}

Room number:

Please fill in an answer or check one from given answers on following questions:

1. How old are you? (Number)

2. Are you ...... __ Female (0) __ Male(1)

3. How many quarters have you lived in jour present room? (Number)

4. Did you live in this dorm before you moved to your present room?

W Yos (How many terms?

Room number

5. What is your class level in Spring, 1980?

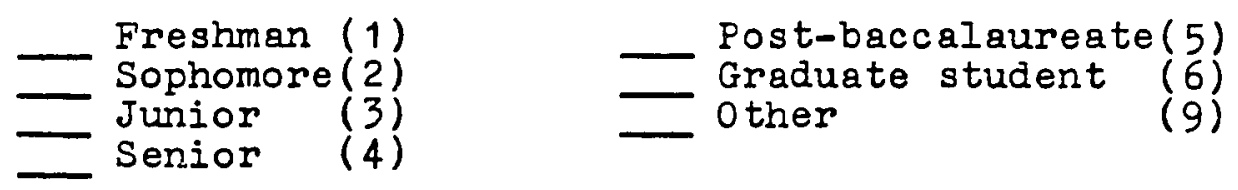

6. How many credit hours are you carrying?

(Number)

7. How would you rate your academic achievement as measured by grades in college?
Mostly $A^{\prime} s(1)$
- Mostly $B^{\prime} s(2)$
$-M o s t I y$
$C$
Mostiy D's
- Mostiy ungraded
(4)

8. Which of the following describes the type of dwelling in which jou lived most of the time while you were growing up?

Single-family $(1$
Duplex
Town houge

Small apartment building (4)

9. Which of the following describes your room most of the time while you were growing up?

- Private room 
Room shared with two persons

- Room shared with three persons or more(4)

- Other (please specify.

10. Would you say that the environment in which you lived most of the time while you were growing up was .......
Very crowded
Very crowded (1)
$(1)$
Somewhat crowded(3)
Not crowded
(4)

11. Approximately how much of your waking time (between the time you get up and go to bed) do you usualiy spend in your room?

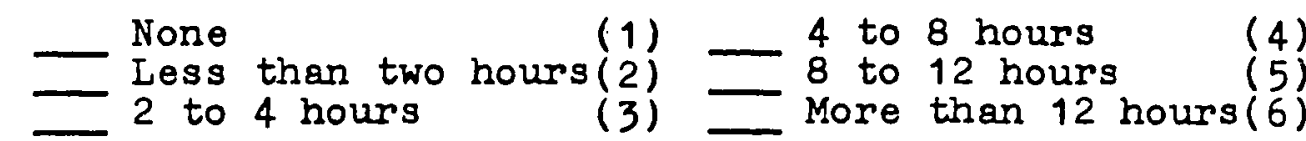

12. One of the following figure has been the typical plan of your present room (if the furnitures are arranged differently, please indicate in the plan where they are placed), please shade the area that you consider as your own territory, where you feel most comfortable.

(Figure 5: Typical Room Plang on page 60 is used here.)

13. In the preceding plan of your room, please indicate which desk, bed, and wardrobe you use most of the time.

14. How many times do you use the lounge of this floor in a typical week?

(Number)

15. How many times do you walk through the hallway of this floor on a typical day? (Number)

16. How many people on this floor could you count for a small favor?

\section{(Number)}

17. How many people on the floor could you count on in an emergency?

(Number)

18. The following figure is the plan of the floor where you live, please shade the rooms and areas that you consider as places part of your territory, where you feel comfortable.

(Figure 2, 3, or 4 on page 56, 57, or 58 is used here.) 
19. How would you describe your roommate?

$\begin{array}{lr}\text { - American Indian/Alaskan native } & \text { (1) } \\ \text { Black/Afro-American } & \text { (2) } \\ \text { Caucasian/White } & \text { (3) } \\ \text { Chicano/Mexican American } & \text { (4) } \\ \text { - Pacific Islander/Asian American stadent (6) }\end{array}$

20. How would you describe yourself?

$\begin{array}{lr}\text { American Indian/Alaskan native } & (1) \\ \text { Black/Afro-Amerlcan } & (2) \\ \text { Caucasian/White } & (3) \\ \text { Chicano/Mexican American } & (4) \\ \text { Pacific Islander/Asian American } & (5) \\ \text { Pesident with visa/International student } & (6)\end{array}$

21. Which of the following describes the type of socioeconomic class in which you grew up?

$\begin{array}{lr}\text { Upper class } & (1) \\ \text { - Middle class } & \text { (2) Lower class (4) } \\ \text { Middle-lower class (3) Don't know (9) }\end{array}$

Here are some sentences used to describe your feeling of your current living environment, as it seems to you. The description of your feeling is furnished with a 5-point scale, ranging from "strongly agree" to "strongly disagree". Please circle the number on the scale that comes closest to your feeling about each following statements.

22. I don't mind living in a dormitory holding hundreds of people.

$$
\text { Strongly agree --- } \begin{array}{llllll}
1 & 2 & 3 & 4 & 5 & ---
\end{array}
$$

23. People on this floor don't know about me and my actions. Strongly agree -- $\begin{array}{ccccccc}1 & 2 & 3 & 4 & 5 & -- \text { Strongly disagree }\end{array}$

24. Very few people participate in social activities of this floor

Strongly agree

25. Although I occasionally enjoying talking to my neighbors, I don't like to get involved with them.

Strongly agree -- $\begin{array}{cccccc}1 & 2 & 3 & 4 & 5 & --\end{array}$ Strongly disagree

26. People on this floor are concerned with helping and supporting one another.

$$
\text { Strongly agree --- } \begin{array}{lllllll}
1 & 2 & 3 & 4 & 5 & --- \text { Strongly disagree }
\end{array}
$$

27. People on the floor tend to rely on themselves when a 
problem comes up.

Strongly agree --- $\begin{array}{llllll}1 & 2 & 3 & 4 & 5 & -- \text { Strongly disagree }\end{array}$

28. It is easy to meet people on the floor and to build friendship.

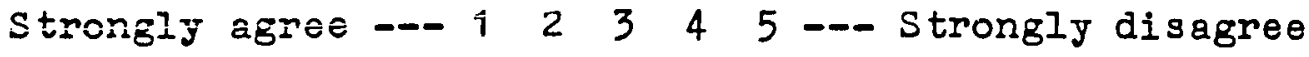

29. There is a feeling of unity and cohesion among floormates.

Strongly agree -- $\begin{array}{cccccc}1 & 2 & 3 & 4 & 5 & --\end{array}$

30. I would say this floor is a friendly place to live. Strongly agree --- $\begin{array}{llllll}1 & 2 & 3 & 4 & 5 & ---\end{array}$ Strongly disagree

Please circle the number on the scale that comes the closest to your feeling about each following question.

31. How often do you say "hello" or "good morning" to people on this floor?

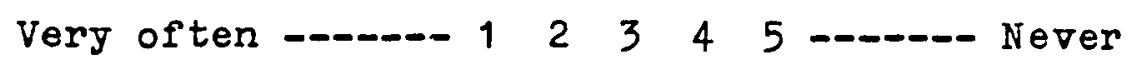

32. How well do you think people on the floor know each other?

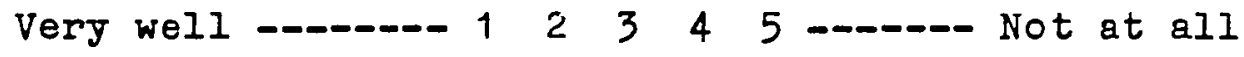

33. About how many of them would you say that you know by name?

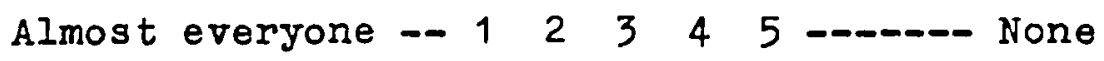

34. How often do you go to eat, to movies, to picnics, or other things like that with others on the floor?

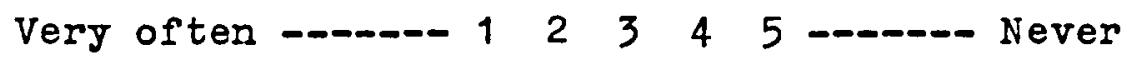

35. How often do you and your neighbors exchange or borrow things such as books, tools, and food from one another?

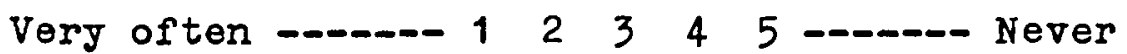

36. How extensively have you been involved in social, athletic, or governmental activities of this floor?

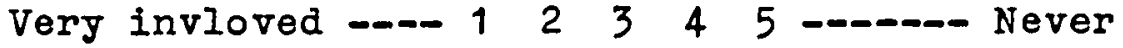

37. How extensively have you involved in social, athletic, or governmental activities of this dorm?

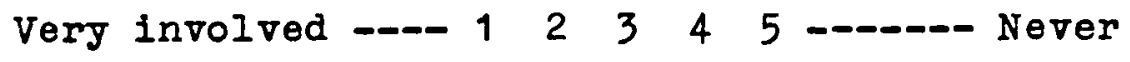

38. How often do you hear noise through the walls of your room?

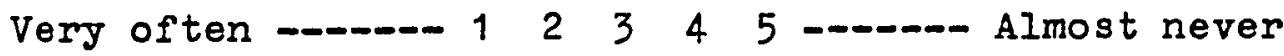


39. How often does the noise bother your sleeping or studying?

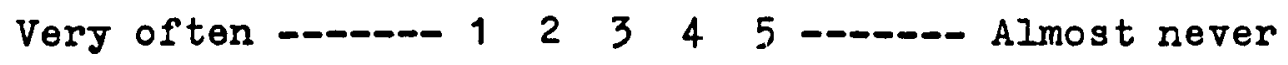

40. How much privacy would jou say that jou have from your roommate?

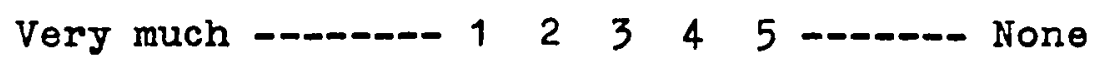

41. How much privacy would you say that you have from your neighbors?

Very much -

42. How often do you have to wait to use the facilities in the suite or floor bathroom?

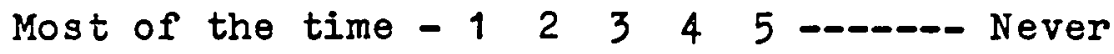

43. How many people do you usually see in the lounge on the floor when you are there?

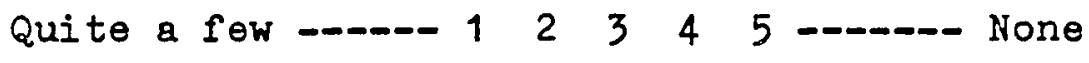

44. How often do you see others in the lounge on the floor whom Jou don't know?

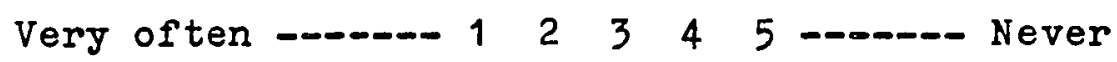

45. How many people do jou usually see in the hallway on

the floor when you walk through it?

Quite a few - - $123345 \ldots$

46. How often do you see others in the hallway on the floor whom you don't know?

Very often - $-12345-\infty-\infty$ Never

47. How crowded do you feel living in this dorm?

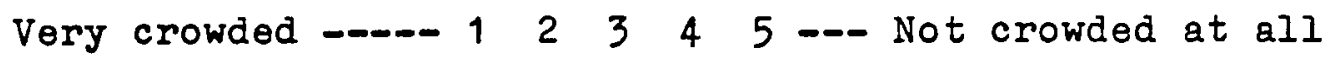

48. How adequate do you feel the space on this floor?

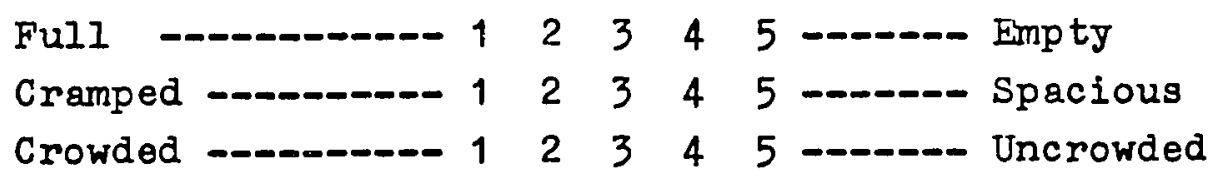

49. How adequate do you feel the space in your room?

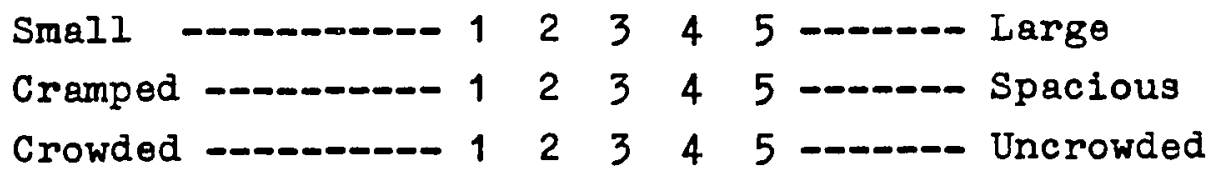


50. How well do you get along with your roommate? Very well _...- $123345 \ldots$ Not at all

51. How satisfied are you with living in your present room? Very satisfied - $\begin{array}{lllllll}1 & 2 & 3 & 4 & 5\end{array}$

52. How satisfied are you with living in this dorm? Very satisfied - $\begin{array}{lllllll}1 & 2 & 3 & 4 & 5\end{array}$

Please add any additional comments you would like to make on the following blank area. Thanks again for jour valuable time! 


\section{APPENDIX D}

CORRELATION MATRIX FOR OVERALL PERCEIVED CROWDING

$\begin{array}{lllllll} & 1 & 2 & 3 & 4 & 5 & 6\end{array}$


APPENDIX E

CORRELATION MATRIXES FOR PERSONAL AND SOCIAL VARIABLES

\begin{tabular}{|c|c|c|c|c|c|c|c|c|c|}
\hline Personal Items & 1 & 2 & 3 & 4 & 5 & 6 & 7 & 8 & 9 \\
\hline 1. Age & & & & & & & & & \\
\hline 2. $\operatorname{sex}$ & .08 & & & & & & & & \\
\hline 3. Ethnicity & .12 & .06 & & & & & & & \\
\hline 4. SES & -.09 & -.02 & -.13 & & & & & & \\
\hline $\begin{array}{l}\text { 5. Residency } \\
\text { length }\end{array}$ & .26 & -.04 & -.07 & -.09 & & & & & \\
\hline 6. Credit load & -.14 & .03 & .06 & .03 & .01 & & & & \\
\hline $\begin{array}{l}\text { 7. Past dwelling } \\
\text { type }\end{array}$ & -.12 & .06 & .04 & .15 & -.14 & -.14 & & & \\
\hline $\begin{array}{l}\text { 8. Past roommate } \\
\text { number }\end{array}$ & -.08 & -.05 & -.05 & -.10 & -.10 & -.04 & -.34 & & \\
\hline $\begin{array}{l}\text { 9. Past porceived } \\
\text { crowding }\end{array}$ & .05 & .06 & -.04 & -.17 & .10 & .01 & -.12 & -.34 & \\
\hline
\end{tabular}


APPENDIX E (Continued)

Social Items

1. Degree of easiness to make frierds on floor

2. Degree of floormate cohesion

3. Degree of feeling floor as a friendly place

4. Degree of floormate acquaintanc $\theta$

5. Frequency of doing things with nelghbors

6. Frequency of exchanging things with neighbors

7. Intensity of floor activity participation

8. Intensity of dorm activity participation

9. Degree of privacy from neighbors

10. Degree of privacy from roomnate

11. Degree of getting along with roommate 